\title{
Mapping Riparian Habitat Availability in Canada's Agricultural Landscapes using Earth Observation
}

\author{
By \\ Amelia Johnson \\ A thesis submitted to the Faculty of Graduate and Postdoctoral Affairs \\ in partial fulfillment of the requirements for the degree of
}

Master of Science

in

Geography

Carleton University

Ottawa, Ontario

(C)2021

Amelia Johnson 


\section{Abstract}

Riparian zones disproportionately increase biodiversity. Monitoring them should be prioritized for sustainability. Unfortunately, agricultural riparian zones are often highly modified, narrow, and heterogenous, making imagery classification and monitoring more challenging. The Canadian government operationally maps all agriculture - it would be ideal to include the adjacent riparian land. Several classification and masking methods were tested on riparian zones in three watersheds (Ontario and Prince Edward Island) using several thematic resolutions to determine an operational classification method.

A pixel-based $60 \mathrm{~m}$ buffer method using $5 \mathrm{~m}$ imagery with reduced thematic resolution was successful for riparian classification and was used to demonstrate application of the Riparian Wildlife Habitat Availability on Farmland Indicator. Including riparian land in the annual crop inventory is not operationally feasible until the higher-resolution imagery becomes less expensive, as the riparian zone is often too narrow to spectrally separate riparian vegetation using lower resolution imagery. 


\section{Acknowledgements}

I would like to thank both Andrew Davidson and Scott Mitchell for all their patience and support through this very, very, long process. Thank you both for sticking with me while I recovered from my concussion and subsequent illness.

To Andrew, thank you for always being so positive and keen to explore this topic in all its facets. Your enthusiasm is contagious. Where others see problems, you see opportunities.

Thank you to Scott for being so patient, following my ADHD brain and bringing me back on track. Encouraging me to streamline my ideas and get to the heart of the matter is always appreciated, and often needed.

I am proud to have been a part of the Agriculture and Agri-food Canada (AAFC) project to determine biodiversity and riparian health in Agriculture zones across Canada. A big shout out to Steve Javorek and Matt Grant for sharing the Wildlife Habitat Availability on Farmland Indicator and an acknowledgement of how much work went into creating the habitat use databases I used for my thesis. 
I could not have completed this project without the notable help of Bahram Daneshfar (Classification and Technology), Patrick Rollin (PEI Data Collection), and Dan Bert (Computers and GIS), thank you all.

Thank you to everyone from the Science and Technology Branch who drove me around for data collection when I was unable to drive, assisted in my data collection, or helped me figure out my processes.

I want to thank my Dad and Mom for always being there for me and supporting me, Thomas for encouraging me and pushing me when I need it most, and to friends who have listened to me talk about this for years.

I would not have been able to do this project without the generous support from Agriculture and Agri-Food Canada (Research Affiliate Program), Carleton University (Graduate Program), GLEL (Office Space and Tech Assistance), and Planet Labs (Data).

"Life isn't about waiting for the storm to pass. It's about learning how to dance in the rain."

- Vivian Greene

Author and motivational speaker 


\section{Table of Contents}

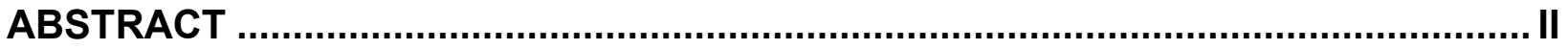

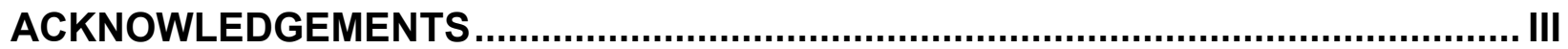

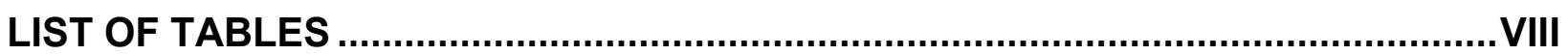

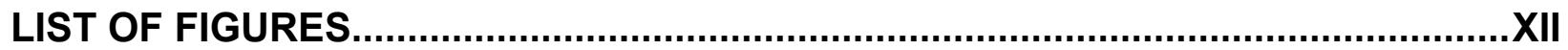

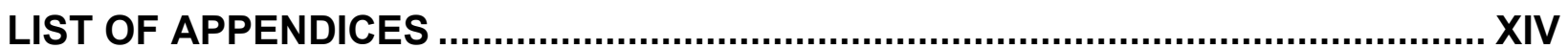

\section{A ERROR! BOOKMARK NOT DEFINED.}

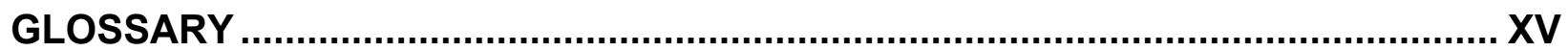

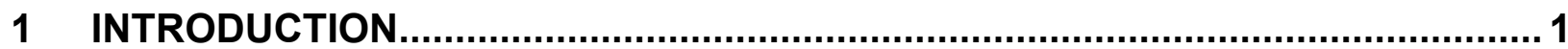

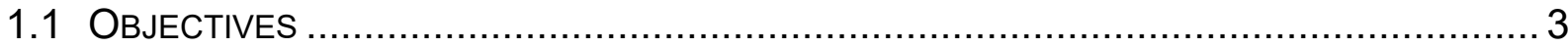

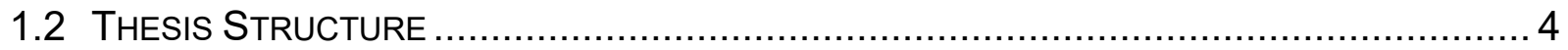

2 BACKGROUND

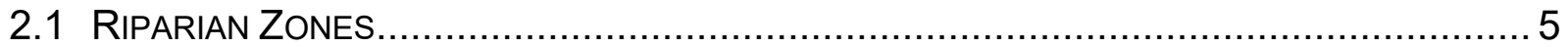

2.1.1 Ecosystem services provided by riparian zones................................... 7

2.2 Space-BASed Earth ObServation (SBEO) ............................................... 12

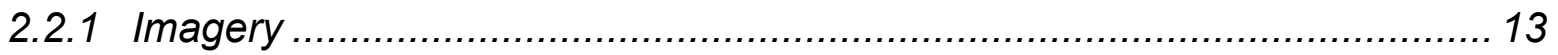

2.2.2 The AAFC Annual Space-Based Canadian Crop Inventory ...................... 15

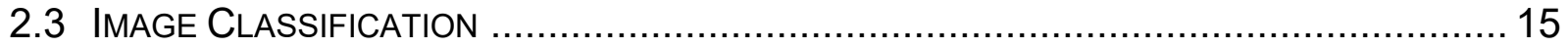

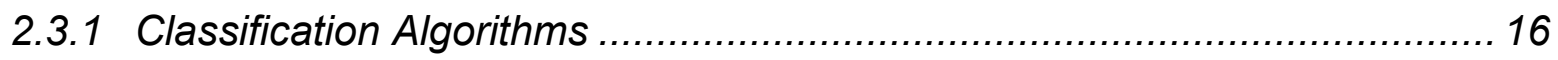

2.3.2 Pixel-based vs object-based classification ............................................. 17

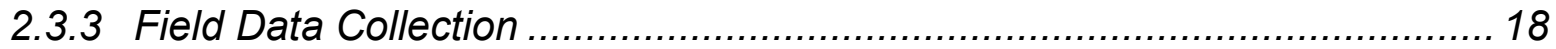

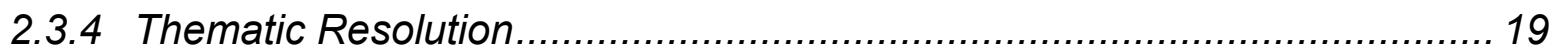

2.4 RIPARIAN WILDLIFE HABITAT AVAILABILITY ON FARMLAND INDICATOR (RWHAFI) ...... 21 


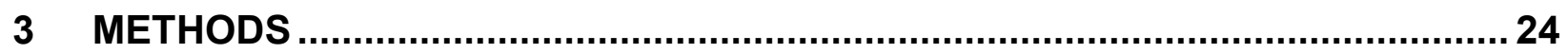

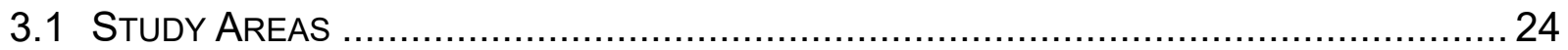

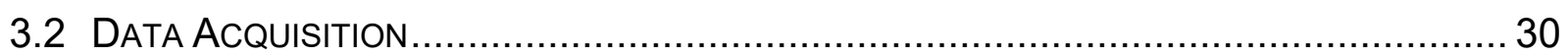

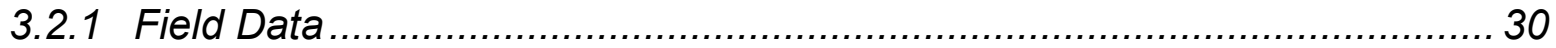

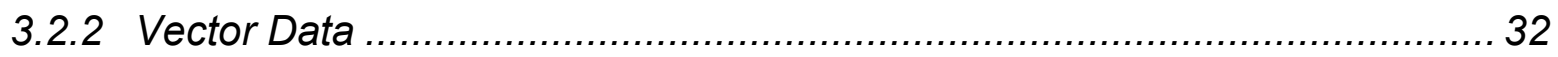

3.2.3 Earth Observation Data (Satellite Imagery) ......................................... 34

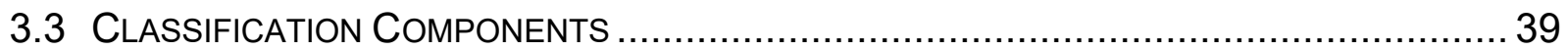

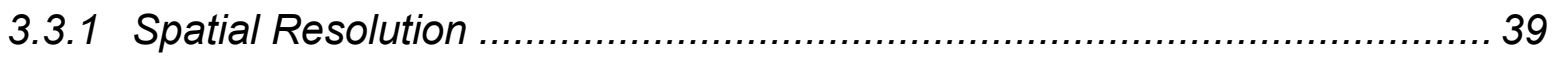

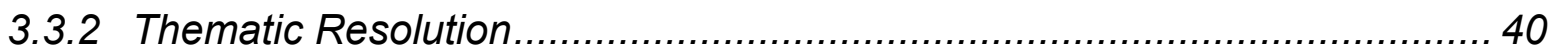

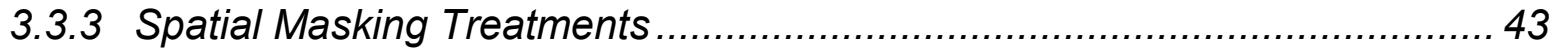

3.3.4 Pixel-based vs. Object-based Classification ......................................... 45

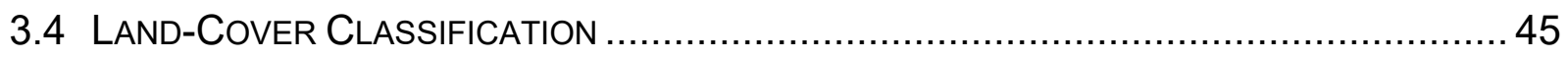

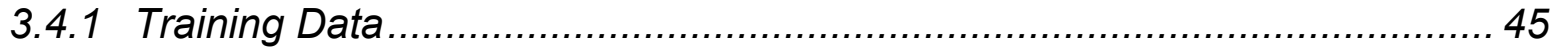

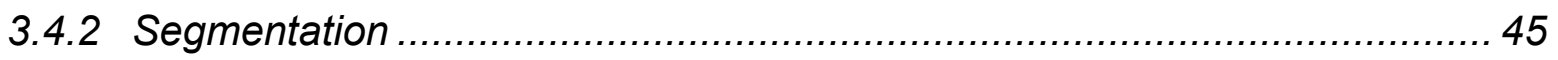

3.4.3 Maximum Likelihood Classification....................................................... 46

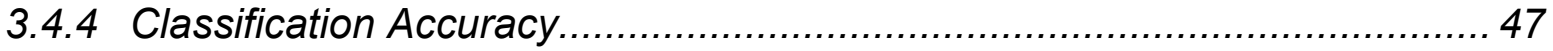

3.5 The Riparian Wildife Habitat AVAILABILITy on FARMLAND INDICATOR (RWHAFI) 49

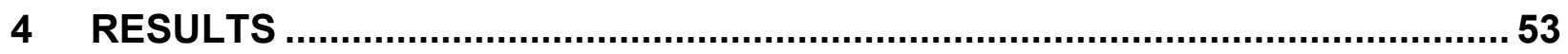

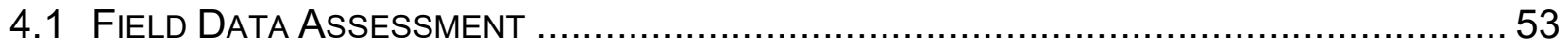

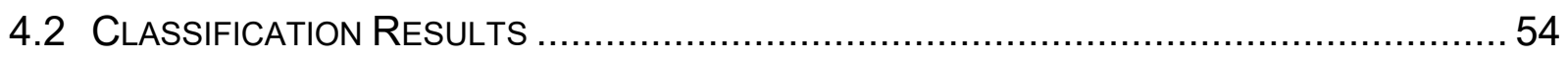

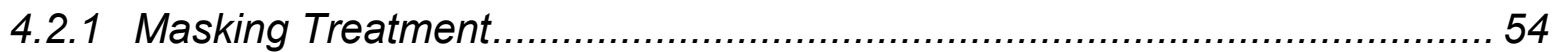

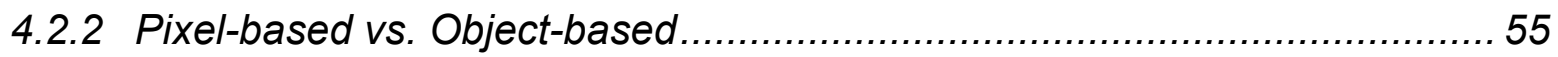

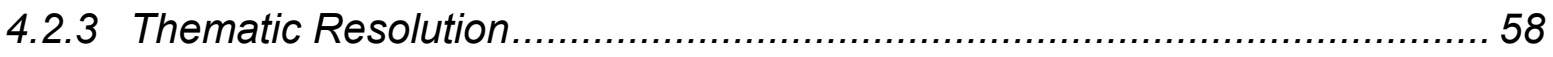

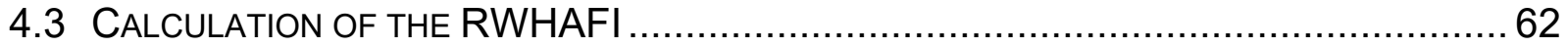

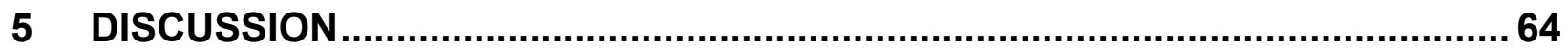

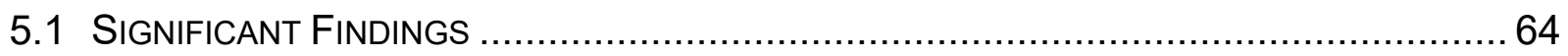




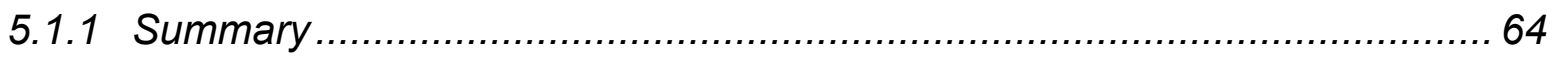

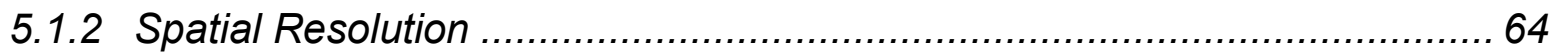

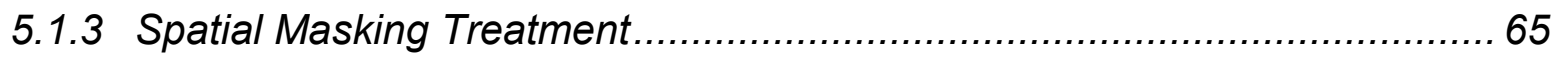

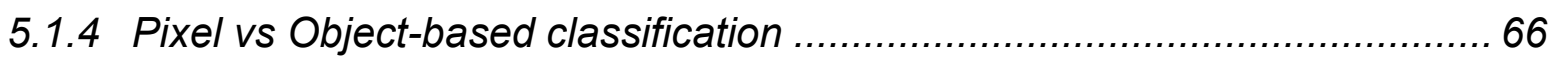

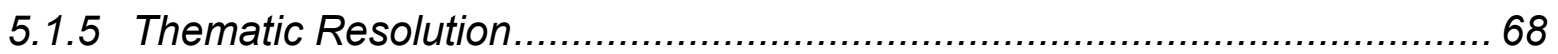

5.1.6 Available Habitat in the Riparian zone .............................................. 70

5.2 LIMITATIONS AND FUTURE POSSIBILITIES ..................................................... 71

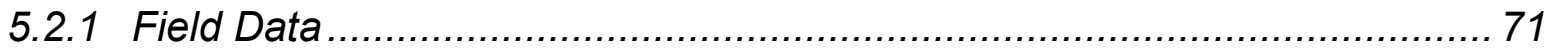

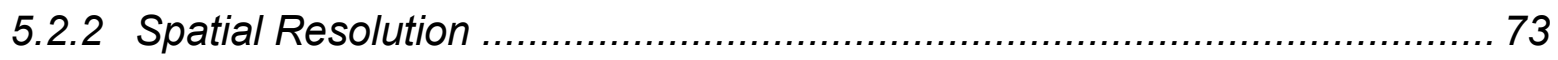

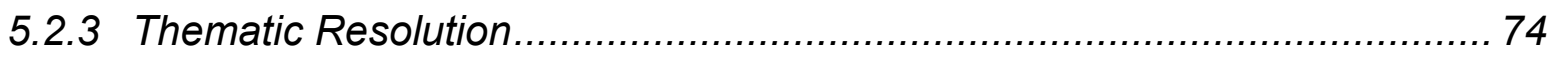

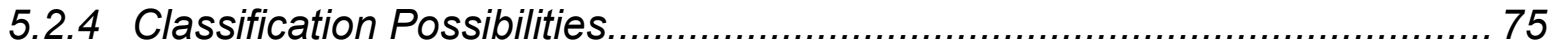

5.2.5 Habitat Availability Indicator Limitations and Possibilities......................... 80

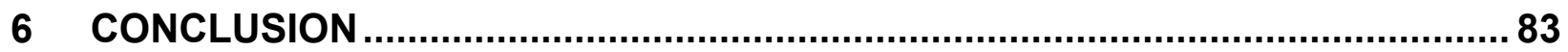

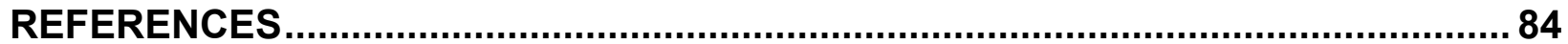

APPENDIX

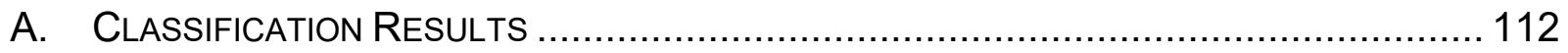




\section{List of Tables}

Table 1: Counts of field data polygons for each watershed for each masking treatment (described below) using RapidEye

Table 2: Datasets used for planning, processing, and delineating the study area......... 33

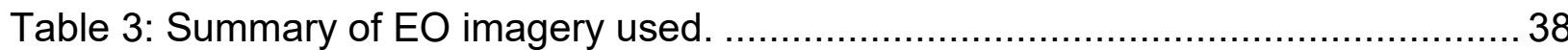

Table 4: Thematic resolution, description of the classes collected, and the classes used

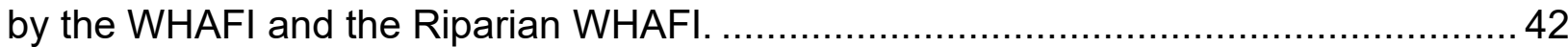

Table 5: Parameters used for image segmentation by watershed. ............................ 46

Table 6: Sample subset of the RWHAFI Habitat Use Matrix for the Mixed Wood Plains, with values between 0 and 3 (Javorek and Grant, unpublished) .............................5 50

Table 7: Summary of results for all three watersheds using RapidEye imagery............55

Table 8: Summary of the differences in the method accuracy between pixel-based and object-based classification. Positive values show higher accuracy of pixel-based method. Two are highlighted for the most difference in classification accuracy. 56 Table 9: Confusion matrix of accuracy results of the pixel-based MLC for South Nation River watershed using the $60 \mathrm{~m}$ buffer treatment. Grey fields are where points were correctly classified, green fields with bolded text are the Accuracy (0.709) and kappa Confidence (0.660). Tree subclasses are bordered with thicker lines

Table 10: Accuracy results of the South Nation pixel-based classification 60 m buffer treatment for the four Riparian HAl classes.

Table 11: Areal proportion landcover percentages for the Riparian WHAFI classes in the South Nation watershed in 2015 from the pixel-based $60 \mathrm{~m}$ buffer treatment of

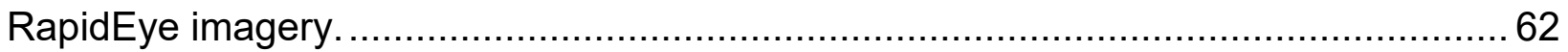


Table 12: Calculation of Riparian WHAFI using the landcover proportions and the Habitat Association Matrix habitat use value summations

\section{Appendix Tables}

Table A - 1: Confusion matrix of accuracy results from the South Nation watershed pixel-based classification of 2015 RapidEye imagery using the Whole area treatment.

Table A - 2: Confusion matrix of accuracy results from the South Nation watershed object-based classification of 2015 RapidEye imagery using the Whole area treatment.

Table A - 3: Confusion matrix of accuracy results from pixel-based classification of 2015 RapidEye imagery from the South Nation watershed using the Crop Cookie Cutter treatment.

Table A - 4: Confusion matrix of accuracy results from object-based classification of the South Nation watershed 2015 RapidEye imagery using the Crop Cookie Cutter treatment with segmented data. 115

Table A - 5: Confusion matrix of accuracy results from pixel-based classification of the South Nation watershed 2015 RapidEye imagery using the 60 m buffer treatment. ... 116 Table A - 6: Confusion matrix of accuracy results from object-based classification of the South Nation watershed 2015 RapidEye imagery using the 60m buffer treatment. .... 117 
Table A - 7: Confusion matrix of accuracy results from pixel-based classification of 2016 RapidEye imagery of the Dunk River watershed using the Whole area treatment. ..... 118 Table A - 8: Confusion matrix of accuracy results from object-based classification of the Dunk River watershed 2016 RapidEye imagery using the Whole area treatment. ...... 119 Table A - 9: Confusion matrix of accuracy results from pixel-based classification of 2016 RapidEye imagery of the Dunk River watershed using the Crop Cookie Cutter treatment.

Table A - 10: Confusion matrix of accuracy results from object-based classification of 2016 RapidEye imagery of the Dunk River watershed using the Crop Cookie Cutter method.

Table A - 11: Confusion matrix of accuracy results from pixel-based classification of 2016 RapidEye imagery of the Dunk River watershed using the $60 \mathrm{~m}$ buffer treatment.

Table A - 12: Confusion matrix of accuracy results from object-based classification of the Dunk River watershed 2016 RapidEye imagery using the 60m buffer treatment. . 123 Table A - 13: Confusion matrix of accuracy results from pixel-based classification of 2016 RapidEye imagery of the Souris River watershed using the Whole area treatment.

Table A - 14: Confusion matrix of accuracy results from object-based classification of the Souris River watershed 2016 RapidEye imagery using the Whole area treatment. 
Table A - 15: Confusion matrix of accuracy results from pixel-based classification of the Souris River watershed 2016 RapidEye imagery using the Crop Cookie Cutter

treatment. 126

Table A - 16: Confusion matrix of accuracy results from object-based classification of the Souris River watershed 2016 RapidEye imagery using the Crop Cookie Cutter treatment.

Table A - 17: Confusion matrix of accuracy results from pixel-based classification of the Souris River watershed 2016 RapidEye imagery using the $60 \mathrm{~m}$ buffer treatment. .... 128 Table A - 18: Confusion matrix of accuracy results from object-based classification of the Souris River watershed 2016 RapidEye imagery using the 60m buffer treatment. 129 


\section{List of Figures}

Figure 1: Transect of the riparian zone around a waterway, depicting lowland and the

upland areas.

Figure 2: Results from original WHAFI project showing the Habitat Capacity of the Mixedwood Plains in 1986, by Ecoregion and SLC polygons. (Javorek and Grant, 2011)

Figure 3: Location map showing the South Nation Watershed in the easternmost part of Ontario adjacent to Quebec. 25

Figure 4: Location map of the two PEI watersheds in relation of eastern Canada and within PEI. Dunk River watershed is located mid-island and Souris River watershed is located on the easternmost tip. Watersheds in this map are delineated by the gray lines.

Figure 5: Map of South Nation watershed with $\sim 60 \%$ Agriculture and $\sim 19 \%$ Forest represented based on AAFC 2015 crop map.

Figure 6: Map of Dunk River watershed with $\sim 69 \%$ Agriculture and $\sim 18 \%$ Forest represented from the AAFC crop map 2016.

Figure 7: Map of Souris River watershed with 38\% Agriculture and $\sim 37 \%$ Forest represented from the AAFC crop map 2016

Figure 8: DRAPE 2014 image of the South Nation River showing the size of Landsat pixels (red boxes) in the $60 \mathrm{~m}$ riparian buffer with a $10 \mathrm{~m}$ grid overlay. 35

Figure 9: Overview of the Land Cover Classification Components. 39 
Figure 10: Dunk River watershed showing the different preprocessing methods: a) whole area, b) crop cookie cutter, and c) $60 \mathrm{~m}$ buffer.

Figure 11: Classification results for the South Nation River $60 \mathrm{~m}$ buffer method. a) RapidEye imagery, b) segmented image, c) pixel-based classification, and d) objectbased classification.

Figure 12: South Nation River 60 m buffer classified using pixel-based methods at the low thematic resolution. 60 


\section{List of Appendices}

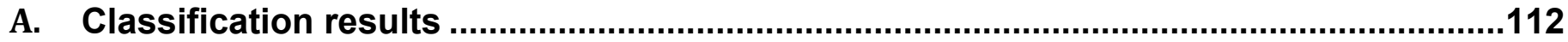

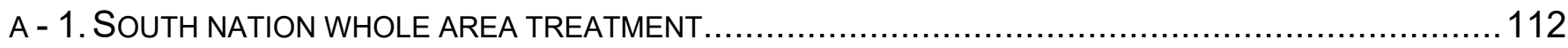

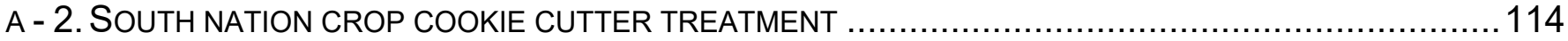

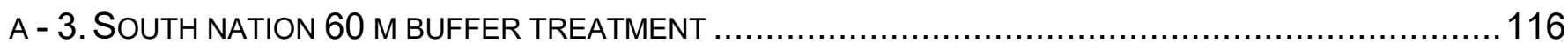

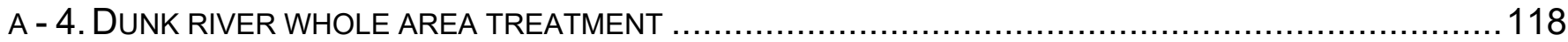

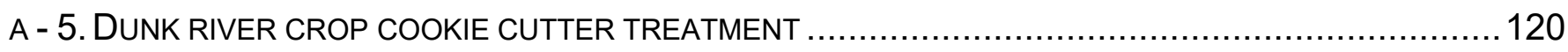

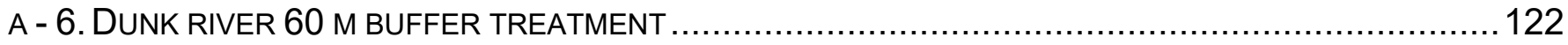

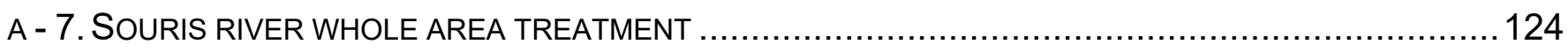

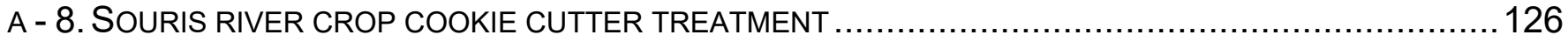

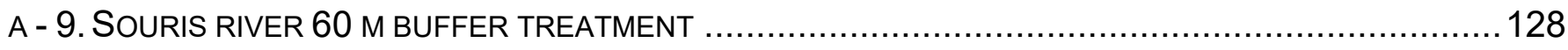




\section{Glossary}

AAFC - Agriculture and Agri-Food Canada - Canadian government agency associated with agriculture.

$\mathrm{ACI}$ - Annual Crop Inventory - Every year AAFC creates a classified map from Earth observation data of all crops across Canada.

Biodiversity - A measure of how many different species and the number of individuals present in an area.

DRAPE - Digital Raster Acquisition Project for Eastern Ontario.

EO - Earth Observation- Images or data of the Earth collected using sensors.

Habitat Capacity - The amount of habitat available for species in a region.

Indicator - A calculation, measurement, or product of simulation from a complex model, or simplified model from available important input variables that shows changes in the system.

LiDAR - Light Detection and Ranging.

MLC - Maximum Likelihood Classification - Supervised classification algorithm.

MMU - Minimum Mapping Unit- Smallest group of pixels needed as input for classification.

NIR - Near Infrared wavelength.

Operational - Routine, feasible procedure.

Riparian - Land adjacent to water features such as rivers, lakes, streams, and wetlands. Typically, there is a moisture gradient and unique vegetation associated with this region.

Riparian Buffer - A strip of land adjacent to a water feature measured perpendicular to the shore or edge.

Riparian Habitat - Any land adjacent to water or wetlands used by a species of interest. 
RWHAFI - Riparian Wildlife Habitat Availability on Farmland Indicator - An AAFC metric of habitat based on riparian land cover adjacent to farmland and an expansion/subset of the WHAFI.

Species Richness - The number of different species present in an area.

WHAFI - Wildlife Habitat Availability on Farmland Indicator - An AAFC metric of habitat based on the annual crop inventory.

Terms/Synonyms for Riparian Zone - riparian areas, riparian buffers, riparian management areas, riparian ecosystems, streamside protection zones, riparian zones, vegetated buffer strips, riverine, transitional zones, lowland, seasonal flood zones.... 


\section{Introduction}

Over the last three decades, remotely sensed data from space-based satellite platforms have become more accessible, accurate, cost effective, and reliable. In Canada, Agriculture and Agri-Food Canada (AAFC) - the government department responsible for Canada's agriculture and agri-food sector - has taken advantage of these technologies to map and monitor agricultural land use and its change. AAFC uses data acquired by sensors that span the optical and microwave regions of the electromagnetic spectrum and operate at a range of spatial (pixel) resolutions from $5 \mathrm{~m}$ to $250 \mathrm{~m}$.

The value of Space-Based Earth Observation (SBEO) data has already been demonstrated by AAFC scientists who are providing cost-effective, accurate, scalable, and timely, land use and land change information on a national scale (McNairn et al., 2009; Shang et al., 2009; Deschamps et al., 2012; Fisette et al., 2013 and 2014;

Champagne et al., 2014; Jiao et al., 2014; Pei et al., 2011; El-Khoury et al., 2014, 2015; Davidson et al., 2017). In the future, AAFC's ability to meet the sector's information needs will improve as new satellite sensor technologies are launched, brought online, and made available. The SBEO approach will thus be critical to the development of the AAFC's next generation of useful and authoritative information products.

A priority area of interest to AAFC is the application of SBEO to the monitoring of terrestrial biodiversity, and some advances in this realm have been made over the past 
decade with the development of AAFC's Wildlife Habitat Availability on Farmland Indicator (WHAFI) (Javorek \& Grant, 2011). The WHAFI uses the AAFC Annual SpaceBased Crop Inventory ( $\mathrm{ACl}, 30 \mathrm{~m}$ spatial resolution) landcover maps and knowledge of species distribution ranges and habitat use preferences, to determine the amount of usable land available for vertebrate species, as a proxy for biodiversity/health. The current implementation of the WHAFI to mapping biodiversity over Canada's agricultural landscapes is limited by the relatively coarse spatial resolution of natural, semi-natural, and riparian cover types within the $\mathrm{ACl}$. Pilot studies at $\mathrm{AAFC}$ have used the $\mathrm{ACl}$ as input to the WHAFI to provide a more detailed characterization of biodiversity across select Canadian test sites.

AAFC is particularly interested in the application of the RWHAFI to monitor riparian health, especially in an operational context. Habitat preference databases required for the RWHAFI were provided by AAFC. An effective method of mapping the riparian zone as part of the $\mathrm{ACl}$ operational classification would allow for the RWHAFI to be used to monitor riparian health over time.

Riparian zones, defined most generally as the transitional zone between aquatic and terrestrial habitats, are highly productive and are often subject to intense modification and human pressure. Because agricultural regions are areas that undergo significant modification of the land and are commonly found adjacent to water, riparian zones within these regions are often vulnerable to habitat and biodiversity loss. 
Riparian zone health is inconsistently defined across the literature, and ways to determine and measure it can vary widely. Nonetheless, in the absence of a universally accepted definition, riparian health will be defined as the ability of the riparian system to support vertebrate wildlife species (Clearwater et al., 2016), and it is this definition that is used throughout this dissertation. The main challenge of mapping riparian health from SBEO, however, is that riparian zones tend to be small in area and narrow, and thus, the $30 \mathrm{~m}$-resolution $\mathrm{ACl}$ may be too coarse for this task. As a result, testing methods of mapping riparian areas using a finer spatial resolution data (generally, pixel resolutions of $5 \mathrm{~m}$ or finer) and developing consistent and potentially innovative approaches for mapping these systems operationally at a national scale would contribute to long term monitoring goals.

\subsection{Objectives}

The overarching goal of this study is to define criteria for operational implementation of space-based riparian mapping and subsequent monitoring through the RWHAFI. To identify a geographically portable classification method, several spatial and thematic resolutions, masking treatments, as well as different classification methods, are all tested on riparian zones of varying complexity. A successful classification method would ultimately be incorporated into Agriculture and Agri-Food Canada's operational spacebased agricultural land use and land cover mapping. Those resulting maps would then be used for operational mapping of riparian habitat availability within agricultural regions across Canada. 


\subsection{Thesis Structure}

This thesis is organized into six chapters. This first chapter introduces the importance of using Earth observation for riparian monitoring and details the objectives and goals. Chapter 2 addresses background information on riparian zones, space-based image capture, classification methods, and the Wildlife Habitat Availability on Farmland Indicator. Methods are outlined in Chapter 3, describing the spatial resolutions of the available data, masking treatments, classification strategies, and thematic resolutions applied in the study areas, and calculation of the RWHAFI. Chapter 4 presents the Results. Chapter 5 discusses the most accurate classification method, the Habitat Availability results, and presents limitations and future considerations of this research. In Chapter 6, conclusions and highlights of the study are presented. 


\section{Background}

This section summarizes information from the literature needed to put this study in context. It starts by defining riparian zones and discussing several of the key ecosystem services they provide. Then the imagery characteristics and classification methods used to create landcover maps are introduced. It concludes by discussing the history of the RWHAFI.

\subsection{Riparian Zones}

Ecologically, riparian zones are defined as transitional areas occurring along and between upland and freshwater ecosystems, characterized by unique soil, hydrology, and biotic conditions strongly influenced by water (Marczak et al., 2010; Klemas, 2014). Using this definition, these zones include the river or stream edge, floodplain/lowland, the slope, and the vegetation that is reliant on the moisture gradient near the water's edge. They are variable in width and can be strongly influenced by the local topography and land use (Betz, Lauermann \& Cyffka, 2018). This is illustrated in Figure 1 below. 


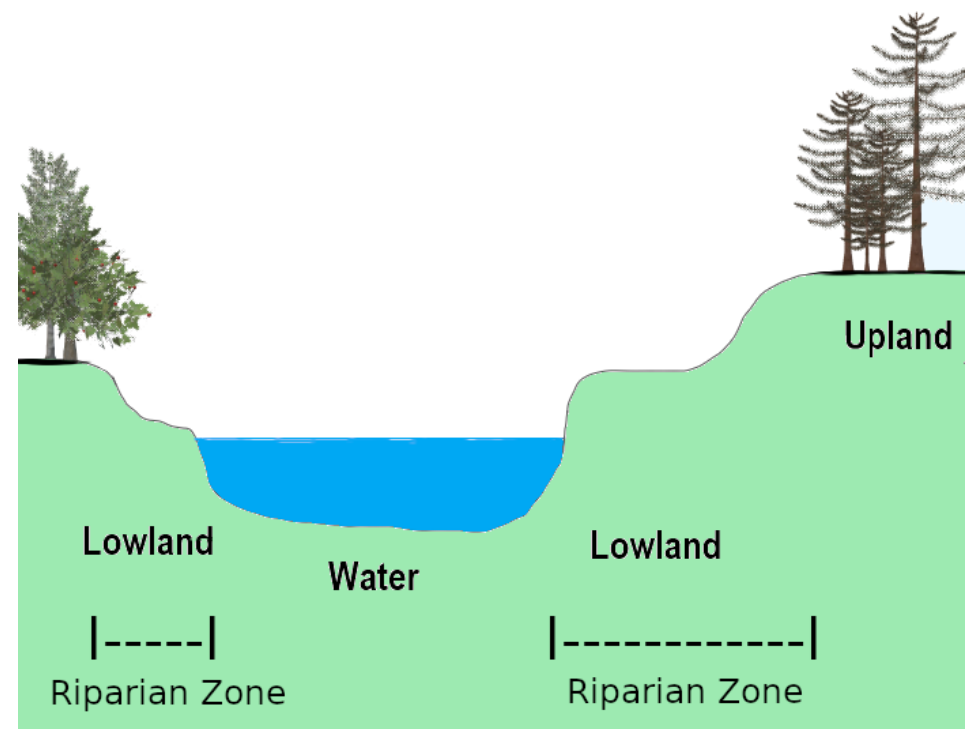

Figure 1: Transect of the riparian zone around a waterway, depicting lowland and the upland areas.

For simplicity of implementation, many regulatory jurisdictions have "vegetated buffer" laws or guidelines, primarily for the maintenance of water quality, but also for species diversity and ecosystem services, particularly in modified habitats/agricultural regions (Marczak et al., 2010). These vegetated buffers are usually a uniform distance on either side of the water, composed of natural cover along rivers, streams, lakes, and wetlands (Marczak et al., 2010; Richardson et al., 2012; Sass et al., 2012). For conservation purposes, riparian buffer distances varying from 5-200 m have been used to preserve water quality and conserve natural processes and the ecological functions of riparian zones (Marczak et al., 2010).

In Ontario, the Nutrient Management Act of 2002 states that if nutrients are to be added to an agricultural field, there must be a minimum of a three-meter vegetated buffer from 
the top of the streambank, consisting of continuous vegetated cover (Government of Ontario, 2002). This continuous vegetated cover can be perennial forage crops, perennial grasses, trees, or forbs (Government of Ontario, 2002). As of 2019, Ontario regulations now require six meters, or as deemed necessary by an engineer (Government of Ontario, 2019). In 2008, the Watercourse and Wetland Protection Regulations of Prince Edward Island (PEI) stated that the ground or soil within 15 meters of the water must be undisturbed except with a permit (Watercourse and Wetland Protection Regulations, 2008). These regulated buffer distances are useful for simplicity of implementation, though they may not include all the riparian habitat, or encompass all the ecosystem services that riparian zones can provide (Richardson et al., 2012).

\subsubsection{Ecosystem services provided by riparian zones}

Riparian zones provide a suite of important abiotic and biotic services to the local ecosystem. Many of these serve to moderate the impacts of neighbouring land use such as logging, agricultural uses, and urbanization -on river and stream water quality (Klemas, 2014; Piedelobo et al., 2019). Riparian zones have the potential to support numerous species and structures, which collectively can provide abiotic ecosystem services including, but not limited to sediment trapping, nutrient capture, bank stabilization, flood mitigation, stream temperature moderation, and organic matter transfer (Fernandez et al, 2014; Klemas, 2014; Sosa et al., 2018; Woodward et al., 2018). 
Riparian vegetation helps to maintain water quality by providing sediment and nutrient trapping ecosystem services (Klemas, 2014; Croke et al., 2017). By slowing the passing of sediment-laden water from upland regions, sediment settles out of solution before reaching the waterway (Sosa et al., 2018; Croke et al., 2017). Similarly, if nutrients are transported from fields in runoff, the slowing of water through riparian vegetation facilitates greater nutrient absorption by plants and prevents the nutrients from passing directly into the waterways (Sosa et al., 2018; Tánago \& Jalón, 2011). Vegetation also increases the amount of organic matter in the soil which increases its water holding capacity, increasing filtering, and reducing flooding (Sosa et al., 2018; Aguiar et al., 2015). The roots of the vegetation provide bank stabilization and soil retention services as the roots bind the soil and prevent it from washing into the water (Croke et al., 2017; Krzeminska et al., 2019; Tánago \& De Jalón, 2011). This can also keep the banks taller, which can help reduce flooding.

As well as supporting the riverbank and reducing sediment, having trees along the bank helps to moderate water temperatures by shading the water from some of the direct solar radiation (Li, Jackson, \& Kraseski, 2012; Klemas, 2014). This can be important for many aquatic species as colder water has a higher dissolved oxygen content than warmer water (Li, Jackson, \& Kraseski, 2012). Trees along the water are also part of a nutrient cycle, with plant matter falling into the water providing nutrients to the benthic communities, and insects coming out of the water providing food sources for species that live in the riparian zone (Baxter et al., 2005; Ferreira et al., 2016). 
Riparian zones provide food, water, shelter, shade, connectivity, and structure which supports many biological ecosystem services, processes, and increased biodiversity (Marczak et al., 2010; Sosa et al., 2018; Woodward et al., 2018; González et al., 2017). These unique habitats in the riparian zones provide habitat for a number of species that are not usually found elsewhere, as well as key breeding habitats (Gundersen et al., 2010; Richardson et al., 2012; Clearwater et al., 2016). Several studies have found higher species richness in riparian areas than in nearby upland areas (Bennett et al., 2014). For example, it was found that riparian habitat supported different species than upland areas, which increases regional species richness by greater than $50 \%$ worldwide (Sabo et al., 2005; Hylander, 2006). In a worldwide meta-analysis species richness was found to be $38 \%$ higher in regions containing a riparian area than forested areas not containing riparian land (Gunderson et al., 2010). Indeed, riparian forests host more species of breeding birds than any other habitat in North America (Barry et al., 2006; Gunderson et al., 2010).

Riparian vegetated strips can create dispersal corridors for species to safely traverse modified landscapes and connect with other populations, breeding areas, and/or new habitat (Marczak et al., 2010; Fernandez et al., 2014). Many birds live in the trees adjacent to water and use the connectivity of the riparian strips for dispersal (Gundersen et al., 2010) as well as supplementing their diets with emerging aquatic insects (Baxter et al., 2005; Woodward et al., 2018). Most vertebrate species found in the agricultural 
regions rely on the riparian strip for at least some part of their lifecycle (Clearwater et al., 2016; Woodward et al., 2018).

Food web connections and material exchanges between aquatic and land ecosystems occur in the riparian zone, making these zones important for the health of both ecosystems (Baxter et al., 2005; Ferreira et al., 2016). These transitional zones are also important for species that have different life cycle needs, such as frogs that lay eggs in water and whose juvenile stage is aquatic, while the adults are more terrestrial (Felix et al., 2010). Vegetation and deadfall along the riverbanks create structure and shelter for many juvenile/aquatic stages such as juvenile fish, tadpoles, insects, and amphibian egg clusters (Lyon et al., 2019). These juvenile/aquatic stages are often found along the edge of the water in sheltered areas where larger aquatic predators cannot get to them, where they are sheltered from direct sunlight, and they are less impacted by currents. These structures created by riparian vegetation lead to higher biodiversity in the aquatic system. Understanding and protecting areas of food web exchange, high productivity, and high species richness such as riparian zones is important for the preservation of biodiversity (Marczak et al., 2010).

The preservation of biodiversity has been a major global concern over the last few decades, as seen through global agreements such as the United Nations Convention on Biological Diversity (United Nations Environment Program, 2020), United Nations 2030 Sustainable Development goals, and Canadian programs like the Federal Sustainable Development Strategy (Environment and Climate Change Canada, 2019). Habitat 
loss/modification is often listed as one of the main drivers of species extinction and biodiversity loss (Fahrig, 2001). Agricultural regions are areas where there has been significant modification of the land (Jeong et al., 2016). Due to implications for water quality, riparian habitat/vegetated strips have generally been left untilled or with natural vegetation in many agricultural areas (Maseyk et al., 2017; Nutrient Management Act, 2019) though the buffer requirements are often narrow when considering vertebrate species needs (Marczak et al., 2010).

Operational monitoring is the first step in observing landcover changes. Being able to map changes over time allows managers and policy makers to take stock of what is there, see changes as they happen, and make recommendations for improvements. Canada is committed to maintaining and improving the sustainability of agriculture practices through the Federal Sustainability Development Strategy program (FSDS, Environment and Climate Change Canada, 2019). In order to measure those targets, long-term monitoring strategies are needed. Monitoring of riparian zones can be done through field work, remote sensing, or a combination of the two.

Given the size of Canada and the cost of field research, riparian habitat is not mapped in any detail for most regions. As finer resolution imagery becomes more accessible and computer processing improves, adding the riparian area to the space-based image classification already being done operationally by AAFC is becoming more feasible. Determining effective and efficient methods of classifying the riparian zone from 
remotely sensed imagery would significantly improve existing operational monitoring methods and data products.

\subsection{Space-Based Earth Observation (SBEO)}

Space-based Earth observation systems have allowed terrestrial ecosystems to be mapped and monitored from local to global scales. Information on the state and change of terrestrial ecosystems that was once difficult and expensive to obtain over vast areas is now becoming accessible. The current availability of numerous satellite data streams, including both those from commercial vendors and open access, means that it is possible to select sensors that best meet specific user requirements, such as study area coverage, spatial resolution, repeat frequency, spectral resolution and period of study.

Advances in image processing and classification have also improved dramatically since the days of manual classification of air photo images. However, there is still thematic and locational error associated with each classification, and the error increases with the complexity and diversity of the landcover. For example, identifying a huge area of one cover type can usually be easily accomplished with a fair amount of certainty, but if the landcover is heterogeneous, the pixels are large, and there are limited data, the algorithms are less accurate at modeling landcover (Corbane et al., 2015).

Many factors can reduce classification accuracy, including but not limited to, highly diverse landcover, small patches, small strips, meandering strips, and fuzzy boundaries, all of which are typical for the agricultural riparian zones (Corbane et al., 2015). Riparian 
zones are commonly affected by hydrological disturbances making them highly heterogeneous (Capon \& Pettit, 2018) and as a transitional zone they will often have fuzzy boundaries between the different land cover classes (Woodward et al., 2018; Betz et al., 2018). This affects our ability to accurately identify the riparian landcover within agriculture zones, even with all the advances of Earth Observation technology.

\subsubsection{Imagery}

There are currently many satellites orbiting Earth, with different sensors that collect observations of varying spatial resolution in different portions of the electromagnetic spectrum. Commonly used Earth observation data include reflected energy in shortwave optical (blue, green, red), infrared (near infrared (NIR), shortwave infrared (SWIR), and thermal infrared (TIR) wavelengths, and backscattered microwave energy (C-band, L-band, X-band Synthetic Aperture Radar (SAR)) and passive microwave radiometers, and topographical information from LiDAR (Light Detection and Ranging). For consistency between sensors for operational land use and cover mapping at various spatial resolutions, this study uses imagery acquired from sensors that collect observations in the visible and infrared portions of the spectrum.

Observations from optical satellite platforms and sensors comprise mixed spectra. This "mixed pixel" problem occurs because the reflectance of each pixel in an image, no matter how small that pixel is, corresponds to the mean of the reflectance spectra from all its contributing components, such as vegetation, soil, water, and the neighbouring 
landcover (Dronova, 2015). Mixed spectra are ubiquitous in land remote sensing due to the inherent complexity of plant canopies. The mixed pixel problem can, at least in part, be addressed using finer spatial resolution imagery (e.g. 5 m RapidEye vs. $30 \mathrm{~m}$ Landsat-8), where there are fewer different contributing elements to pixel reflectance (Huylenbroeck et al., 2020). However, from an operational national-scale mapping perspective, the use of such higher spatial resolution imagery is often not feasible due not only to prohibitive cost, but also larger data volumes that require significantly more computational overhead to download and process.

Despite the issues of mixed spectra, some landcover types are relatively easy to identify spectrally. This includes deep or large water bodies (due to their very high absorption in the NIR and SWIR spectral bands compared to other non-water landscape components) (Merchant et al., 2019) and vegetation (due to their high absorption in the red and high reflectance in the NIR, compared to other non-vegetated landscape components) (Nguyen et al., 2019). Observations over vegetated surfaces can often be broken down further into more detailed landcover types (e.g. forest vs. cropland vs. wetland) given observations of suitable spatial resolution (to minimize the mixed pixel problem) and temporal resolution (to differentiate vegetation on the basis of their growth (phenological) cycles). Nonetheless, for mapping riparian zones, which are generally narrow non-linear features, problems associated with mixed spectra will persist, and need to be directly addressed. 


\subsubsection{The AAFC Annual Space-Based Canadian Crop Inventory}

The Annual Crop Inventory ( $\mathrm{ACl})$ maps are operationally created by the Science and Technology Branch of Agriculture and Agri-Food Canada (AAFC). Using a combination of synthetic aperture radar (SAR) and optical Landsat satellite imagery and field data collection, AAFC creates the crop inventory at $30 \mathrm{~m}$ spatial resolution with a goal of $85 \%$ minimum mapping accuracy for crop classification across all of Canada each year (Davidson et al., 2017). The ACl has more than 60 landcover classes primarily focused on the crop classification. Ideally, the operational crop inventory will eventually include operational mapping of riparian zones within agriculture zones.

\subsection{Image Classification}

Satellite image classification is an important tool for many remote sensing applications. Classification involves the implementation of algorithms that identify different landcover types from spectral data to produce a thematic map. During this process, image data (pixels or objects, see following sections) are sorted into target classes on the basis of their spectral characteristics (Esri, 2016). With the goal of operational mapping of the riparian zone within the agricultural regions of Canada, a successful classification method needs to be efficient, reproducible, and portable. There are several components that could be chosen for each classification method: 
(1) classification algorithm

(2) pixel-based vs object-based classification

(3) field data collection

(4) thematic resolution

\subsubsection{Classification Algorithms}

Supervised classification algorithms are the most commonly used type of classification. The supervised classification approach uses in situ (ground) observations to "train" the classification algorithm, where it defines the spectral characteristics (signatures) of each target class (Esri, 2016). The algorithm then compares each pixel in the image to those signatures and assigns the pixel to the target class which it most closely resembles (Esri, 2016). The accuracy of the final classification is evaluated (validated) using a selection of the ground reference points not used to train the classification (Davidson et al, 2017). Of the available supervised classification algorithms, Maximum Likelihood Classification (MLC) is a simple and readily available approach that assigns each pixel to the most likely class according to the training data (Lillesand, Kiefer \& Chipman, 2004). The likelihood of each pixel belonging to each class is evaluated by calculating the Mahalanobis distance (Richards, 1996) of the pixel's location in spectral space to the centre of each training cluster, and the shortest distance identifies the most likely, therefore assigned, class (Foody, 1990; Mitchell et al. 2008). While there are newer algorithms for satellite imagery classification, like machine learning classifiers, support vector machines, decision trees, and ensemble classifiers, they are usually more computationally intensive, and more complex (Maxwell et al., 2018). It has also been 
found that rarer classes may not be discriminated well with machine learning classifications, likely due to the smaller sample size of observations associated with such classes, which has been shown in many cases to reduce the performance of this approach (Maxwell et al., 2018, Wen \& Hughes, 2020). Those newer algorithms might have increased overall accuracy when compared to MLC, but with the data available, the operational mapping goal, and the issues identified above, MLC was used in this study to determine a baseline successful method. If the methods are successful with MLC, machine learning methods could be applied in the future to test for higher classification accuracies.

\subsubsection{Pixel-based vs object-based classification}

MLC can be applied to classify imagery using both pixel-based and object-based approaches. In a pixel-based approach, the classification algorithm is applied to imagery on a pixel-by-pixel basis. Riparian zones can be highly variable, and thus a pixel-based classification may be more precise than object-based classification for the smaller patches and/or rarer classes found in the narrow riparian zones (Dingle Robertson \& King, 2011). In an object-based approach, the classification algorithm is applied to homogenous aggregations of pixels (known as objects). To implement an object-based classification, images are segmented, where the image is divided into pieces, or objects (Esri, 2020). The objects may represent tree crowns, roads, or any area of the image with similar texture, colour, or shape. Once the image is segmented, a classification algorithm is applied, and each object is classified instead of each pixel. 
A number of studies have shown that image segmentation before classification can improve classification accuracies (Liu \& Xia, 2010). Classifying objects can also reduce the noise often seen in pixel-based classification (Makinde et al., 2016) and classifying the larger objects can add more training information to the spectral signature and potentially increase the accuracy (Liu \& Xia, 2010). Several studies have found improvement in wetland mapping with object-based classification (Dronova, 2015; Dingle Robertson \& King, 2011). Given the successes that other studies have had with object-based methods, they were added to this study.

\subsubsection{Field Data Collection}

For the supervised classification of satellite imagery, field data should be collected with a few considerations. Sites that are physically close together may be spatially autocorrelated (Congalton \& Green, 2019). This is problematic because the presence of spatial autocorrelation in ground data needs to be explicitly corrected for when using these data with any traditional (parametric) statistics. In addition, it is recommended that field data collection sites should meet a minimum size and it is commonly suggested to use a Minimum Mapping Unit (MMU) for all training areas (Demers et al., 2015). This is because a pixel's spectral signature is influenced by the adjacent pixels through the bidirectional reflectance distribution function, which varies widely for vegetation (Maillard \& Alencar-Silva, 2013). Therefore, larger MMUs will help to reduce spectral impacts of other adjacent classes, and larger MMUs can also help to reduce error from slight positional error of the imagery (Knight \& Lunette, 2003). 
Riparian zones are often spatially heterogeneous and contain landcover classes that often have high within-class variability. Riparian wetlands are one such example and are highly spectrally and spatially variable (Corbane et al., 2015; Dronova, 2015). Wetlands are strongly influenced by local hydrological properties, soil moisture levels, and atmospheric moisture (Corbane et al., 2015; Dronova, 2015), meaning that wetlands may present differently within the same image, making their identification and classification even more challenging.

A sufficient amount of high-quality field data points are needed to adequately capture the spectral variance of each class. This can be challenging, especially for rarer classes, where there may be insufficient collection sites in the study area, where the areal coverage of the class may be smaller than the MMU for the image resolution being used, and where the sample size required to adequately spectrally define the class in question may be impossible to define beforehand. As a result, inadequate field sampling will impact accuracy, as well as the number of possible classes for the thematic resolution.

\subsubsection{Thematic Resolution}

In the context of this study, thematic resolution refers to the number of classes to be defined through the process of classification of a satellite image. The ideal thematic resolution of a landscape classification depends on the heterogeneity of the landscape, the spatial resolution of the imagery, and the goal of the study (Congalton \& Green, 
2019). If the class definitions are too specific, the resulting classification will often result in many classes mapped with low accuracy. However, if the class definitions used are too broad, only a few classes will be defined, which will be insufficient to characterize the heterogeneity of the landscape being mapped. Capturing as much variability as possible is beneficial when considering the goal of mapping biodiversity and habitat availability (Maskell et al., 2019).

The spatial resolution of the imagery strongly influences the potential thematic resolutions. A finer spatial resolution may allow for a higher thematic resolution in a heterogeneous landscape, because smaller pixels are required to adequately characterize the short-distance spatial complexity found within that landscape. On the other hand, spatial resolution can be less important in a more homogeneous landscape, or when looking to classify fewer classes or classes that cover large geographical areas. For example, Canada currently maps forest attributes to a spatial resolution of $250 \mathrm{~m}$ with a thematic resolution of only 4 classes: vegetated, non-vegetated, treed, or non-treed (Natural Resources Canada, 2017). In comparison, the ACl (discussed above) has more than 60 landcover classes at $30 \mathrm{~m}$ pixel resolution. Generally, agricultural fields are large and homogenous making classification to a higher thematic resolution from medium resolution imagery possible. 


\subsection{Riparian Wildlife Habitat Availability on Farmland Indicator (RWHAFI)}

The WHAFI (landscape level) is already being used in some areas as a metric of sustainability, using $\mathrm{ACl}$ maps as input for its calculation (Government of Canada, 2019). It is one of the Agri-Environmental Indicators in the Canadian Environmental Sustainability Indicators (CESI) program as part of the Federal Sustainability Development Strategy (Government of Canada, 2019). Adding a riparian component to this indicator would contribute to the long-term monitoring of healthy agriculture and ecological preservation across the landscape.

This study evaluated RWHAFI as an operational method for monitoring riparian habitat availability and biodiversity in agricultural regions in Canada. This extends existing work with the WHAFI (Neave and Neave 1998; Javorek and Grant 2011) to identify and assess changes in habitat capacity in the agricultural regions over time. Javorek and Grant (2011) calculated the WHAFI for agricultural regions based on $\mathrm{ACl}$ data from 1986-2006 (Figure 2). The WHAFI combines landcover data from the ACl with tables of Habitat Use Values (sample in the Methods) to calculate the amount of land available for vertebrate species, as a proxy for biodiversity/health. While neither the WHAFI nor the RWHAFI account for the presence of the species, they are sensitive to the presence of the species' preferred or required habitat types in agricultural regions. The WHAFI is an indicator that is simple, straightforward, and cheap to apply when there are available landcover maps 


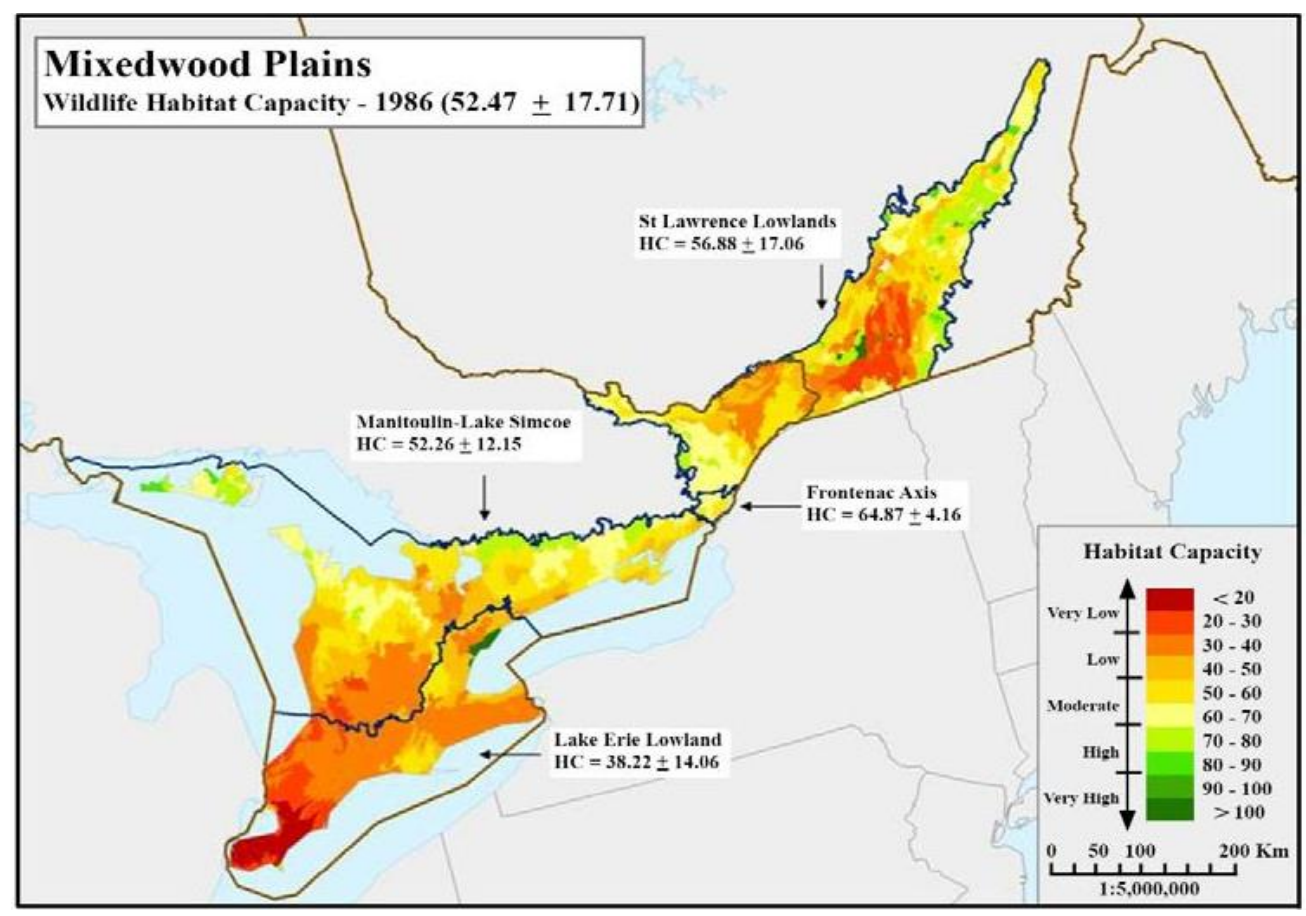

Figure 2: Results from original WHAFI project showing the Habitat Capacity of the Mixedwood Plains in 1986, by Ecoregion and SLC polygons. (Javorek and Grant, 2011)

The WHAFI has been used to assess farmland wildlife capacity for several regions across Canada (Clearwater, Martin, \& Hoppe, 2016). That report recommends changing or modifying the indicator methodology because so many species are dependent on the "All Other Land" landcover category of the WHAFI, rather than agricultural classes. The "All Other Land" class comprises mostly "idle land" which includes riparian forest, wetland, shrubland, and the riparian vegetated strip (Clearwater et al., 2016). The report states that only $3 \%$ of the species included in the indicator could meet all their breeding and feeding needs in only the annual crop areas and that the rest were partially or fully dependent on the natural and semi-natural habitats, including pasture and all other land (Clearwater et al., 2016). This dependence further shows the need to monitor this critical habitat. 
The developers of the WHAFI also created habitat use databases specifically for the agricultural riparian habitats. Classification of the riparian zone within agricultural regions would create the landcover maps needed to calculate the RWHAFI. My thesis aims to fill the gap in this indicator by using EO techniques to separately classify the riparian part of the "All Other Land" class and then apply the RWHAFI operationally. 


\section{Methods}

\subsection{Study Areas}

With the primary goal of national operational mapping of agricultural riparian landcover, this study focused on three agricultural watersheds, located in two Canadian provinces. These watersheds were chosen for their accessibility, the availability of ground and image data over the watershed, their range in size, and their variability in amount of the agricultural landcover. In addition, because these watersheds cover two ecozones, they allow for the development and testing of a more general, geographically portable, methodology that is not ecozone-specific.

The largest watershed is located on the south eastern boundary of Ontario, the South Nation River watershed is part of the northern arm of the "Mixed Wood Plains". Being close to Ottawa, AAFC, Geomatics and Landscape Ecology Lab, and Carleton University, the South Nation watershed was chosen for the ease of field data collection, as well as existing geospatial data sets. The Mixed Wood Plains is the most southern ecozone in Canada and its forests are mixed coniferous-deciduous, dominated by red and white pine, maple, hemlock, oak, and birch (Parks Canada, 2003).

The smaller watersheds are both located on Prince Edward Island (PEI), with the Dunk River watershed near the middle of the island and the Souris River watershed located on the easternmost tip (Figure 4). Watersheds in PEI were chosen because of the accessibility to data through the original WHAFI project leads based in PEI, and the 
availability of an AAFC team member to collect field data in the appropriate time range. The Dunk River and Souris River watersheds were selected to reflect watersheds of different sizes and proportion of agricultural activity. Both are part of the "Atlantic Maritime" ecozone which encompasses the southeastern part of Canada. Its forests are also mixed coniferous-deciduous, dominated by red spruce, red and white pine, sugar maple, balsam fir, birch, and eastern hemlock (Parks Canada, 2003).

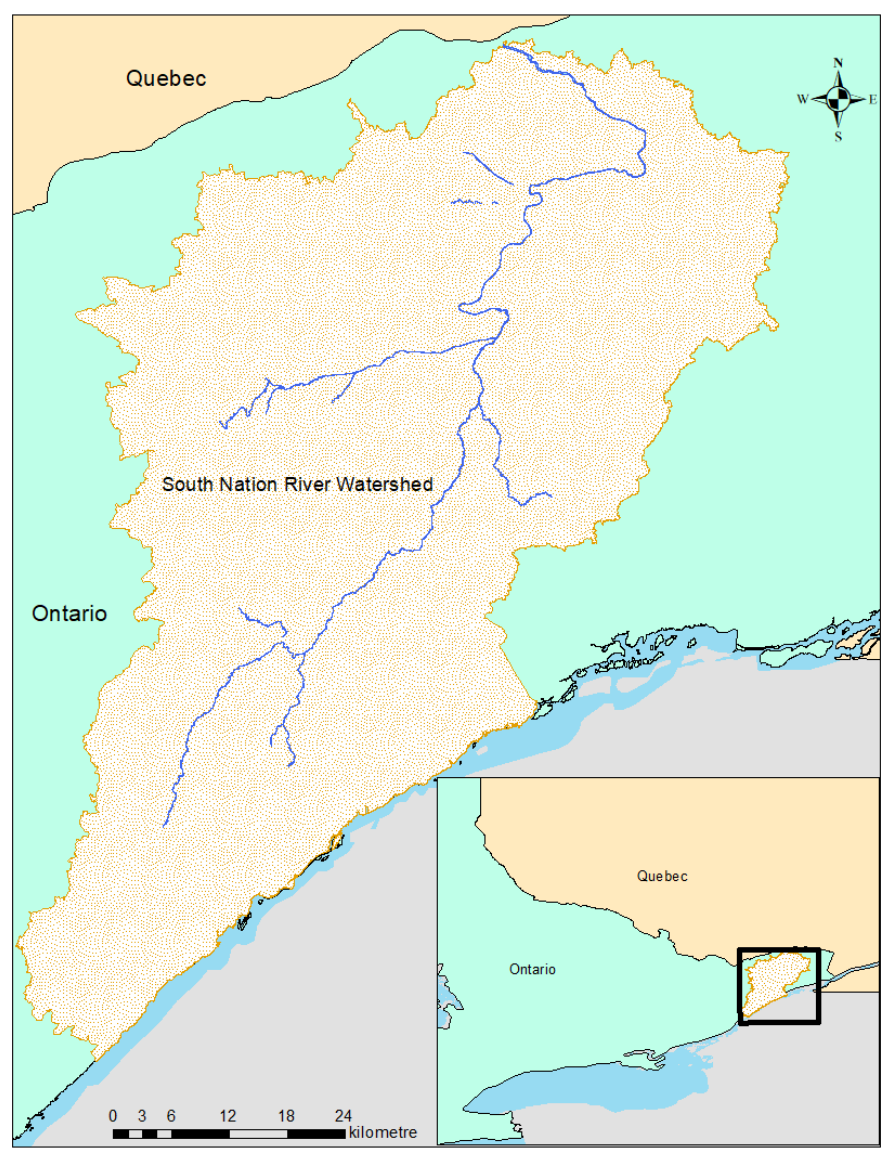

Figure 3: Location map showing the South Nation Watershed in the easternmost part of Ontario adjacent to Quebec. 


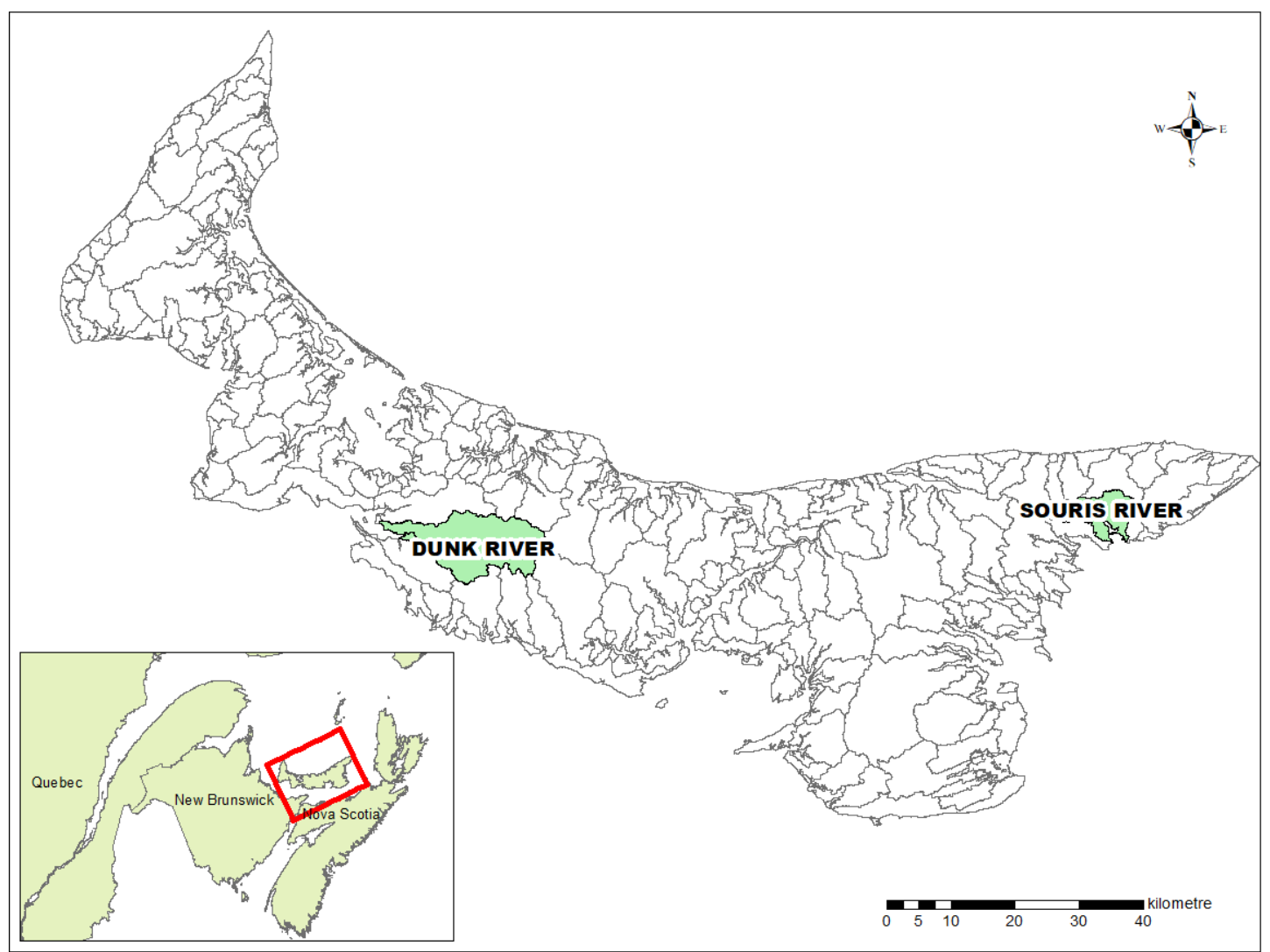

Figure 4: Location map of the two PEI watersheds in relation of eastern Canada and within PEl. Dunk River watershed is located mid-island and Souris River watershed is located on the easternmost tip. Watersheds in this map are delineated by the gray lines.

All three watersheds have a mix of forest and agriculture which allows the testing of methods for different landscape compositions (Figure 5, Figure 6, \& Figure 7). AAFC $\mathrm{ACl}$ maps were used to calculate the approximate spatial coverage of land use and cover classes within each watershed. The South Nation watershed had $\sim 60 \%$ agriculture and $\sim 19 \%$ forest (Figure 5); Dunk River, $\sim 69 \%$ agriculture, $\sim 18 \%$ forest (Figure 6); and Souris River, $\sim 38 \%$ agriculture and $\sim 37 \%$ forest (Figure 7 ). The most common agricultural products for South Nation were soybean, corn, and forages, while the PEI watersheds were dominated by forage and potato production. 
These three watersheds are different sizes to test the classification methods across geographic extents. The largest is the South Nation River watershed at $4441 \mathrm{~km}^{2}$ (South Nation Conservation, 2018), the Dunk River watershed is mid-sized at $167 \mathrm{~km}^{2}$ (Bedeque Bay Environmental Management Association, 2019), and the smallest is the Souris River watershed at $60 \mathrm{~km}^{2}$ (Souris \& Area Branch PEI Wildlife Federation, 2006). This range in characteristics should improve the geographic portability of the methods tested in this study. 


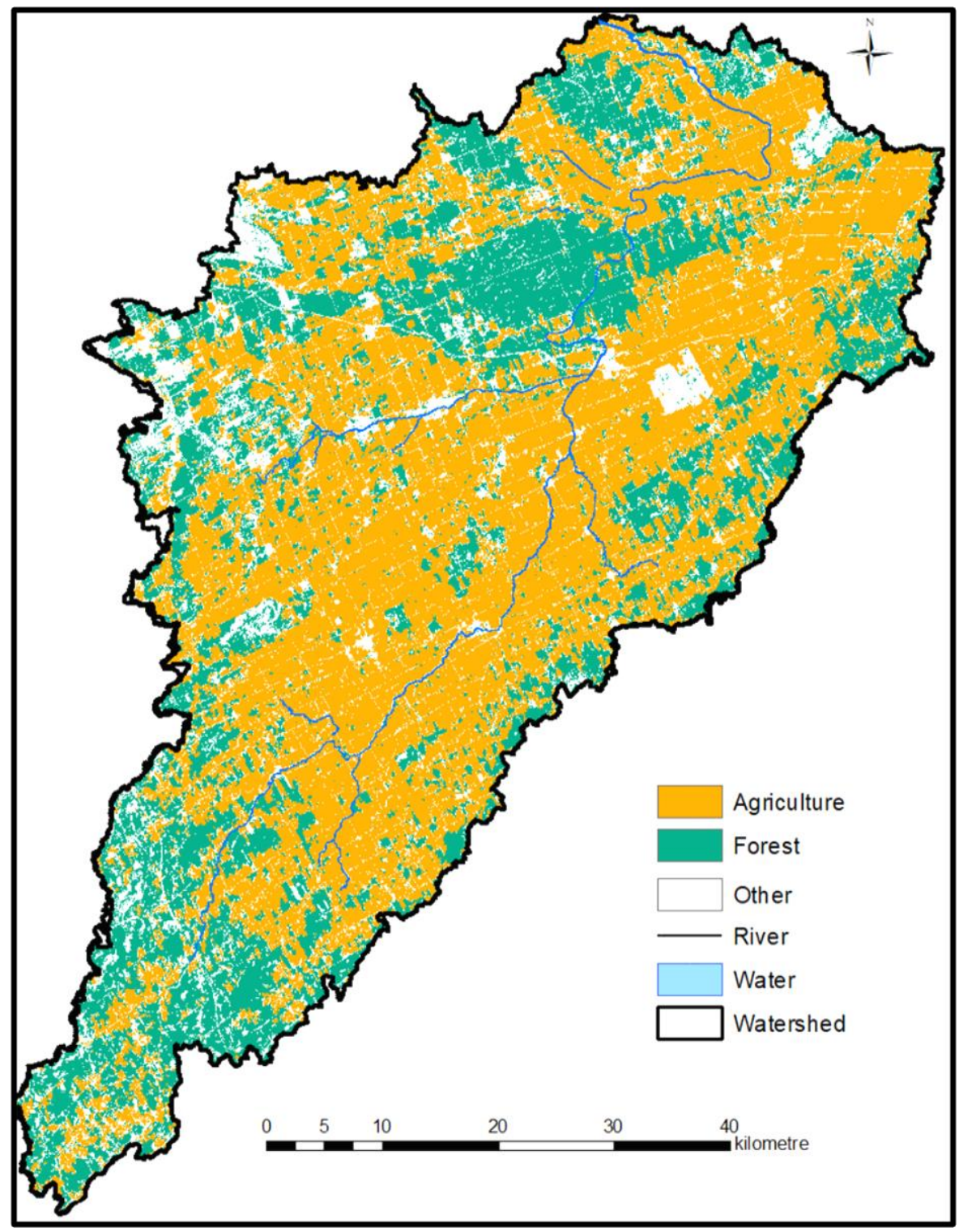

Figure 5: Map of South Nation watershed with $\sim 60 \%$ Agriculture and $\sim 19 \%$ Forest represented based on AAFC 2015 crop map. 


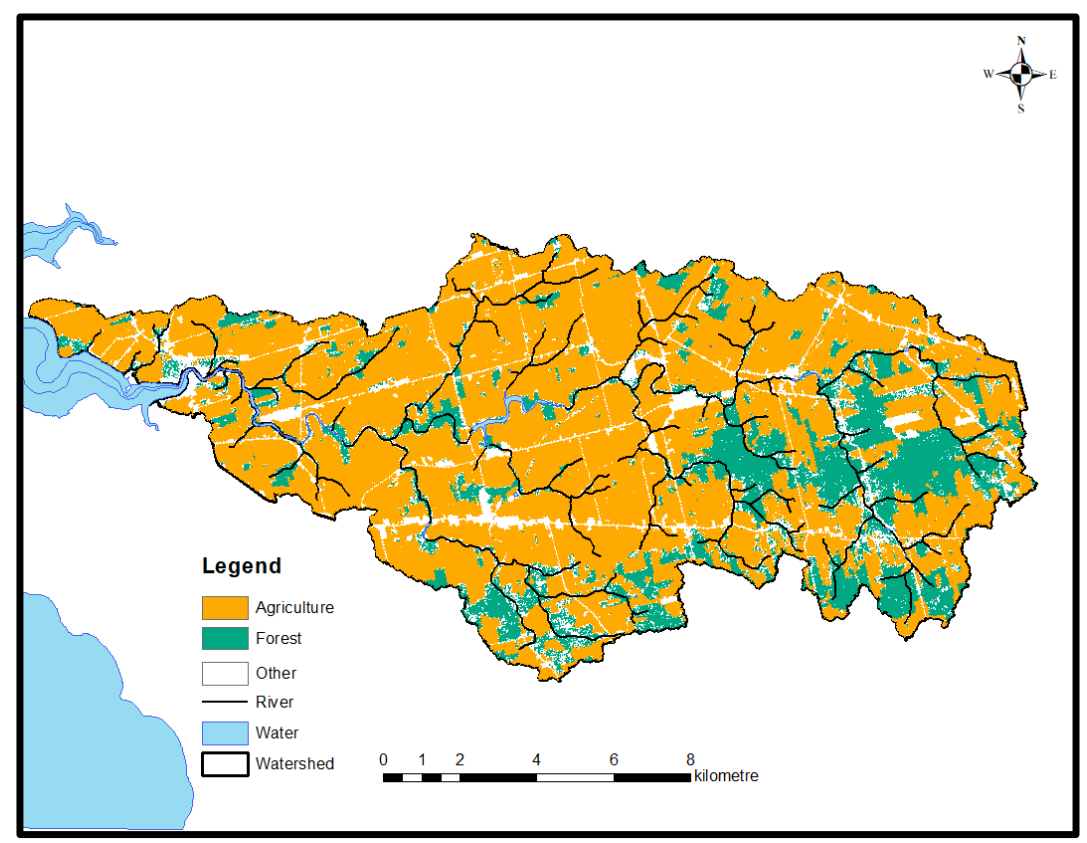

Figure 6: Map of Dunk River watershed with $\sim 69 \%$ Agriculture and $\sim 18 \%$ Forest represented from the AAFC crop map 2016.

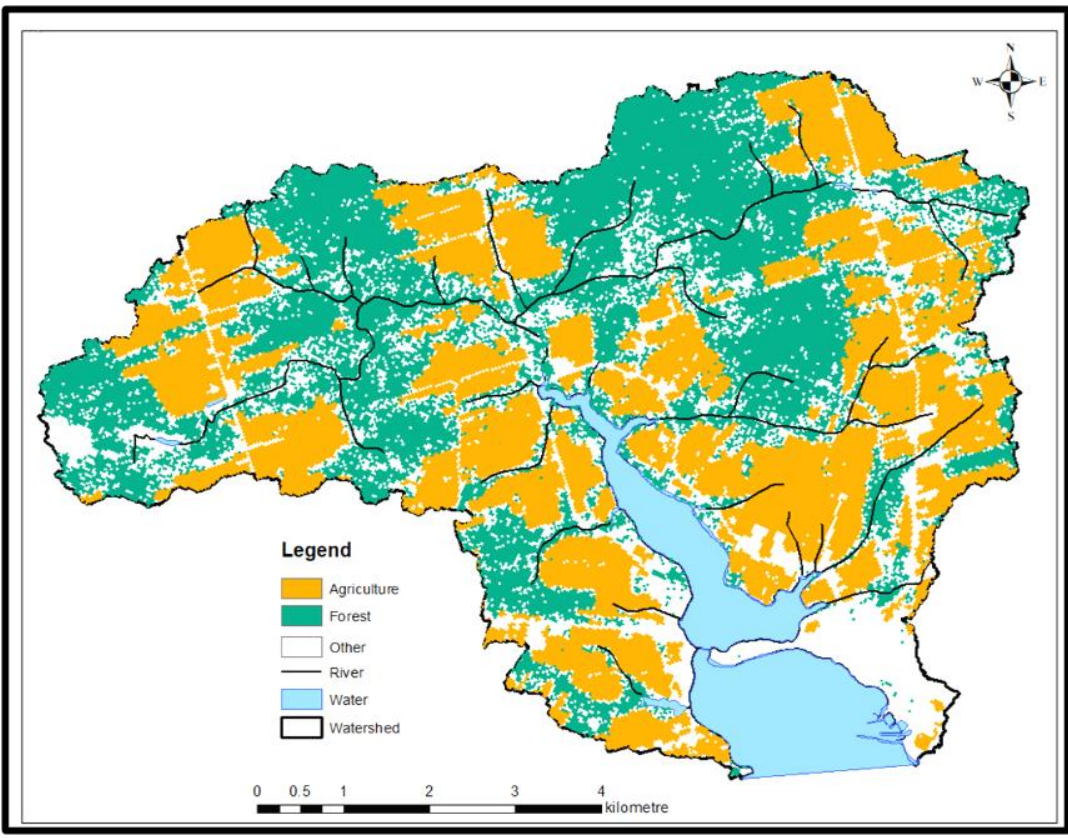

Figure 7: Map of Souris River watershed with 38\% Agriculture and 37\% Forest represented from the AAFC crop map 2016. 


\subsection{Data Acquisition}

\subsubsection{Field Data}

Given the heterogeneity of riparian landcover and a goal of mapping biodiversity, this project began by collecting and mapping as many classes as possible. Data collection (sample) sites were selected within each watershed where water met a road and was accessible to a driver (without trespassing), with greater emphasis placed on collecting data at wider areas of the river, rather than at small ephemeral streams. At each collection site, field data points of all cover types that could be accurately identified from the road were classed. Aggregating the classes after collection is always possible and it seemed prudent to include as much variability as possible. The riparian landcover type changed so rapidly that spatial autocorrelation impacts were deemed negligible.

The field data points for the South Nation watershed were collected in July and August 2015, while in PEI they were collected on July 24 and 25, 2015. Field data were collected on portable computers and geolocated using ArcPad software. To help orient the data collection, the software interface was configured to show background imagery from a $1 \mathrm{~m} 2010$ orthorectified satellite image for the PEI sites, and a $5 \mathrm{~m}$ RapidEye image from 2013 for Ontario. 
High spatial resolution imagery was used for post hoc refinement of the field data point placement. For the South Nation River, field data sampling locations were refined and added through comparison with RapidEye background maps from 2015 and DRAPE imagery from 2014. Similarly, for the PEI watersheds, point refinement and addition was undertaken using the same process with a $1 \mathrm{~m}$ pixel Worldview satellite image (2010), a 1m Land Use Land Cover map from 2010, and RapidEye from 2016. Additional points $(5-10)$ for cover classes that were under-represented in the field sampling but were clearly identifiable from imagery, such as water, agriculture, and conifer forest, were added.

A polygon was manually drawn around each field data point to cover an area that met, or exceeded, the suggested MMU of 3 pixels by 3 pixels to make all training areas (Demers et al., 2015). Some rarer classes were not well represented in the dataset or did not meet the MMU. If there were fewer than 10 polygons of a class, it was removed, or merged with a lower thematic resolution class, such as merging tall and short shrubs into the shrubland class, and managed and unmanaged grassland into grassland.

Small sample sizes cause many classification challenges. It is recommended to have a minimum of $10 n-100 n$ pixels (where $n$ is the number of bands) of training sample pixels for each class (Muise, 2011). For testing classification results, it is common to remove a subset of the training data to use as validation data, and there must be a sufficient amount of input field data so that the accuracy is not determined by just a few 
pixels. A commonly used subset of $70 / 30$ was chosen, with $70 \%$ of the field data used for classification training, and $30 \%$ used for testing.

There were fewer field data sites that met the MMU needed for input polygons than expected. The South Nation River watershed data were collected at too fine a spatial resolution and so many points did not meet the MMU needed. For the South Nation River watershed, 1686 field data points were collected, though they resulted in only 207 polygons; similarly, 664 points in the Dunk River watershed became 581 polygons, and 236 points for the Souris River watershed became 140 polygons. A summary of the points used for each treatment and study area is presented in Table 1.

Table 1: Counts of field data polygons for each watershed for each masking treatment (described below) using RapidEye.

\begin{tabular}{|c|c|c|c|}
\hline \multicolumn{4}{|c|}{ Field Data Polygon Counts } \\
\hline & \multicolumn{3}{|c|}{ Masking Treatment } \\
\cline { 2 - 4 } & Whole Area & Crop Cookie Cutter & $60 \mathrm{~m}$ Buffer \\
\hline South Nation River & 207 & 165 & 163 \\
\hline Dunk River & 581 & 272 & 451 \\
\hline Souris River & 140 & 103 & 108 \\
\hline
\end{tabular}

\subsubsection{Vector Data}

All analysis was done using ArcMap (Esri Inc., 2019), ArcGIS Pro (Esri Inc., 2019), and Excel (Microsoft Corporation, 2018) and the vector datasets used for bounding and processing are listed in Table 2. 
Table 2: Datasets used for planning, processing, and delineating the study area.

\begin{tabular}{|c|c|c|}
\hline Date & Dataset & Source \\
\hline $\begin{array}{l}\text { January } 25, \\
2012\end{array}$ & $\begin{array}{l}\text { National Hydro } \\
\text { Network- } \\
\text { South Nation }\end{array}$ & $\begin{array}{l}\text { Ministry of Natural Resources } \\
\text { https://open.canada.ca/data/en/dataset/a4b190fe- } \\
\text { e090-4e6d-881e-b87956c07977 }\end{array}$ \\
\hline 2008 & $\begin{array}{l}\text { PEI } \\
\text { Waterbodies }\end{array}$ & $\begin{array}{l}\text { Atlas of Canada Natural Resources Canada } \\
\text { maritdrnetwork_1m_v6-0.shp }\end{array}$ \\
\hline May 2014 & $\begin{array}{l}\text { National Road } \\
\text { Network }\end{array}$ & $\begin{array}{l}\text { Natural Resources Canada } \\
\text { http://www.geogratis.gc.ca/ }\end{array}$ \\
\hline 2010 & $\begin{array}{l}\text { South Nation } \\
\text { Watershed }\end{array}$ & $\begin{array}{l}\text { Ontario Ministry of Natural Resources } \\
\text { http://geo.scholarsportal.info/\#r/details/_uri@=158952 } \\
3613\end{array}$ \\
\hline 2008 & $\begin{array}{l}\text { PEI } \\
\text { Watersheds }\end{array}$ & $\begin{array}{l}\text { Government of Prince Edward Island } \\
\text { http://www.gov.pe.ca/gis/download.php3?name=wate } \\
\text { rsheds08\&file_format=SHP }\end{array}$ \\
\hline 2016 & Provinces & $\begin{array}{l}\text { Statistics Canada Cartographic Boundary } \\
\text { http://geo.scholarsportal.info/\#r/details/_uri@=749265 } \\
\text { 755\$DLI_2016_Census_CBF_Eng_Nat_pr }\end{array}$ \\
\hline 2015 & $\begin{array}{l}\text { Ontario } \\
\mathrm{ACl}\end{array}$ & $\begin{array}{l}\text { AAFC - Crop Inventory } \\
\text { https://open.canada.ca/data/en/dataset/3688e7d9- } \\
\text { 7520-42bd-a3eb-8854b685fef3 }\end{array}$ \\
\hline 2016 & $\begin{array}{l}\mathrm{PEI} \\
\mathrm{ACl}\end{array}$ & $\begin{array}{l}\text { AAFC - Crop Inventory } \\
\text { https://open.canada.ca/data/en/dataset/b8e4da73- } \\
\text { fb5f-4e6e-93a4-8b1f40d95b51 }\end{array}$ \\
\hline $\begin{array}{l}\text { February } 1 \\
2000\end{array}$ & $\begin{array}{l}\text { Ecozones } \\
1: 7500000\end{array}$ & $\begin{array}{l}\text { Atlas of Canada } \\
\text { https://www.ccea.org/ecozones-downloads/ }\end{array}$ \\
\hline
\end{tabular}




\subsubsection{Earth Observation Data (Satellite Imagery)}

\section{Landsat 8}

For operational monitoring, Landsat 8 is an attractive EO choice as it provides frequent images covering all of Canada, reasonable spatial detail (30 m) with wide swaths, has historical archives stretching back as far as the 1980s, and is available to the public at no charge. The utility of the Landsat series of satellites for national-scale mapping has been clearly demonstrated by Agriculture and Agri-Food Canada, which has relied heavily on this mission since 2008 to operationally map landcover and land use across Canada's full agricultural extent (Agriculture and Agri-Food Canada, 2019). Unfortunately, the RWHAFI uses a $60 \mathrm{~m}$ riparian strip definition (discussed below) and MMU recommendations for Landsat imagery could not be met within the RWAHFI riparian zone (Figure 8). Also, there were very few places that the riparian vegetation patches were large enough to meet MMU, even ignoring the riparian definition of $60 \mathrm{~m}$. This showed that Landsat is not appropriate for mapping these narrow features, so no further processing was applied. 


\section{South Nation Watershed with 10 meter grid overlay}

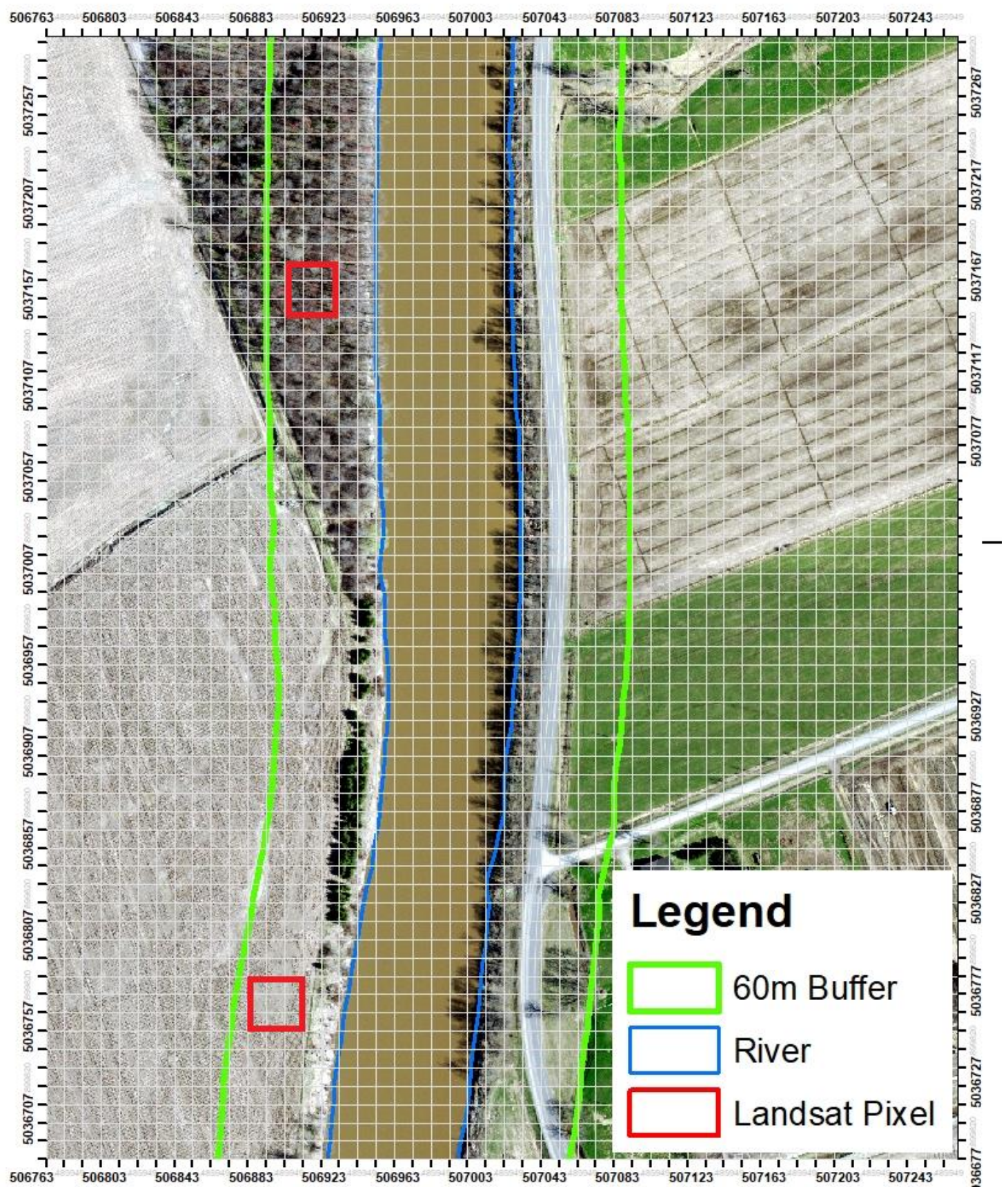

Figure 8: DRAPE 2014 image of the South Nation River showing the size of Landsat pixels (red boxes) in the $60 \mathrm{~m}$ riparian buffer with a $10 \mathrm{~m}$ grid overlay. 


\section{RapidEye}

RapidEye refers to a constellation of five satellites that collect images in five spectral bands (blue, green, red, red-edge, and near infrared) at $5 \mathrm{~m}$ spatial resolution, with individual scenes covering $77 \mathrm{~km}^{2}$. Data are pre-processed by the vendor with radiometric, sensor, and geometric corrections before distribution (Planet Labs, 2016). Because RapidEye imagery is costly, especially for multi-temporal collections over large areas, it is not currently used by AAFC in its operational land use and cover mapping. However, it is frequently used in the research and development stage for testing the effects of finer spatial resolution data on new mapping methodologies, and it is for this reason these data are used in this study. This is especially important for mapping smaller and narrower landcover features such as riparian zones that cannot be mapped well using medium spatial resolution sensors such as Landsat 8.

The RapidEye imagery of South Nation River was collected in 2015. However, PEI did not have cloud free imagery during the growing season for 2015, so imagery from 2016 was used for those watersheds. It was expected that land cover changes over one year would be minimal for the non-agricultural landcover.

Land cover spectral reflectance can be influenced by antecedent weather conditions. This is especially true for small waterways whose sediment loads can increase after significant rain events. All three study watersheds had $<15 \mathrm{~mm}$ precipitation in the nearest city's weather station in the 2 days before collection of the RapidEye imagery 
(Government of Canada, 2020). This amount of precipitation should not impact the imagery or the classification.

\section{DRAPE}

DRAPE- Digital Raster Acquisition Project for Eastern Ontario- is a high-resolution air photo imagery data set of Eastern Ontario with $20 \mathrm{~cm}$ pixels and was collected in 2014 (MNRF, 2019). DRAPE is the result of a public and private collaboration and was received by Carleton from the Ministry of Natural Resources and Forestry (MNRF, 2019). 
Table 3: Summary of EO imagery used.

\begin{tabular}{|l|l|l|l|}
\hline Date & Image & Resolution & Source \\
\hline 2013 & $\begin{array}{l}\text { RapidEye } \\
\text { South Nation River }\end{array}$ & $5 \mathrm{~m}$ & $\begin{array}{l}\text { USGS } \\
\text { www.planet.com/products/plan } \\
\text { et-imagery/ }\end{array}$ \\
\hline $\begin{array}{l}\text { April 28th - } \\
\text { June 7th, 2014 }\end{array}$ & $\begin{array}{l}\text { DRAPE Air Photo } \\
\text { South Nation River }\end{array}$ & $20 \mathrm{~cm}$ & $\begin{array}{l}\text { OMNR or MNRF } \\
\text { http://geo.scholarsportal.info/\#r } \\
\text { /details/_uri@=1863583366 }\end{array}$ \\
\hline $\begin{array}{l}\text { May 29 and } \\
\text { August 17th, } \\
2015\end{array}$ & $\begin{array}{l}\text { Landsat } \\
\text { South Nation River }\end{array}$ & $30 \mathrm{~m}$ & $\begin{array}{l}\text { USGS } \\
\text { https://earthexplorer.usgs.gov/ }\end{array}$ \\
\hline June 3, 2015 & $\begin{array}{l}\text { RapidEye } \\
\text { South Nation }\end{array}$ & $5 \mathrm{~m}$ & $\begin{array}{l}\text { Planet Labs } \\
\text { www.planet.com/products/plan } \\
\text { et-imagery/ }\end{array}$ \\
\hline 2010 & $\begin{array}{l}\text { Worldview } \\
\text { PEl }\end{array}$ & $1 \mathrm{~m}$ & $\begin{array}{l}\text { USGS } \\
\text { https://worldview.earthdata.nas } \\
\text { a.gov/ }\end{array}$ \\
\hline $\begin{array}{l}\text { September 12, } \\
2016\end{array}$ & $\begin{array}{l}\text { RapidEye } \\
\text { Dunk River }\end{array}$ & $5 \mathrm{~m}$ & $\begin{array}{l}\text { Planet Labs } \\
\text { www.planet.com/products/plan } \\
\text { et-imagery/ }\end{array}$ \\
\hline $\begin{array}{l}\text { August 31, } \\
2016\end{array}$ & $\begin{array}{l}\text { RapidEye } \\
\text { Souris River }\end{array}$ & $\begin{array}{l}\text { Planet Labs } \\
\text { www.planet.com/products/plan } \\
\text { et-imagery/ }\end{array}$ \\
\hline
\end{tabular}




\subsection{Classification Components}

Figure 9 presents an overview of the multiple landcover classification strategies used in this study to determine the most successful method for classifying riparian zones. Each classification strategy combined components from each of the following: Study Area, Spatial Resolution, Thematic Resolution, Masking Treatment, and Pixel vs. Object based approaches. Each is explained further in the following sections.

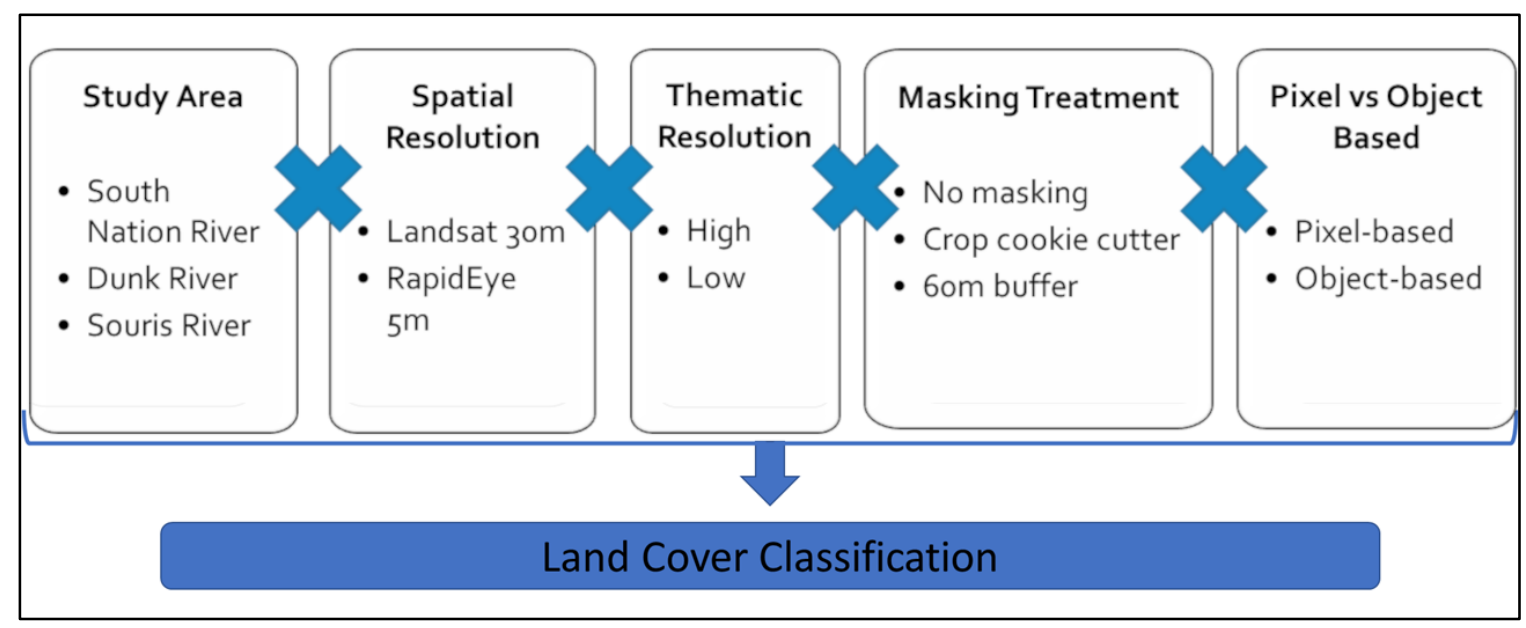

Figure 9: Overview of the Land Cover Classification Components.

\subsubsection{Spatial Resolution}

There were two image spatial resolutions chosen to classify the study areas. Landsat, with 30 m pixels, was chosen because it is already used operationally by AAFC for their $\mathrm{ACl}$. RapidEye, with $5 \mathrm{~m}$ pixels, was chosen because it is commonly used by AAFC to test new methods at finer spatial resolutions than those used in their operational 
activities. For operational mapping, the coarsest spatial resolution that produces acceptable results is desirable because it minimizes the computational overhead required for mapping at national scales.

RapidEye imagery has a more appropriate spatial resolution for classifying the study watersheds because $5 \mathrm{~m}$ pixels allows more of the narrow riparian vegetation to be included and using this imagery kept more field data for classification. In field observations of the riparian areas, much of the vegetated riparian strip was $<15$ m wide ( $\sim 3$ pixels). Given the $60 \mathrm{~m}$ width of the riparian zone for the RWHAFI and the configuration of the riparian vegetation landcover, RapidEye was used for the processing of all the methods.

\subsubsection{Thematic Resolution}

The landcover classes were selected based on expected cover types found in the riparian zone, in combination with the WHAFI classes. In an effort to get the finest thematic resolution possible, the 10 cover types/classes I collected were: Conifer, Deciduous/Broadleaf, Mixed Forest, Shrubland (Tall and Short), Barren (bare soil or rock), Wetland, Water, Grassland (Managed and Unmanaged), Developed, and Agriculture.

The WHAFI uses all 62 AAFC crop classes, as well as several forest area classes (Forest $\leq 2$ ha or Forest $\geq 2$ ha), though the WHAFI has much of the riparian and "idle" 
land classified as "other" and not considered. Given the issues with riparian classification, the RWHAFI uses lower thematic resolution with broader classes than the WHAFI, with only Riparian Woody, Riparian Herbaceous, Riparian Agriculture, and Other. See Table 4 for an overview of the classes used in each context and a short description.

My aim was to classify the riparian zone to the highest thematic resolution possible. Classification at the highest thematic resolution (the collection resolution of 10 classes) was not possible. As detailed above, there were insufficient data for the rarer classes and most of the subclasses had to be merged. I started by testing all the classification methods at the high thematic resolution to determine its accuracy, then applied that method to the low thematic resolution as input for the RWHAFI. 
Table 4: Thematic resolution, description of the classes collected, and the classes used by the WHAFI and the Riparian WHAFI.

\begin{tabular}{|c|c|c|c|c|}
\hline $\begin{array}{l}\text { Field } \\
\text { collected } \\
\text { Subclasses }\end{array}$ & Classes & $\begin{array}{l}\text { RWHAFI } \\
\text { Classes }\end{array}$ & WHAFI Classes & Description \\
\hline & $\begin{array}{l}\text { High } \\
\text { (7 Classes) }\end{array}$ & $\begin{array}{l}\text { Low } \\
\text { (4 Classes) }\end{array}$ & (62 Classes) & \\
\hline Conifer & Conifer & Woody & $\begin{array}{l}\text { Conifer } \\
\text { \& Conifer >2ha }\end{array}$ & $\begin{array}{l}\text { Conifer trees \& } \\
\text { Conifer forest }\end{array}$ \\
\hline Broadleaf & Broadleaf & Woody & $\begin{array}{l}\text { Broadleaf } \\
\& \text { Broadleaf }>2 \text { ha }\end{array}$ & $\begin{array}{l}\text { Broadleaf trees \& } \\
\text { Broadleaf forest }\end{array}$ \\
\hline Mixed Trees & $\begin{array}{l}\text { Mixed } \\
\text { Trees }\end{array}$ & Woody & \begin{tabular}{|l} 
Mixed trees \& \\
Mixed Forest >2ha
\end{tabular} & $\begin{array}{l}\text { Mix of Conifer and } \\
\text { Broadleaf Trees }\end{array}$ \\
\hline Short & Shrubland & Woody & Shrubland & $<2 \mathrm{~m}$ tall \\
\hline Tall & Shrubland & Woody & Shrubland & $>2 \mathrm{~m}$ tall \\
\hline Natural & Grassland & Herbaceous & Grassland & Unmowed \\
\hline Managed & Grassland & Herbaceous & Grassland & Mowed \\
\hline Developed & $\begin{array}{l}\text { Developed/ } \\
\text { Bare Soil }\end{array}$ & & Developed & $\begin{array}{l}\text { Developed land, } \\
\text { roads, buildings }\end{array}$ \\
\hline Barren & $\begin{array}{l}\text { Developed/ } \\
\text { Bare Soil }\end{array}$ & & Exposed & Exposed ground \\
\hline Wetland & Wetland & & Wetland & Water and vegetation \\
\hline Water & Water & & Water & Any water \\
\hline Agriculture & Agriculture & & $\mathrm{ACl}$ Crop classes & Crops \\
\hline
\end{tabular}




\subsubsection{Spatial Masking Treatments}

All satellite imagery was mosaicked and extracted to each of the three watersheds before the masking treatments were applied. Visual examples from Dunk River watershed are provided below (Figure 10). To test potential operationally feasible masking methods aimed at better classifying the riparian areas, three different treatments were compared:

First, the whole watershed was classified, with no spatial masking (Figure 10a).

The second option, hereafter referred to as the "Crop Cookie Cutter treatment" (Figure 10b) assumed that the $\mathrm{ACl}$ (Agriculture and Agri-Food Canada, 2019) would be better at classifying the agricultural classes than could be accomplished separately in this study. This mask was included based on the goal to add the riparian vegetation to the operational $\mathrm{ACI}$ making the landcover map more robust. Crops and urban areas from the crop inventory map were masked out (analogous to using a cookie cutter) before classifying the vegetation adjacent to the water and crops.

The third treatment applied a fixed $60 \mathrm{~m}$ buffer around all water based on a vector file (Figure 10c), chosen because this defined width is used by the RWHAFI. 

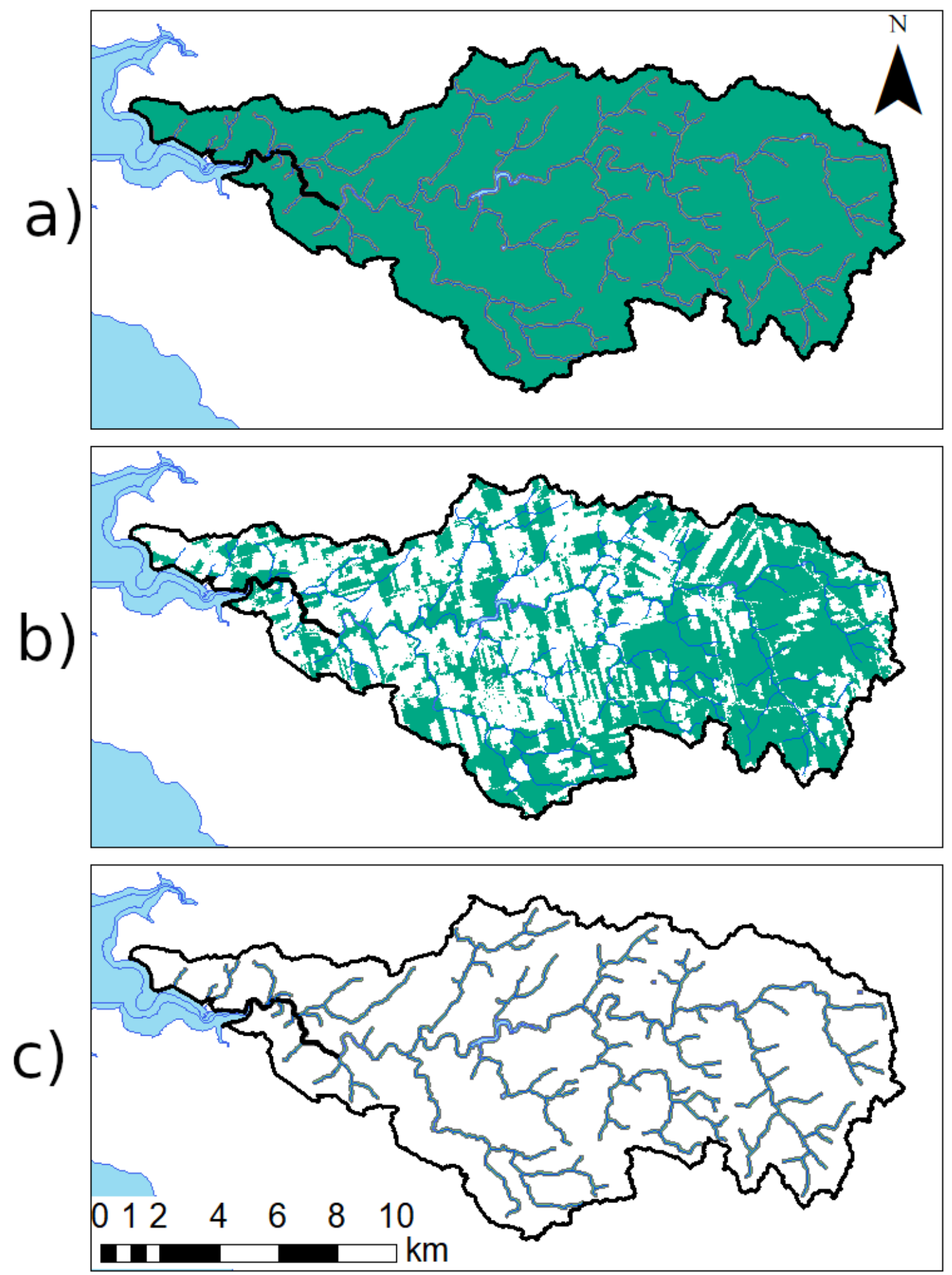

Figure 10: Dunk River watershed showing the different preprocessing methods: a) whole area, b) crop cookie cutter, and c) $60 \mathrm{~m}$ buffer. 


\subsubsection{Pixel-based vs. Object-based Classification}

Each combination of the methods was processed with the pixel-based classifier and again with the segmented image included as the object-based classification. Using the accuracy values from each method, the pixel-based vs. object-based results were compared by subtracting the object-based accuracy results from the pixel-based accuracy results for each treatment. If the result is positive then pixel-based methods had higher accuracy, if the result is negative then object-based methods had higher accuracy.

\subsection{Land-Cover Classification}

\subsubsection{Training Data}

After the images and field data were processed for each treatment, the field data were subset to create a training dataset $(70 \%$ of samples) and validation dataset ( $30 \%$ of samples). These datasets were visually assessed for sufficient representation across classes to ensure there were samples of each class in both the training and validation subsets. This was done to prevent accuracy results being based on the classification of one specific validation area.

\subsubsection{Segmentation}

Segmentation parameters were adjusted to find the "best fit" for each watershed 
Table 5) by adjusting the importance of the spectral and spatial detail parameters, as well as the number of pixels per object (Esri, 2021). The image is then segmented using the parameters that result in the best separation of landcover classes based on visual inspection. The "spectral detail" parameter ranges from 1.0 - 20.0 where higher values put more emphasis on differentiation of segments based on the spectral reflectance or colour of the pixels, while the "spatial detail" (range $1-20$ ) focuses on proximity of the pixels, and lastly the "minimum segment size" is the smallest number of pixels that should be grouped (Esri, 2021). The object-oriented version of each treatment uses the same field data as the pixel-based method but is classifying the segmented image. Instead of classifying the pixels, each segment/object is classified compared to a signature created from the objects.

Table 5: Parameters used for image segmentation by watershed.

\begin{tabular}{|l|c|c|c|}
\hline Study Area & Spectral detail & Spatial detail & $\begin{array}{l}\text { Minimum segment } \\
\text { size in pixels }\end{array}$ \\
\hline South Nation River & 18.5 & 8 & 20 \\
\hline Dunk River & 17.5 & 5 & 20 \\
\hline Souris River & 16.5 & 10 & 20 \\
\hline
\end{tabular}

\subsubsection{Maximum Likelihood Classification}

A supervised classification approach was used, creating a spectral reflectance "signature" for each landcover class using the distribution of spectral reflectance values in the EO image in the training areas collected in the field (Esri, 2020). 
Spectral signatures were created from the $70 \%$ training subset of the field data polygons. For the object-based methods, the segmented image was used for the classification process. The pixel-based MLC classification and object-based classification were run for each masking treatment in each of the three watersheds.

\subsubsection{Classification Accuracy}

The accuracy of each classification is determined by how much of the resulting map is correctly identified when compared to independent validation (field) data. The Equalized Stratified Random (ESR) accuracy tool puts equal emphasis on rare and common classes by creating the same number of testing points per class (Esri, 2020). Selecting an accuracy method that accounts for rarity is needed as several of the classes, while present and important, are less commonly found in these highly modified landscapes.

The validation subset, the remaining $30 \%$ of the field data polygons, were used to determine the accuracy of the classification using the Equalized Stratified Random sampling strategy. This strategy randomly assigned 50 points per class within the validation polygon areas, thus all classes have equal impact on the overall accuracy and the impacts of unequal distributions of field data points is reduced. The results of each classified image are compared to the validation data points. Those results are presented in confusion matrices and the overall accuracy is the metric of successful classification. 
Each classification accuracy has an associated kappa value. This value is not used for comparing the different methods but is reported as part of the output from the accuracy calculation. The value is based on the probability that the classification is more accurate than random chance with 1 being perfect agreement and -1 being perfect disagreement. It is calculated from the Kappa coefficient equation (Congalton \& Green, 2019):

Kappa coefficient $=\frac{\text { Agreement }- \text { ChanceAgreement }}{1-\text { ChanceAgreement }}$

where Agreement is the sum of all correctly classified pixels compared to the validation pixels, and the ChanceAgreement is the summation of the User's accuracies multiplied by the Producer's accuracies.

To determine the most successful preprocessing treatment, I calculated an average classification accuracy for each masking treatment and method. The highest average accuracy was termed the most successful. Consistently accurate and geographically portable classification methods are needed to create high quality landcover maps needed as input for the RWHAFI. 


\subsection{The Riparian Wildlife Habitat Availability on Farmland Indicator (RWHAFI)}

For the RWHAFI, AAFC scientists developed habitat association matrices for terrestrial vertebrate species found within $60 \mathrm{~m}$ of the water in agricultural regions for each ecozone (i.e. 324 species in the "Mixed Wood Plains") from range maps, local knowledge, and literature reviews, representing an enormous amount of work done previously by AAFC scientists (Javorek \& Grant, 2011, Javorek \& Grant, unpublished; Neave \& Neave, 1998). These scientists focused on six life cycle requirements: Rutting, Feeding, Lounging, Cover, Wintering, and Staging/Migration. For each species and life cycle habitat requirement, each cover type was given a rank of primary, secondary, tertiary, or N/A with an associated Habitat Use Value (HUV) of 3, 2, 1, or 0, respectively (Javorek \& Grant, unpublished). Strongly preferred or dependent habitats are considered primary, used but not dependent habitats are considered secondary, occasionally used but not needed habitats are considered tertiary, and unused habitat is considered not applicable (Javorek \& Grant, 2011).

The RWHAFI uses 4 agricultural riparian land cover types, Agricultural, Herbaceous, Woody, and Other, unlike the landscape WHAFI that considers most crop types, forest type and size, and several other landcovers (62 landcover types). Below, Table 6 presents a simplified example of a Riparian Habitat Association Matrix showing the HUV for each species, each life stage requirement, and each habitat. 
Table 6: Sample subset of the RWHAFI Habitat Use Matrix for the Mixed Wood Plains, with values between 0 and 3 (Javorek and Grant, unpublished).

\begin{tabular}{|c|c|c|c|c|c|c|c|}
\hline \multirow[t]{2}{*}{ Species } & \multirow[t]{2}{*}{ Habitat } & \multicolumn{6}{|c|}{ Life Stage } \\
\hline & & 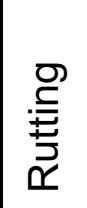 & 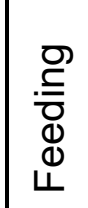 & 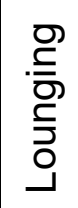 & 㐫 & 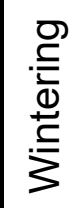 & 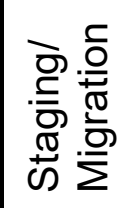 \\
\hline Garter Snake & Woody & 2 & 2 & 0 & 2 & 2 & 0 \\
\hline Garter Snake & Herbaceous & 2 & 2 & 0 & 2 & 2 & 0 \\
\hline Garter Snake & Agriculture & 2 & 2 & 0 & 2 & 2 & 0 \\
\hline Mudpuppy & Herbaceous & 1 & 1 & 0 & 1 & 1 & 0 \\
\hline Mudpuppy & Agriculture & 2 & 2 & 0 & 2 & 2 & 0 \\
\hline Mudpuppy & Woody & 1 & 1 & 0 & 1 & 1 & 0 \\
\hline
\end{tabular}

Using the classified results from the riparian SBEO classification, areal proportion is calculated then used as input for the indicator equation below. The input maps should aim to meet the minimum classification accuracy of $85 \%$ used by the AAFC crop inventory team. However, given the challenges of mapping riparian zones and the much smaller amount of data available for classification compared to crop classification, lower accuracy may still have some utility. The RWHAFI is calculated using the Habitat Use 
Matrix (Table 6), the percent landcover in the study area, and the WHAFI process (Javorek \& Grant, 2011):

RWHAFI $=\sum\left(\left(\% L C \times H U V_{R}\right)_{n}+\left(\% L C \times H U V_{F}\right)_{n}+\left(\% L C \times H U V_{L}\right)_{n} \ldots\right)$

where RWHAFI = Riparian Habitat Availability on Farmland Indicator, \%LC = the percentage of a landcover class in the summary area, HUV = Habitat Use Value for: Rutting (R), Feeding (F), Lounging (L), Cover (C), Wintering (W), and Staging/Migration (S), and $\mathbf{n}=$ all the species in the ecozone.

The equation used to calculate the RWHAFI produces a value between 0 and 2020 (Mixed Woods Plains) representing the habitat availability on riparian farmland for all vertebrate species in that ecozone for each summary area. The RWHAFI can be summarized to any summary area within the ecozone depending on the goals of the studies or the needs of the managers. This pilot study summarizes it to the watershed.

To calculate the range of the RWHAFI values, the table of habitat use summations was used. In the "Mixed Woods Plains" ecozone, the Woody cover type has the highest habitat use values, so if $100 \%$ of the riparian area was Woody, the highest possible value for the RWHAFI would be 2020 , while the lowest value would be 0 , if all the riparian zone was composed of something like pavement or urban classes that are part of the "other" category. The value increases as the habitat became more vegetated and forested. Agriculture has generally lower values than the Herbaceous or Woody, but the 
habitat use values for the Other category are 0 , which includes the water, barren, urban, and developed landcovers. The Habitat Use Value databases have some generalizations and potential errors as they are based on distribution maps. The uncertainty of the indicator habitat use values is assumed to be higher than the uncertainty of the landcover mapping (Kirby, 2015) so error propagation was not considered worthwhile. However, assuming the stay constant through time, they should give consistent results that would be appropriate to use for monitoring. The RWHAFI habitat availability matrices were only available for the "Mixed Wood Plains" ecozone, where the South Nation River watershed is located, so it was used as a pilot study. 


\section{Results}

The results section reports field observations and data, then summarizes the accuracies of the various landcover classifications for the three study areas at the highest thematic resolution possible. The classification method with the highest accuracy is presented in detail, then the results of the classification components are presented. Then the classification accuracy of the low thematic resolution and the RWHAFI result are presented last.

\subsection{Field Data Assessment}

Point placement of the field data had some placement uncertainty. Most of the riparian habitat in the South Nation River is privately owned so all field data were collected from a distance to avoid trespassing. Even with the $5 \mathrm{~m}$ pixel imagery that was used as background for the GPS-enabled tablet used for data collection, it was difficult to precisely locate sample points. The landcover in the vegetative strip adjacent to the water changed rapidly, was generally very narrow, and was commonly a mix of several landcover classes based on visual observation. Accurately placing field data points on these small patches of landcover was a challenge, particularly from a distance. However, overall, this problem was not considered to be severe enough to significantly affect the results of the study. 


\subsection{Classification Results}

\subsubsection{Masking Treatment}

The pixel-based $60 \mathrm{~m}$ buffer preprocessing treatment was the most accurate method across the three study areas with an average accuracy of $60 \%$. The classification accuracy from all methods for the three watersheds at the high thematic resolution using RapidEye imagery are summarized in Table 7. The highest accuracy was for the South Nation watershed, with an accuracy of 0.709 , followed by the Souris River watershed with an accuracy of 0.578 . For the Dunk River watershed $60 \mathrm{~m}$ buffer pixel-based method had an accuracy of 0.510 , which was a negligible $2.5 \%$ less than the object-based whole area method with an accuracy of 0.535. Therefore, the pixel-based $60 \mathrm{~m}$ buffer method had the highest accuracy overall. 
Table 7: Summary of results for all three watersheds using RapidEye imagery. Each watershed has an overall accuracy and kappa for each treatment, both pixelbased and object-based. The grey shaded values are the highest accuracy for each watershed and the green shaded value is the highest average accuracy. The detailed confusion matrices are located in the Appendix.

\begin{tabular}{|l|l|l|l|l|l|l|l|}
\hline & $\begin{array}{l}\text { South } \\
\text { Nation } \\
\text { Accuracy }\end{array}$ & Kappa & $\begin{array}{l}\text { Runk } \\
\text { River } \\
\text { Accuracy }\end{array}$ & Kappa & $\begin{array}{l}\text { River } \\
\text { Accuracy }\end{array}$ & Kappa & $\begin{array}{l}\text { Average } \\
\text { Accuracy }\end{array}$ \\
\hline $\begin{array}{l}\text { Whole area } \\
\text { (Pixel) }\end{array}$ & 0.594 & 0.527 & 0.528 & 0.460 & 0.543 & 0.467 & 0.55 \\
\hline $\begin{array}{l}\text { Crop Cookie } \\
\text { Cutter (Pixel) }\end{array}$ & 0.662 & 0.605 & 0.422 & 0.340 & 0.519 & 0.425 & 0.53 \\
\hline $\begin{array}{l}\text { 60m Buffer } \\
\text { (Pixel) }\end{array}$ & 0.709 & 0.660 & 0.510 & 0.440 & 0.578 & 0.508 & 0.60 \\
\hline & & & & & & & \\
\hline $\begin{array}{l}\text { Whole area } \\
\text { (Object) }\end{array}$ & 0.543 & 0.467 & 0.535 & 0.469 & 0.371 & 0.267 & 0.48 \\
\hline $\begin{array}{l}\text { Crop Cookie } \\
\text { Cutter (Object) }\end{array}$ & 0.309 & 0.192 & 0.361 & 0.272 & 0.505 & 0.409 & 0.39 \\
\hline $\begin{array}{l}\text { 60m Buffer } \\
\text { (Object) }\end{array}$ & 0.629 & 0.567 & 0.453 & 0.374 & 0.229 & 0.108 & 0.44 \\
\hline
\end{tabular}

\subsubsection{Pixel-based vs. Object-based}

The pixel-based methods had higher average accuracies than the object-based methods for eight of the nine classifications (where the comparison gave a positive result in Table 8). Six of the nine classification methods were comparable between object-based and pixel-based however the other three had much higher accuracies with the pixel-based classification. 
Table 8: Summary of the differences in the method accuracy between pixel-based and object-based classification. Positive values show higher accuracy of pixel-based method. Two are highlighted for the most difference in classification accuracy.

\begin{tabular}{|c|c|c|c|c|c|c|}
\hline & $\begin{array}{l}\text { South } \\
\text { Nation River }\end{array}$ & $\begin{array}{l}\mathbb{0} \\
\stackrel{0}{0} \\
\stackrel{\mathbb{T}}{1}\end{array}$ & $\begin{array}{l}\text { Dunk } \\
\text { River }\end{array}$ & $\begin{array}{l}\frac{\pi}{2} \\
\frac{2}{2} \\
\underline{T}\end{array}$ & $\begin{array}{l}\text { Souris } \\
\text { River }\end{array}$ & 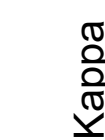 \\
\hline Whole area (Pixel) & 0.59 & 0.53 & 0.53 & 0.46 & 0.54 & 0.47 \\
\hline Whole area (Object) & 0.54 & 0.47 & 0.54 & 0.47 & 0.37 & 0.27 \\
\hline Difference & 0.05 & & -0.01 & & 0.17 & \\
\hline Crop Cookie Cutter (Pixel) & 0.66 & 0.60 & 0.42 & 0.34 & 0.52 & 0.43 \\
\hline Crop Cookie Cutter (Object) & 0.31 & 0.19 & 0.36 & 0.27 & 0.51 & 0.41 \\
\hline Difference & 0.35 & & 0.06 & & 0.01 & \\
\hline 60m Buffer (Pixel) & 0.71 & 0.66 & 0.51 & 0.44 & 0.58 & 0.51 \\
\hline 60m Buffer (Object) & 0.63 & 0.57 & 0.45 & 0.37 & 0.23 & 0.11 \\
\hline Difference & 0.08 & & 0.06 & & 0.35 & \\
\hline
\end{tabular}



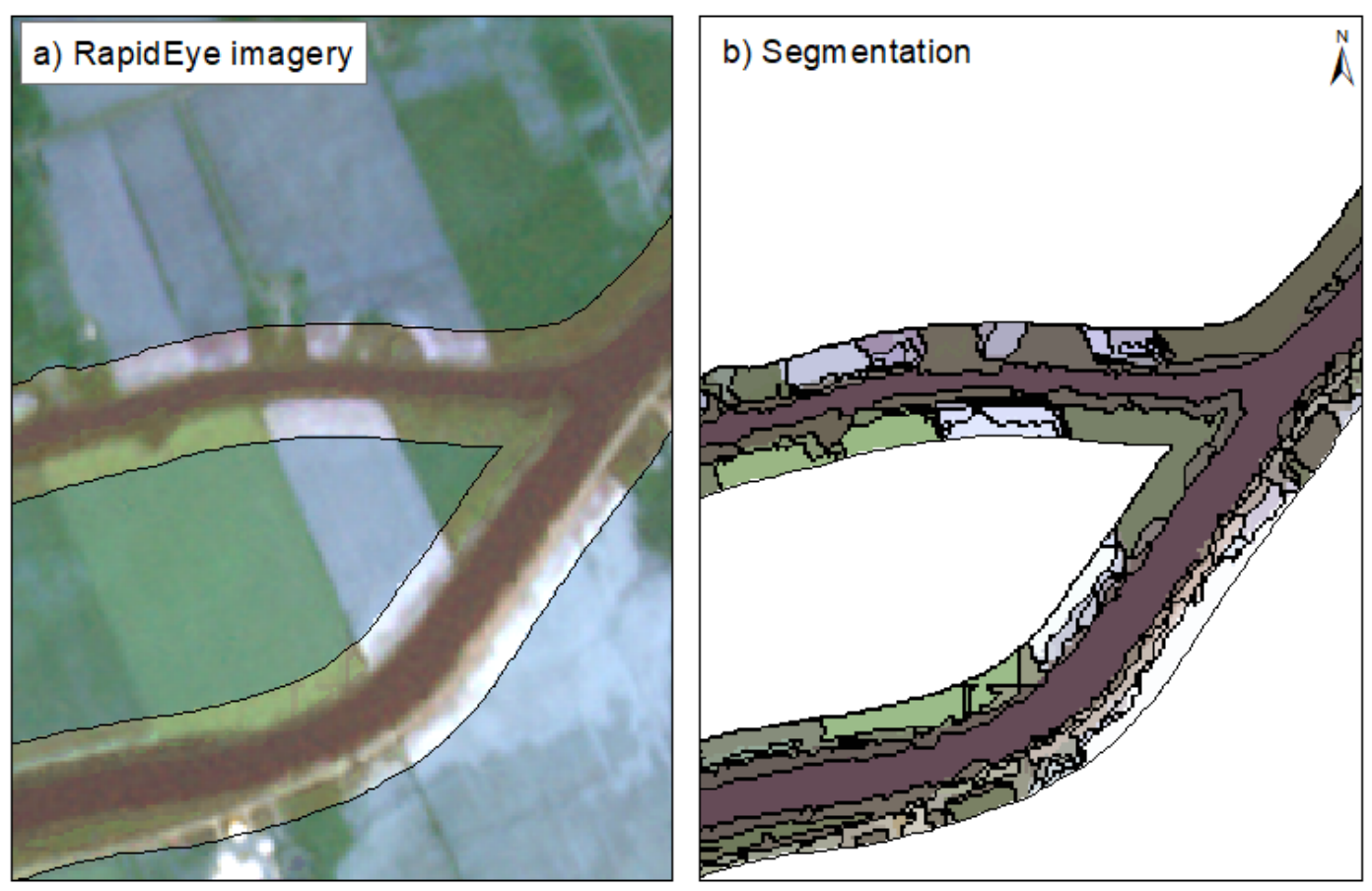

\section{c) Pixel-based results}

d) Object-based results
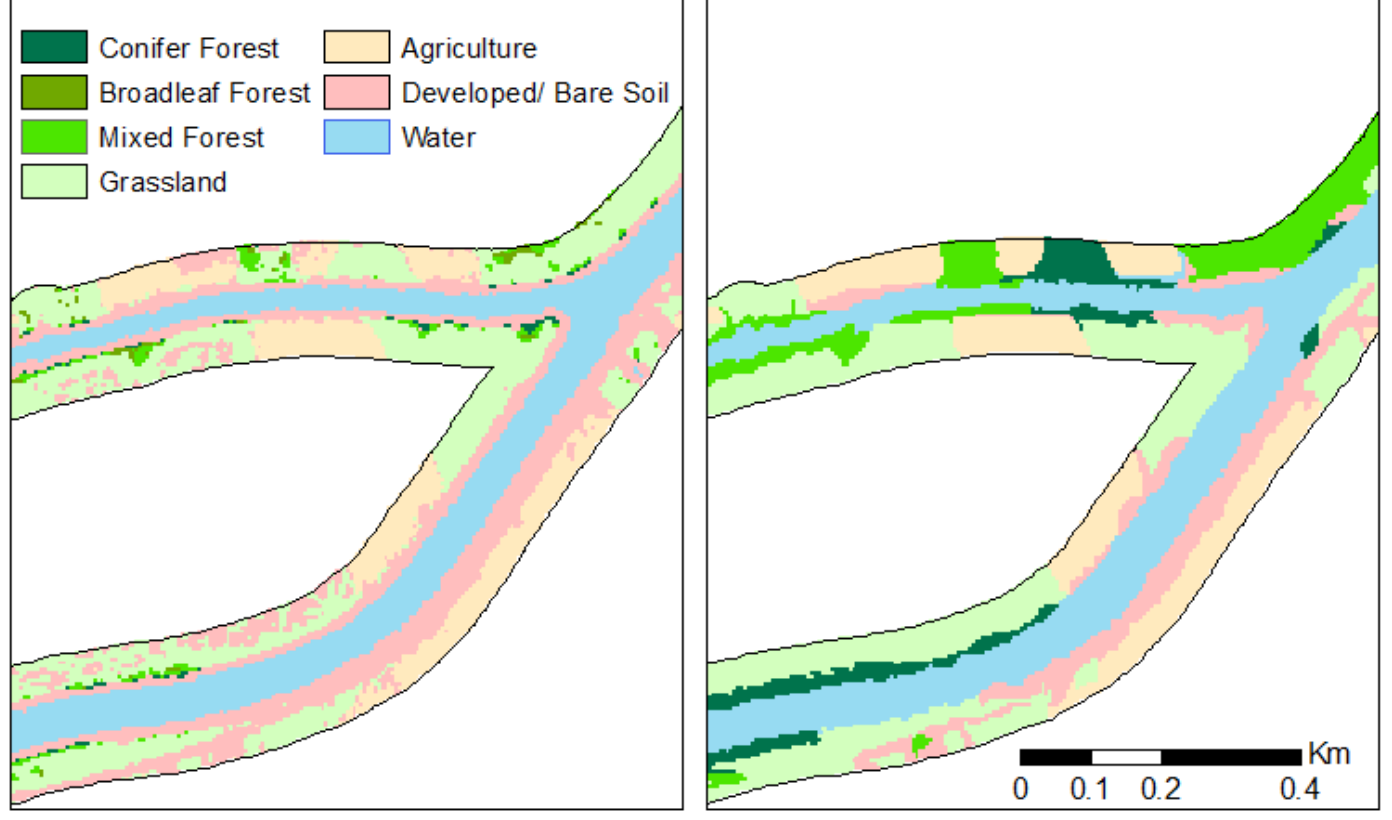

Figure 11: Classification results for the South Nation River $60 \mathrm{~m}$ buffer method. a) RapidEye imagery, b) segmented image, c) pixel-based classification, and d) objectbased classification. 
Figure 11 is a comparison of the classification results from the pixel-based (accuracy = 0.71 ) and the object-based (accuracy $=0.63$ ) methods. The pixel-based results have many stray pixels and a lot of patchiness which is consistent with field observations. The object-based results have much larger groupings of landcover classes with much less patchiness.

\subsubsection{Thematic Resolution}

\section{High Thematic Resolution}

Using the high thematic resolution, the highest accuracy of all the classification method combinations was 0.709. A visual analysis of the full confusion matrix (Table 9) shows that most of the error came from misclassed tree subclasses. The conifer class had a classification (producer's) accuracy of $34 \%$, deciduous was $40 \%$, and mixed forest was $46 \%$. However, when looking at all forest as one merged class in the same results (Table 9 ), $80 \%$ of the conifer points would be classed as forest, $100 \%$ of the deciduous classed as forest, and $84 \%$ of mixed forest classed as forest.

For the South Nation watershed, where all three tree subclasses were included, both the "deciduous" and the "conifer" classes were often misclassed as "mixed forest" and less commonly misclassed with each other (Table 9). Only the deciduous and mixed forest classes had enough data to be used in the Dunk River, and they were consistently misclassed. However, for the Souris River, where only the conifer and mixed forest classes had enough data, they seemed to be 
better differentiated, and the pixel-based methods had close to $100 \%$ of the conifer and mixed forest points classed as forest, though they were intermingled (Table A - 13, Table A - 15 and Table A - 17, in the Appendix). Overall, the mixed forest class was regularly misclassed with the other forest classes or vice versa.

Table 9: Confusion matrix of accuracy results of the pixel-based MLC for South Nation River watershed using the $60 \mathrm{~m}$ buffer treatment. Grey fields are where points were correctly classified, green fields with bolded text are the Accuracy (0.709) and kappa Confidence (0.660). Tree subclasses are bordered with thicker lines.

\begin{tabular}{|c|c|c|c|c|c|c|c|c|c|c|c|c|}
\hline $\begin{array}{l}\text { South } \\
\text { Nation } 60 \\
\text { m }\end{array}$ & & & 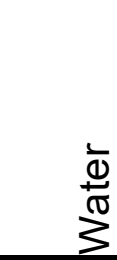 & 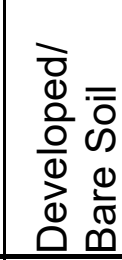 & & $\begin{array}{l}\overline{0} \\
\frac{1}{0} \\
\frac{0}{0} \\
\frac{\pi}{0} \\
0 \\
\end{array}$ & 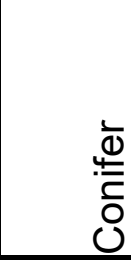 & $\begin{array}{l}\frac{0}{7} \\
\frac{0}{2} \\
\frac{0}{0} \\
0 \\
0\end{array}$ & 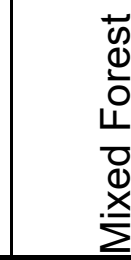 & 㺃 & 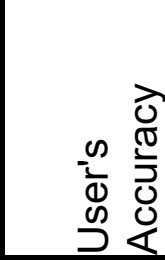 & $\begin{array}{l}\frac{\pi}{2} \\
\frac{0}{2} \\
\underline{\pi} \\
\end{array}$ \\
\hline Agriculture & 50 & & 0 & 0 & 0 & & 4 & 0 & 0 & 54 & 0.93 & 0 \\
\hline Water & 0 & & 47 & 0 & 0 & & 0 & 0 & 0 & 47 & 1.00 & 0 \\
\hline $\begin{array}{l}\text { Developed } \\
\text { /Bare Soil }\end{array}$ & 0 & & 3 & 50 & 2 & & 6 & 0 & 7 & 68 & 0.74 & 0 \\
\hline Grassland & 0 & & 0 & 0 & 41 & & 0 & 0 & 1 & 42 & 0.98 & 0 \\
\hline Conifer & 0 & & 0 & 0 & 0 & & 17 & 0 & 3 & 20 & 0.85 & 0 \\
\hline Deciduous & 0 & & $\underline{0}$ & 0 & 4 & & 9 & 20 & 16 & 49 & 0.41 & 0 \\
\hline \begin{tabular}{|l|} 
Mixed \\
Forest \\
\end{tabular} & 0 & & 0 & 0 & 3 & & 14 & 30 & 23 & 70 & 0.33 & 0 \\
\hline Total & 50 & & 50 & 50 & 50 & & 50 & 50 & 50 & 350 & 0.00 & 0 \\
\hline $\begin{array}{l}\text { Producer's } \\
\text { Accuracy }\end{array}$ & 1 & & 0.94 & 1 & 0.82 & & 0.34 & 0.4 & 0.46 & 0 & 0.709 & 0 \\
\hline Kappa & 0 & & 0 & 0 & 0 & & 0 & 0 & 0 & 0 & 0 & 0.660 \\
\hline
\end{tabular}


Low Thematic Resolution

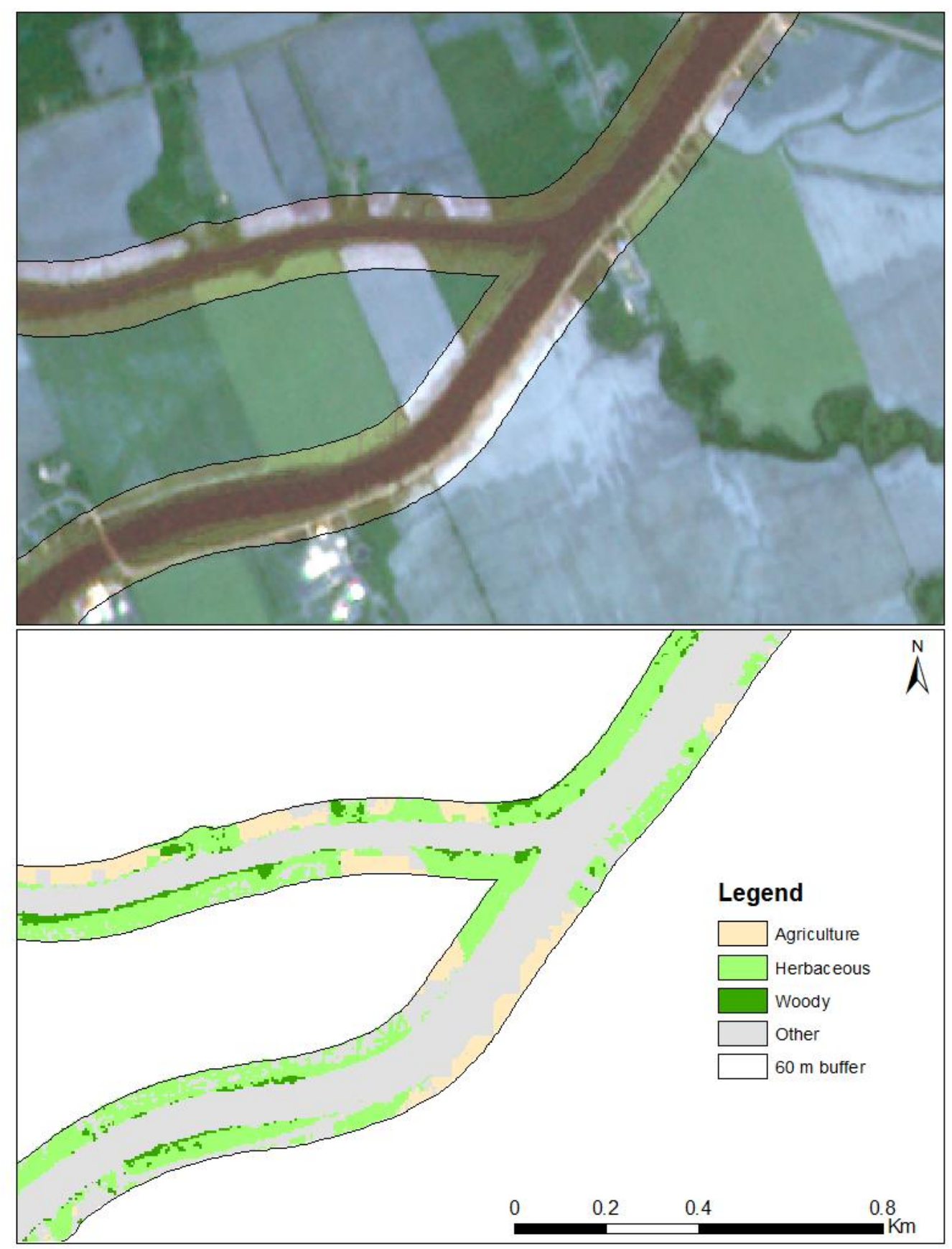

Figure 12: South Nation River 60 m buffer classified using pixel-based methods at the low thematic resolution. 
Figure 12 is a subset of the landcover map from the low thematic resolution for the South Nation watershed, the pixel-based $60 \mathrm{~m}$ buffer method resulted in a classification accuracy of $94.5 \%$ (Table 10). As expected, the Woody class was over $90 \%$ accurate when all the forest classes aggregated into one class. This result was more than sufficient for input into the RWHAFI.

Table 10: Accuracy results of the South Nation pixel-based classification $60 \mathrm{~m}$ buffer treatment for the four Riparian HAl classes.

\begin{tabular}{|c|c|c|c|c|c|c|c|}
\hline Classes & 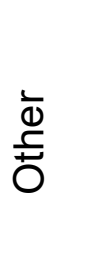 & $\begin{array}{l}\text { ते } \\
\text { ठ } \\
3 \\
3\end{array}$ & $\begin{array}{l}\frac{0}{0} \\
0 \\
\mathbb{d} \\
0 \\
\mathbb{0} \\
\frac{0}{\frac{0}{0}} \\
\frac{0}{1}\end{array}$ & $\begin{array}{l}\frac{0}{\frac{0}{3}} \\
\frac{1}{5} \\
\frac{0}{0} \\
\frac{0}{4}\end{array}$ & $\begin{array}{l}\bar{\pi} \\
\frac{\pi}{0} \\
\vdash\end{array}$ & 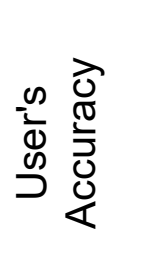 & $\begin{array}{l}\frac{\pi}{2} \\
\frac{0}{\mathbb{N}} \\
\underline{x}\end{array}$ \\
\hline Other & 50 & 4 & 2 & 0 & 56 & 0.893 & 0 \\
\hline Woody & 0 & 46 & 5 & 0 & 51 & 0.902 & 0 \\
\hline Herbaceous & 0 & 0 & 43 & 0 & 43 & 1 & 0 \\
\hline Agriculture & 0 & 0 & 0 & 50 & 50 & 1 & 0 \\
\hline Total & 50 & 50 & 50 & 50 & 200 & 0 & 0 \\
\hline $\begin{array}{l}\text { Producer's } \\
\text { Accuracy }\end{array}$ & 1 & 0.92 & 0.86 & 1 & 0 & 0.945 & 0 \\
\hline Карра & 0 & 0 & 0 & 0 & 0 & 0 & 0.927 \\
\hline
\end{tabular}




\subsection{Calculation of the RWHAFI}

The areal proportion was calculated using the classified map of the South Nation River from the pixel-based $60 \mathrm{~m}$ buffer method and the lower thematic resolution that had an accuracy of $94.5 \%$. As seen in Table 11, Agriculture was $\sim 12.6 \%$ of the landcover within the riparian zone, Woody was $\sim 21.5 \%$, Herbaceous was $\sim 23.9 \%$, and $\sim 42 \%$ was classed as 'other' and not used in the RWHAFI calculation.

Table 11: Areal proportion landcover percentages for the Riparian WHAFI classes in the South Nation watershed in 2015 from the pixel-based $60 \mathrm{~m}$ buffer treatment of RapidEye imagery.

\begin{tabular}{|l|c|}
\hline Riparian WHAFI Class & Landcover $\%$ \\
\hline Agriculture & 12.6 \\
\hline Woody & 21.5 \\
\hline Herbaceous & 23.9 \\
\hline Other & 42.0 \\
\hline
\end{tabular}

Table 12 describes the use of the landcover percentages in combination with the "Mixed Wood Plains" Riparian Habitat Association Matrix to calculate the Riparian WHAFI. The calculated riparian habitat availability of the South Nation River riparian zone was 884.4 out of a maximum of 2020. 
Table 12: Calculation of Riparian WHAFI using the landcover proportions and the Habitat Association Matrix habitat use value summations.

\begin{tabular}{|c|c|c|c|c|c|c|c|c|}
\hline \multirow[b]{2}{*}{ Classes } & \multirow[b]{2}{*}{ Landcover \% } & \multicolumn{6}{|c|}{ Lifecycle Habitat Requirement Summation } & \multirow{9}{*}{$\begin{array}{l}\text { Riparian } \\
\text { WHAFI }\end{array}$} \\
\hline & & 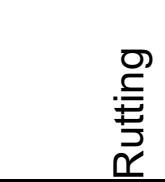 & $\begin{array}{l}\text { D } \\
\text { : } \\
\mathbb{D} \\
\mathbb{D} \\
\stackrel{4}{L}\end{array}$ & 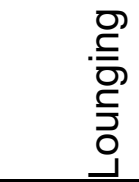 & $\overbrace{0}^{\bar{D}}$ & 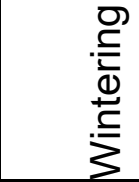 & $\begin{array}{l}\text { D } \\
\stackrel{D}{\Phi} \\
\text { ஸे }\end{array}$ & \\
\hline Agriculture & 12.6 & 103 & 272 & 96 & 157 & 156 & 189 & \\
\hline Woody & 21.5 & 389 & 438 & 133 & 424 & 272 & 364 & \\
\hline Herbaceous & 23.9 & 198 & 352 & 112 & 244 & 204 & 257 & \\
\hline \multicolumn{2}{|c|}{ Calculation Results } & \multicolumn{6}{|c|}{ Landcover* Lifecycle } & \\
\hline \multicolumn{2}{|c|}{ Agriculture } & 12.98 & 34.29 & 12.10 & 19.79 & 19.66 & 23.82 & \\
\hline \multicolumn{2}{|l|}{ Woody } & 83.76 & 94.31 & 28.64 & 91.30 & 58.57 & 78.38 & \\
\hline \multicolumn{2}{|l|}{ Herbaceous } & 47.33 & 84.14 & 26.77 & 58.32 & 48.76 & 61.43 & \\
\hline & & & & & & & & 884. \\
\hline
\end{tabular}




\section{Discussion}

Below the significant findings are summarized, followed by a more in-depth discussion of each result. For each of the different methods, the results are discussed in the context of the available literature highlighting key successes and challenges found by this study. Lastly, the challenges and limitations of the study are paired with future considerations and research opportunities.

\subsection{Significant Findings}

\subsubsection{Summary}

Using the high thematic resolution and $5 \mathrm{~m}$ imagery, the $60 \mathrm{~m}$ buffer treatment with pixel-based classification had the highest accuracy $(\sim 70 \%)$ of the methods tested across the three watersheds. That more accurate method from the high thematic resolution was applied to the low thematic resolution needed for the RWHAFI and a classification accuracy of $94.5 \%$ for the South Nation River watershed was achieved. This landcover map resulted in a RWHAFI value of 884.4 for the watershed. This value would be used to compare year over year results to monitor habitat availability changes.

\subsubsection{Spatial Resolution}

Although using Landsat $(30 \mathrm{~m})$ would have been ideal for operational mapping, the RapidEye $(5 \mathrm{~m})$ imagery was more appropriate for this study when considering the $6 \mathrm{~m}$ (Ontario) or $15 \mathrm{~m}$ (PEI) vegetative strip regulations for riparian zones within agricultural 
areas (Government of Ontario, 2019; Department of Environment, 2008). The $5 \mathrm{~m}$ imagery allowed for more of the riparian vegetation classes to be included. Most vegetation patches were small and narrow, barely meeting the MMU requirements for RapidEye, and definitely not meeting the Landsat MMU requirements. With the goal of mapping riparian habitat availability, using the RapidEye imagery retains more of the riparian vegetation classes.

Several studies classifying riparian and/or wetland using Landsat imagery achieved only 30-40\% accuracy (Maillard \& Alencar-Silva, 2013). Additionally, it was found that Landsat was not able to identify smaller streams effectively enough for long term monitoring of riparian zones (Klemas, 2014). In the largest watershed, at the widest part of the South Nation River, the water was barely three Landsat pixels wide - and in many parts less than one pixel wide. A resulting classification from Landsat for the RWHFAI would only be $\sim 1-2$ pixels on either side of the water. Mapping as much habitat variability as possible is ideal from a biological perspective as more diverse habitats can support a greater diversity of species (Maskell et al., 2019; Alavi \& King, 2020), so longterm monitoring at a finer spatial resolution would be beneficial.

\subsubsection{Spatial Masking Treatment}

Conveniently, the $60 \mathrm{~m}$ buffer method, based on the RWHAFI definition of the Riparian zone, was the most successful. The success of the $60 \mathrm{~m}$ buffer method makes sense, given that the field data was predominantly collected adjacent to the water. The riparian microclimate adjacent to the water would have a different assemblage of plant species 
and different soil moisture content, making the spectral reflectance different from upland areas (Olson et al., 2007; Li et al., 2017). The spectral reflectance of the riparian classes will be influenced by the atmospheric moisture and the soil moisture gradient found near the water (Corbane et al., 2015; Li et al., 2017) and the angle of light incidence and image capture may be different for the vegetation on the riparian slope so the bidirectional reflectance distribution function would also come into play making the riparian vegetation spectral signature different from upland vegetation (Pande-Chhetri et al., 2017).

The riparian zone is a microclimate that is distinct from upland areas (Dolanc \& Hunsaker, 2017) and classification training sites should be from within the zone of interest. The $60 \mathrm{~m}$ buffer method is ideal as it focusses on a smaller area, reducing processing time, and it is more geographically portable as it is independent of the crop inventory. From both an operational and an administrative perspective, the fixed width buffer is the simplest masking approach (Richardson et al., 2012).

\subsubsection{Pixel vs Object-based classification}

The pixel-based methods had much greater success than the object-based methods in this study. Even with the higher resolution imagery, the narrow and heterogeneous landcover made creating objects problematic. Unlike large agricultural fields, the riparian zones are often more dynamic, smaller, and as a transitional zone, they are likely to change gradually from one class to another, rather than displaying an abrupt 
class change boundary, making classification and segmentation more challenging (Corbane et al., 2015; Dronova, 2015).

While many studies have found improved classification with object-based methods, one concern for object-based classification is that smaller and rarer classes can have lower accuracies with object-based classification (Dingle-Robertson \& King, 2011). Losing the smaller patches and rarer classes is not ideal when mapping for riparian habitat availability and biodiversity. Accounting for the heterogeneity of the riparian habitat is needed for measuring biodiversity (Maskell et al., 2019).

For object-based methods to be used, the features of interest need to be larger than the pixel size (Costa et al., 2014). In many areas the vegetated strip was so narrow and heterogeneous that making objects out of the riparian strip vegetation with the moderate resolution imagery was often not possible. However, to use very-high resolution imagery for operational mapping, would be cost prohibitive. It was found that there was no statistically significant improvement in machine learning classification accuracies when using object-based methods compared to pixel-based when classifying agricultural landscapes using $10 \mathrm{~m}$ multispectral imagery (Duro et al., 2012). Also, for large regions (e.g. across Canada), object-based classification is often not feasible, as it requires high resolution imagery, expert knowledge, and the methods may need to change from one region to another (Costa et al., 2014), making them less portable and less suitable for operational mapping. The object-based methods did not support the goal of operationally mapping the riparian habitat availability. 


\subsubsection{Thematic Resolution}

The field data were collected at the highest thematic resolution to capture as much of the variability of the riparian zone as possible. Insufficient quantities of field samples for the rarer classes made the high thematic resolution (rather than the highest) the most reasonable choice to test the methods. The high thematic resolution only achieved a classification accuracy of $70 \%$ in the South Nation river watershed. Currently, the Riparian WHAFI uses the low thematic resolution which had a classification accuracy of 94.5\% for the South Nation watershed, which was more than sufficient for input into the Riparian WHAFI.

Tree differentiation was the main source of error for the high thematic resolution. For the tree subclasses, the misclassifications were mostly between conifer with mixed forest, and deciduous with mixed forest. These misclassifications are responsible for most of the lower accuracy in both the South Nation and the Souris River. Forest type differentiation is more complicated than simply mapping the presence of forest land classes (Remmel et al. 2005), and a single-date multispectral image with a moderate spatial resolution is commonly insufficient (Corbane et al., 2015). Some of the forest misclassification may also be due to the limited field data for the forest subtypes, as both Dunk River and Souris River only had two of the three tree classes included in the study, and several conifer training points had to be added from very high-resolution imagery in the South Nation River watershed. These transitional and mixed forest areas are challenging to classify as they contain varying amounts of the subclasses and will have high within class spectral variability. The low thematic resolution, with only four 
classes, groups all the forest subclasses and shrubs into one class, eliminating the differentiation problem.

For some of the classes, access to the locations and configuration of the landcover limited the amount of field data collected. The conifer forest that was visible on the very high spatial resolution imagery was generally far from the roads in areas that were not accessible without trespassing. Rarer classes, such as wetlands and shrubland, were not classified as well as common classes, if at all. Wetlands were observed, but not included in the South Nation watershed as they were very narrow bands along the edge of the river, or wet ditch type areas that were long but too narrow to meet MMU. The wetland class was only included in the PEI watersheds, but was poorly classified in all methods tested, likely due to lack of large training areas. For mapping wetlands collecting the imagery at the wettest time of year or at multiple phenological stages to give optimal delineation (Dronova, 2015).

Similarly, shrubs were only seen in narrow strips, mixed with other forest, or in small patches that did not meet MMU. Shrubs were often seen as a narrow transition area from grasses to trees but not as large patches in the South Nation watershed. The long very narrow configuration of the wetland and shrub classes removed both from the South Nation classifications despite their presence. More field samples, finer imagery, or different collection strategies may help to include more class variability in the future allowing for higher thematic resolution. 


\subsubsection{Available Habitat in the Riparian zone}

The watershed level RWHAFI for the South Nation River watershed was 884.4 which is the low end of the middle of the possible range. The RWHAFI result is a dimensionless value that uses a different scale than the WHAFI for the habitat use values, so they are not directly comparable but habitat use values for the RWHAFI being higher makes sense given that the riparian habitat is required by $\sim 97 \%$ of the species to complete at least one aspect of their lifecycle (Clearwater et al., 2016). The indicator results are useful for monitoring year over year changes and for comparing regions within the same ecozone. A good indicator will be sensitive to changes in the environment and can be used to measure and detect change over time. The RWHAFI is sensitive to changes in the composition of the riparian zone, with riparian forest strongly influencing higher results.

The ability to monitor the agricultural riparian zones will help to ensure Canada can measure and meet our international agreements. The United Nations 2030 agenda goal \#2 is to "End hunger, achieve food security and improved nutrition and promote sustainable agriculture" and goal \#15 is "Protect, restore and promote sustainable use of terrestrial ecosystems, sustainably manage forests, combat desertification, and halt and reverse land degradation and halt biodiversity loss" (United Nations General Assembly, 2015). As well for the Convention on Biological Diversity, Canada has a number of targets that relate to biological diversity, sustainability, and agriculture that require monitoring (mainly Target 7: "By 2020 areas under agriculture, aquaculture and forestry are managed sustainably, ensuring conservation of biodiversity.") (United 
Nations Environment Program, 2020). All of these goals require some way to measure progress and success over time and the RWHAFI could be added to the WHAFI as a more robust part of those.

\subsection{Limitations and Future Possibilities}

The limitations mainly stemmed from a shortage of field data for rarer classes and poor forest differentiation when classifying at the high thematic resolution. This creates opportunities for future study using different field data collection methods, various auxiliary datasets, machine learning classifiers, and post-classification processing. Operational mapping of the RWHAFI in the different agricultural regions across Canada would be a great starting point for long-term monitoring of riparian sustainability.

\subsubsection{Field Data}

Overall, one of the largest limitations of the study was a shortage of field data points, particularly for rarer classes. One option for more ground sampling points in the future could be a priori selection of sites corresponding to rarer classes. Another would be adding collection sites where water cannot necessarily be seen from the road, but where larger patches of rarer classes of interest are found near the water. Potential bias is introduced by only collecting field data adjacent to roads where the water is visible. Thick/wide forested areas would make the water not visible from the road thus reducing field data from that class. Also, construction on wetlands would be more difficult so I 
would expect roads to not be placed adjacent to them, again introducing bias to the field data. A targeted field plan including boating along the river might allow for more access to wetland and heavily forested areas that are less likely to be near the roads. It is always possible that the rarer classes may never occur in large enough patches to meet the MMU for RapidEye or larger pixel imagery indicating a potential need for highresolution imagery.

Another option would be using multiple watersheds to gather enough training data for classification. The two PEI rivers are approximately $130 \mathrm{~km}$ apart and the South Nation River is about $175 \mathrm{~km}$ long (South Nation River, 2020) so the distance between points in Souris River and Dunk River would be about the same distance from each other as some of the points along the South Nation River. The PEI watersheds are both part of the same ecoregion and could potentially be merged to train the classifier.

All the agriculture being combined into one class makes it a highly spectrally variable class, which likely reduces its accuracy. Field data collection was predominantly focused on riparian vegetation and it was assumed that any agriculture that fell within the $60 \mathrm{~m}$ RWHAFI buffer was more accurately classified by the AAFC team in the annual crop inventory, so the non-agricultural classes were prioritized and all agriculture cover was considered one class. Using more of the $\mathrm{ACl}$ crop classes in future may improve accuracy as some of the Agriculture was classified as Developed/ Bare Soil, Shrubland, or Grassland in all of the study areas, though it was consistently above $50 \%$ accuracy. Ensuring more varied selection of the crops from the crop inventory may help 
to reduce error by encompassing more of the within class variability in the training data. While it was not the focus of the study, adding more training data to the agriculture class should help improve the classification results overall.

\subsubsection{Spatial Resolution}

For the goal of the Government of Canada's operational mapping across Canada, RapidEye data - and data at similarly fine spatial resolutions from other satellites offered by other commercial vendors - are still prohibitively expensive. With a larger field data set, or in regions with wider riparian vegetated buffer regulations, a $10 \mathrm{~m}$ pixel resolution would likely work. However, for this study, further reducing the amount of usable field data to meet a larger MMU was deemed inappropriate.

In the future, a $10 \mathrm{~m}$ pixel might be a "compromise" resolution to be used, as the riparian zone of interest would be $\sim 6$ pixels across $(60 \mathrm{~m})$ and many features may be visible, particularly with targeted field data collection or the removal of the rarer classes. A 10 m pixel resolution (e.g. Sentinel) is cheaper, requires less storage, and the processing time would be shorter than RapidEye for large areas such as all the Canadian agricultural regions.

However, if the required vegetative buffer for the region is $<15 \mathrm{~m}$, larger pixels will not improve the accuracy for the riparian vegetation. My expectation is that finer pixel resolution will be needed to accurately depict the variability of riparian habitat to 
measure the biodiversity. For best results pixels should be $2-3 \mathrm{~m}$ to map $<15 \mathrm{~m}$ buffers (Klemas, 2014). This would lead to a need for the higher resolution imagery or the continued use of the lower thematic resolution which loses much of the diversity.

Both the Canadian forestry and agriculture mapping use coarser resolution imagery than would be needed to capture all the variability of these riparian habitats. For example, at the national reporting level, the Canadian National Forestry inventory is presented with 250 m pixels based on MODIS imagery (Canada's National Forest Inventory, 2017), which is not appropriate for mapping the riparian zone vegetation. Current operational mapping by AAFC is not fine enough to capture all of the riparian habitat diversity as the adjacent vegetation is not their focus. It may be possible for AAFC to use higher resolution imagery specifically for the riparian areas.

\subsubsection{Thematic Resolution}

Species richness has been positively related to habitat heterogeneity so maintaining as much heterogeneity in the classification is very important (Maskell et al., 2019; Alavi \& King, 2020). Using finer thematic resolutions would make it possible to monitor smaller changes in the heterogeneity (Alavi \& King, 2020). The biggest challenge for the high thematic resolution was the poor differentiation of the forest classes, followed by the lack of field data for rarer classes. The conifer and the deciduous forest classes were often classed as mixed forest or vice-versa, which reduced the classification accuracies dramatically. In future, using temporal-targeted or multitemporal imagery selection, such 
as peak wetness, or leaf-on and leaf-off imagery, could increase the amount of input data (Lu \& Weng, 2007). It is recommended to map wetlands from imagery collected at the wettest time of the year for better delineation or comparing wet-dry imagery for more contrast information (Dronova, 2015). Also, leaf-on leaf-off temporal data may help to validate and separate the three tree subclasses, as conifer and deciduous can be more easily differentiated (Lu \& Weng, 2007). The addition of multitemporal imagery, showing the phenological differences, can improve forest type differentiation (Corbane et al., 2015). For object-based classification using high resolution imagery, the addition of supplementary data like LiDAR or SAR that were not used in this study but may be helpful for future studies and are discussed in further detail below (Corbane et al., 2015).

\subsubsection{Classification Possibilities}

There are many potential classification methods and techniques available, and each has the potential to improve classification accuracy in its own way. The accuracy of imagery classification can be improved at various stages of the classification processes, including the timing of imagery acquisition, image masking, the classification algorithm used, and post-classification procedures implemented. Testing some of these other methods for classifying land cover in the future may help to improve the high thematic resolution classification. 
Image timing can have significant impacts on the results of the classification. Choosing the optimal time to capture the imagery based on phenological characteristics of the focal land cover can have significant impact on the accuracy (Huylenbroeck et al., 2020). One study found that classifying imagery of wetlands from the wettest time of year had greatest accuracy (Dronova, 2015). Similarly, classifying summer leaf-on vegetation will often give more information if you are mapping vegetation, and timing of vegetation greening can give species indications in some regions. For forest differentiation, using multitemporal imagery to compare leaf-on and leaf-off imagery can significantly increase the accuracy of the classification or segmentation where there are both coniferous and deciduous species (Corbane et al., 2015; Huylenbroeck et al., 2020). In the future, the classification accuracy for several classes at the high thematic resolution in the riparian zone could be improved by using time targeted and multitemporal imagery. Such an approach will require the availability of physical or virtual constellations that can provide (open) data streams with high frequency of higher spatial resolutions than currently available. While data streams from the ESA Copernicus program (e.g. Sentinels $1 a$ and $1 b$ for SAR; Sentinels $2 a$ and $2 b$ for optical), as well as the Harmonized Landsat-Sentinel (HLS) data series that cross-calibrates Sentinel-2 and Landsat data into a single higher level data product, clearly demonstrate the clear benefits of open data streams with high-revisit capabilities for land use mapping, they still operate at spatial resolutions (10 $\mathrm{m}$ or coarser) that are too coarse for the accurate mapping of riparian systems (Copernicus, 2020). Commercial systems, such as the very fine resolution daily data provided by Planet Labs Inc., also show promise, but these data are not open data, and their cost currently prohibits their wider 
operational application to national-scale operational mapping by federal departments and agencies in Canada (Davidson, personal communication, December 2020).

Additionally, including auxiliary data into the image pre-processing can improve the differentiation of classes and can be used to improve segmentation for object-based methods. Auxiliary data can include multitemporal imagery, vegetation height, texture layers, as well as other types of additional information related to the study. LiDAR data have been successfully used to supplement segmentation when mapping riparian areas using object-oriented classification (Jeong et al., 2016; Johansen et al., 2010; Michez et al., 2013). Including the canopy height can help differentiate vegetation classes and create objects for classification (Johansen et al., 2010; Michez et al., 2016; Huylenbroeck et al., 2020). Similarly, texture layers can be used to improve segmentation or as additional data for classification (Rapinel et al., 2014; Michez et al., 2013). The addition of auxiliary data to the segmentation process could improve classification accuracy, though more variables and processes will introduce the possibility of more error and greater computational needs.

Another approach for improving classification, given the heterogeneity of the riparian zone and the affordable data, are subpixel classification methods. Sub-pixel classification methods may be useful for heterogeneous regions (Li et al., 2017; Li et al., 2015). Examples of sub-pixel classification techniques include spectral mixture analysis, fuzzy classification, regression modelling, and neural networks (Li et al., 2017). Such methods are often based on the concept of "spectral un-mixing", where the single 
areally-averaged spectral reflectance for a given pixel is "unmixed" to reveal the area coverage of its contributing components (e.g. forest, crop, water, etc.). However, the unmixing process requires an accurate definition of the "pure" spectral characteristics of each contributing cover class (end members), which is often difficult to obtain, and impossible to implement here. However, in the future, with more comprehensive sampling methods, these sub-pixel methods could be used to get areal proportions of each class, and those could be used as input for the RWHAFI.

Machine learning classifiers have increased in popularity over the last decade. Several of the common classifiers are decision tree, random forest, support vector machines, and artificial neural network. In the future they should be tested to see if they improve the accuracy of riparian zone classification at high thematic resolution. Bagging or bootstrap style classifiers, like random forest, can be more successful when working with lower field data counts (Wen \& Hughes, 2020). The field dataset is not initially subset, instead, each iteration uses a random subset of the field data and the classification is run repeatedly, then the results are averaged to make the final classified image (Maxwell et al., 2018). Bagging classifiers have been found to be more accurate than individual classifiers (Wen \& Hughes, 2020; Baker et al., 2006; Fernandes et al., 2014). However, the bagging classifiers did not discriminate the rarer classes as well in coastal wetlands (Wen \& Hughes, 2020), which may also be a concern for riparian zones. Testing these machine learning classifiers with particular attention paid to the rarer classes would be a beneficial next step for this research. 
Ensemble classifiers are another technique that may be useful for retaining rarer classes in this heterogenous landscape. By testing several classifiers to find the classifier that has the highest accuracy for each of the land cover classes, then using the classifier with the highest accuracy to classify each class (Amani et al., 2018). With high within class variability and the heterogeneity of the riparian zone, different classes may be better classified using different classifiers. These methods would more computationally intensive but the possibility of increased sensitivity to rarer classes could be worth it.

There are many promising technologies that are being developed that create opportunities for further research. Testing newer tools, other imagery, and various combinations of them for increased accuracy and sensitivity to rarer classes would be advantageous particularly in an operational capacity. It would be also beneficial to test any methods in regions with a wider vegetative strip, different topography, as well as using both higher and mid-range spatial resolution imagery to ensure portability. There are trade-offs when choosing more involved methods but operationally classifying the riparian zone to a higher thematic resolution and a spatial resolution less than thirty meters would be beneficial to mapping biodiversity, habitat availability, and change detection into the future using the RWHAFI and potentially other metrics. 


\subsubsection{Habitat Availability Indicator Limitations and Possibilities}

Operational mapping of the riparian zone and the subsequent calculation of the RWHAFI would add a piece to the measurement of agricultural riparian sustainability. While it is a useful piece the RWHAFI does have some limitations that should be acknowledged. It does not address quality of a habitat, such as configuration, edge effects, fragmentation, age of a forest stand, or density of a forest. The landscape WHAFI had more consideration of habitat connectivity, with forest classes subset into more than or less than two hectares. Increasing connectivity and landscape heterogeneity has been shown to increase biodiversity (Maskell et al., 2019). Given that riparian corridors can be so important for terrestrial species dispersal and connectivity (Michez et al., 2013), including minimum area subsets in the future would be an asset. Also, neither the WHAFI nor the RWHAFI measures the presence of species. Instead, the indicator measures the amount of available habitat in the region and assumes the species could be there (Javorek and Grant, 2011).

The riparian habitat association matrix is based on a lower thematic resolution than the WHAFI. Ideally, the successful mapping of the riparian zone at a higher thematic resolution would lead to the creation of finer thematic resolution of riparian habitat association matrices with more consideration to the configuration of the land cover. Increased habitat heterogeneity is associated with increased biodiversity (Maskell et al., 2019), and being able to measure that would be beneficial for long term monitoring. The RWHAFI should incorporate or be used in conjunction with other metrics that measure these other landscape characteristics. 
Similar to Canada, Europe has numerous directives such as the EU Water Framework Directive (EU must monitor and improve water quality) and the European Green Deal (Climate neutral by 2050) that call for conservation of water quality, farmland, biodiversity, and riverine habitat all across Europe (European Commission, 2020; European Commission, 2021; Fernandez et al., 2014). Unlike Canada most of Europe uses $50 \mathrm{~cm}$ or smaller scale imagery, either air photos or satellite, to update their geographical databases (Bizzi et al., 2016). Canada is too large to have the same density of data available on a regular basis. Many of the biodiversity metrics seen in the literature use significant inputs of labour and/or very high-resolution imagery to measure and map biodiversity. On a national scale, that is not feasible in Canada so we must rely on remote sensing methods to monitor riparian habitat and the RWHAFI meets those needs.

There are many other riparian indicators such as the Riparian Quality Index, the Riparian Strip Quality Index and so many others from various regions around the world (Novoa et al., 2018: Saha et al., 2020). Most seem to require expert knowledge, significant field work, and fine resolution imagery and various other geospatial data products to calculate (Novoa et al., 2018; Santolini et al., 2015). The RWHAFI is reasonable for national operational level monitoring from space-based imagery but this indicator is just one measuring tool that should be used in conjunction with other information. As part of measuring the sustainability of Canadian agriculture for the United Nations 2030 Agenda for Sustainable Development, adding the RWHAFI 
monitoring to the WHAFI monitoring would provide a more robust measurement of sustainability. 


\section{Conclusion}

Riparian zones within agricultural regions are commonly narrow, modified, and heterogenous, making classification more challenging. The high-resolution imagery was required and focusing on the $60 \mathrm{~m}$ buffer was the most successful, with the pixel-based methods outperforming the object-based ones. Low thematic resolution was needed to get above a $70 \%$ classification accuracy, with much of the error coming from differentiating forest subclasses in the high thematic resolution. With the low thematic resolution, the accuracy increased to $94.5 \%$. The RWHAFI values reported here can be used as a baseline for comparison to future results in the study area.

Further refinement, higher resolution imagery, different methods and techniques, and/or larger sample sizes should be explored to classify the imagery to the higher thematic resolution. Operational mapping is beneficial for monitoring health and sustainability of riparian zones as it can show trends over time and indicate changes that can be used to inform management and protection. The RWHAFI provides a simple summary of the habitat availability in the agricultural riparian zones appropriate for operational mapping, monitoring, and reporting over time. When used in conjunction with other metrics of sustainability the RWHAFI would be an efficient tool to measure the riparian zone within agricultural regions. 


\section{References}

Agriculture and Agri-Food Canada. (2013). Annual Crop Inventory. https://open.canada.ca/data/en/dataset/ba2645d5-4458-414d-b1966303ac06c1c9\#wb-auto-6

Agriculture and Agri-Food Canada. (2015). Annual Crop Inventory 2015. https://open.canada.ca/data/en/dataset/3688e7d9-7520-42bd-a3eb$8854 b 685 f e f 3$

Agriculture and Agri-Food Canada. (2016). An Overview of the Canadian Agriculture and Agri-Food System 2016. https://www.agr.gc.ca/eng/about-ourdepartment/publications/economic-publications/an-overview-of-the-canadianagriculture-and-agri-food-system-2016/?id=1462288050282. Accessed October 26, 2020.

Agriculture and Agri-Food Canada. (2016). Annual Crop Inventory 2016. https://open.canada.ca/data/en/dataset/b8e4da73-fb5f-4e6e-93a48b1f40d95b51

Agriculture and Agri-Food Canada. (2019). AAFC Annual Crop Inventory Data Product Specifications. 
http://www.agr.gc.ca/atlas/supportdocument_documentdesupport/annualCroplnv entory/en/ISO\%2019131_AAFC_Annual_Crop_Inventory_Data_Product_Specific ations.pdf

Agriculture and Agri-Food Canada. (2020). We grow a lot more than you may think. Retrieved from https://www.agr.gc.ca/eng/canadian-agri-food-sector/we-grow-alot-more-than-you-may-think/?id=1251899760841 Accessed October 26, 2020.

Alavi, N., \& King, D. (2020). Evaluating the Relationships of Inter-Annual Farmland Vegetation Dynamics with Biodiversity Using Multi-Spatial and Multi-Temporal Remote Sensing Data. Remote Sensing, 12, 1-22. https://doi.org/10.3390/rs12091479

Amani, M., Salehi, B., Mahdavi, S., Brisco, B., \& Shehata, M. (2018). A Multiple Classifier System to improve mapping complex land covers: a case study of wetland classification using SAR data in Newfoundland, Canada. International Journal of Remote Sensing, 39(21), 7370-7383.

https://doi.org/10.1080/01431161.2018.1468117

Aguiar, T. R., Bortolozo, F. R., Hansel, F. A., Rasera, K., \& Ferreira, M. T. (2015). Riparian buffer zones as pesticide filters of no-till crops. Environmental Science and Pollution Research, 22(14), 10618-10626. https://doi.org/10.1007/s11356$015-4281-5$ 
Baker, C., Lawrence, R., Montagne, C., \& Patten, D. (2006). Mapping wetlands and riparian areas using landsat ETM+ imagery and decision-tree-based models. Wetlands, 26(2), 465-474. https://doi.org/10.1672/02775212(2006)26[465:MWARAU]2.0.CO;2

Barry, D., Fischer, R.A., Hoffman, K.W., Barry, T., Zimmerman, E.G., \& Dickson, K.L. (2006). Assessment of Habitat Values for Indicator Species and Avian Communities in a Riparian Forest Assessment of Habitat Values for Indicator Species and Avian Communities in a Riparian Forest. Southeastern Naturalist, 5(2), 295-310.

Baxter, C.V., Fausch, K.D., \& Carl Saunders, W. (2005). Tangled webs: reciprocal flows of invertebrate prey link streams and riparian zones. Freshwater Biology, 50(2), 201-220. doi:10.1111/j.1365-2427.2004.01328.x

Bedeque Bay Environmental Management Association. (2019). The Bedeque Bay Watershed. https://bbema.ca/bedeque-bay-watershed/

Bennett, A. F., Nimmo, D. G., \& Radford, J. Q. (2014). Riparian vegetation has disproportionate benefits for landscape-scale conservation of woodland birds in highly modified environments. Journal of Applied Ecology, 51(2), 514-523. https://doi.org/10.1111/1365-2664.12200 
Betz, F., Lauermann, M., \& Cyffka, B. (2018). Delineation of the riparian zone in datascarce regions using fuzzy membership functions: An evaluation based on the case of the Naryn River in Kyrgyzstan. Geomorphology, 306, 170-181. https://doi.org/10.1016/j.geomorph.2018.01.024

Bizzi, S., Demarchi, L., Grabowski, R., Weissteiner, C. J., \& Van de Bund, W. (2016). The use of remote sensing to characterise hydromorphological properties of European rivers. Aquatic Sciences, 78(1), 57-70. https://doi.org/10.1007/s00027015-0430-7

Canada's National Forest Inventory. (2017). https://open.canada.ca/data/en/dataset/ec9e2659-1c29-4ddb-87a26aced147a990. Accessed March 26, 2021

Canadian Council on Ecological Areas. (2016). Ecozone Downloads. https://www.ccea.org/ecozones-downloads. Accessed August 12, 2019

Capon, S.J., \& Pettit, N.E. (2018). Turquoise is the new green: Restoring and enhancing riparian function in the Anthropocene. Ecological Management \& Restoration, 19 (August), 44-53. https://doi.org/10.1111/emr.12326 
Champagne, C., McNairn, H., Daneshfar, B., \& Shang, J. (2014). A bootstrap method for assessing classification accuracy and confidence for agricultural land use mapping in Canada. International Journal of Applied Earth Observation and Geoinformation, 29(1), 44-52. https://doi.org/10.1016/j.jag.2013.12.016

Clearwater, R. L., Martin, T., \& Hoppe, T. (2016). Environmental sustainability of Canadian agriculture: Agri-environmental indicator report series - Report \#4. Agriculture and Agri-Food Canada. https://www.agr.gc.ca/eng/agriculture-andthe-environment/agricultural-practices/environmental-sustainability-of-canadianagriculture-agri-environmental-indicator-report-series-report4/?id=1467307820931. Retrieved on Aug 19, 2020.

Corbane, C., Lang, S., Pipkins, K., Alleaume, S., Deshayes, M., Millán,V.E.G., Strasser. T, Borre, J.V., Toon, S., \& Michael, F. (2015). Remote sensing for mapping natural habitats and their conservation status - New opportunities and challenges. International Journal of Applied Earth Observations and Geoinformation, 37, 7-16. https://doi.org/10.1016/j.jag.2014.11.005

Congalton, R. G., \& Green, K. (2019). Assessing the Accuracy of Remotely Sensed Data. In Assessing the Accuracy of Remotely Sensed Data. https://doi.org/10.1201/9780429052729

Copernicus. (2020). Europe's eyes on Earth. https://www.copernicus.eu/en 
Costa, H., Carrão, H., Bação, F., \& Caetano, M. (2014). Combining per-pixel and objectbased classifications for mapping land cover over large areas. International Journal of Remote Sensing, 35(2), 738-753. https://doi.org/10.1080/01431161.2013.873151

Croke, J., Thompson, C., \& Fryirs, K. (2017). Prioritising the placement of riparian vegetation to reduce flood risk and end-of-catchment sediment yields: Important considerations in hydrologically-variable regions. Journal of Environmental Management, 190(December), 9-19. https://doi.org/10.1016/j.jenvman.2016.12.046

Davidson, A.M., Fisette, T., McNairn, H., \& Daneshfar, B. (2017). Detailed crop mapping using remote sensing data (Crop Data Layers). In: J. Delince (ed.), Handbook on Remote Sensing for Agricultural Statistics (Chapter 4). Handbook of the Global Strategy to improve Agricultural and Rural Statistics (GSARS): Rome.

Demers, A. M., Banks, S. N., Pasher, J., Duffe, J., \& Laforest, S. (2015). A comparative analysis of object-based and pixel-based classification of RADARSAT-2 C-band and optical satellite data for mapping shoreline types in the Canadian arctic. Canadian Journal of Remote Sensing, 41(1), 1-19. https://doi.org/10.1080/07038992.2015.1020361 
Department of Environment. (2008). Watercourse and Wetland Protection Regulations PEI Reg EC720/08.

https://www.princeedwardisland.ca/en/legislation/environmental-protectionact/watercourse-and-wetland-protection-regulations

Deschamps, B., McNairn, H., Shang, J., \& Jiao, X. (2012). Towards operational radaronly crop type classification: Comparison of a traditional decision tree with a random forest classifier. Canadian Journal of Remote Sensing, 38(1), 60-68. https://doi.org/10.5589/m12-012

Dibblee, R. (1990). PEI Watershed Boundaries. Department of Agriculture and Forestry. www.gov.pe.ca/gis

Dingle Robertson, L., \& King, D. J. (2011). Comparison of pixel- and object-based classification in land cover change mapping. International Journal of Remote Sensing, 32(6), 1505-1529. https://doi.org/10.1080/01431160903571791

Dolanc, C. R., \& Hunsaker, C. T. (2017). The transition from riparian to upland forest plant communities on headwater streams in the southern Sierra Nevada, California, United States. The Journal of the Torrey Botanical Society, 144(3), 280-295. https://doi.org/10.3159/TORREY-D-15-00073.1 
Dronova, I. (2015). Object-based image analysis in wetland research: A review. Remote Sensing, 7(5), 6380-6413. https://doi.org/10.3390/rs70506380

Duro, D. C., Franklin, S. E., \& Dubé, M. G. (2012). A comparison of pixel-based and object-based image analysis with selected machine learning algorithms for the classification of agricultural landscapes using SPOT-5 HRG imagery. Remote Sensing of Environment, 118, 259-272. https://doi.org/10.1016/j.rse.2011.11.020

El-Khoury, A., Seidou, O., Lapen, D.R., Sunohara, M., Zhenyang, Q., Mohammadian, M., \& Daneshfar, B. 2014. Prediction of land-use conversions for use in watershed-scale hydrological modeling: a Canadian case study. The Canadian Geographer/Le Géographe Canadien, 58: 499-516.

El-Khoury, A., Seidou, O., Lapen, D.R., Que, Z., Mohammadian, M., Sunohara, M., \& Bahram, D. 2015. Combined impacts of future climate and land use changes on discharge, nitrogen and phosphorus loads for a Canadian river basin. Journal of Environmental Management, 151: 76-86.

Environment and Climate Change Canada. (2019). Canadian Environmental Sustainability Indicators: Wildlife Habitat Capacity on Agricultural Land. www.canada.ca/en/environment-climatechange/services/environmentalindicators/wildlife-habitat-capacity-agriculturalland.html. 
Environment and Climate Change Canada. (2019). Sustainable Future- A federal Sustainability Development Strategy for Canada 2019-2022. https://fsdssfdd.ca/downloads/FSDS_2019-2022.pdf

Esri. (2020). ArcMap: Create Accuracy Assessment Points. https://desktop.arcgis.com/en/arcmap/latest/tools/spatial-analyst-toolbox/createaccuracy-assessment-points.htm

Esri. (2021). Segmentation. https://pro.arcgis.com/en/proapp/latest/help/analysis/image-analyst/segmentation.htm

Esri. (2020). Understanding segmentation and classification. https://pro.arcgis.com/en/pro-app/latest/toolreference/image-analyst/understanding-segmentation-andclassification.htm

Esri Inc. (2019). ArcGIS Pro (Version 2.4.2). Esri Inc. https://www.esri.com/enus/arcgis/products/arcgis-pro/.

Esri. (2016). How Maximum Likelihood Classification works. https://desktop.arcgis.com/en/arcmap/10.3/tools/spatial-analysttoolbox/how-maximum-likelihood-classification-works.htm 
Esri. (2016). Producing signature files, class, and cluster analysis.

https://desktop.arcgis.com/en/arcmap/10.3/tools/spatial-analysttoolbox/producing-signature-files-class-and-cluster-analysis.htm

European Commission. (2020). Introduction to the EU Water Framework Directive. https://ec.europa.eu/environment/water/water-framework/info/intro_en.htm

European Commission. (2021). A European Green Deal. https://ec.europa.eu/info/strategy/priorities-2019-2024/european-green-deal_en

Fahrig, L. (2001). How much habitat is enough? Biological Conservation, 100(1), 65-74. https://doi.org/10.1016/S0006-3207(00)00208-1

Felix, Z. I., Wang, Y., \& Schweitzer, C. J. (2010). Effects of Experimental Canopy Manipulation on Amphibian Egg Deposition. Journal of Wildlife Management, 74(3), 496-503. https://doi.org/10.2193/2008-181

Fernández, D., Barquín, J., Álvarez-Cabria, M., \& Peñas, F. J. (2014). Land-use coverage as an indicator of riparian quality. Ecological Indicators, 41, 165-174. https://doi.org/10.1016/j.ecolind.2014.02.008 
Fernandes, M. R., Aguiar, F. C., Silva, J. M. N., Ferreira, M. T., \& Pereira, J. M. C. (2014). Optimal attributes for the object-based detection of giant reed in riparian habitats: A comparative study between Airborne High Spatial Resolution and WorldView-2 imagery. International Journal of Applied Earth Observations and Geoinformation, 32, 79-91. https://doi.org/10.1016/j.jag.2014.03.026

Ferreira, V., Castela, J., Rosa, P., Tonin, A. M., Boyero, L., \& Graça, M. A. S. (2016). Aquatic hyphomycetes, benthic macroinvertebrates and leaf litter decomposition in streams naturally differing in riparian vegetation. Aquatic Ecology, 50(4), 711725. https://doi.org/10.1007/s10452-016-9588-x

Fisette, T., Rollin, P., Aly, Z., Campbell, L., Daneshfar, B., Filyer, P., Smith, A., Davidson, A., Shang, J., \& Jarvis, I. (2013). AAFC annual crop inventory: Status and challenges. 2013 2nd International Conference on Agro-Geoinformatics: Information for Sustainable Agriculture, Agro-Geoinformatics 2013, 270-274. https://doi.org/10.1109/Argo-Geoinformatics.2013.6621920

Fisette, T., Davidson, A., Daneshfar, B., Rollin, P., Aly, Z., \& Campbell, L. (2014). Annual space-based crop inventory for Canada: 2009-2014. International Geoscience and Remote Sensing Symposium (IGARSS), 5095-5098. https://doi.org/10.1109/IGARSS.2014.6947643 
Foody, G. M. (1990). Directed ground survey for improved maximum likelihood classification of remotely sensed data. International Journal of Remote Sensing, $11,1935-1940$.

González, E., Felipe-Lucia, M. R., Bourgeois, B., Boz, B., Nilsson, C., Palmer, G., \& Sher, A. A. (2017). Integrative conservation of riparian zones. Biological Conservation, 211(November), 20-29. https://doi.org/10.1016/j.biocon.2016.10.035

Government of Canada. (2019). About environmental sustainability indicators. https://www.canada.ca/en/environment-climate-change/services/environmentalindicators/about-sustainability.html Accessed Government of Canada website August 25, 2020.

Government of Canada. (2020). Historical Data: Daily Data Report for June 2015. https://climate.weather.gc.ca/climate_data/daily_data_e.html?hlyRange=\%7C\&dl $y$ Range $=1889-11-01 \% 7 C 2020-02-17 \& m l y R a n g e=1889-01-01 \% 7 C 2006-12-$ 01\&StationID=4333\&Prov=ON\&urlExtension=_e.html\&searchType=stnName\&op thimit=specDate $\&$ StartYear=2015\&EndYear=2015\&seIRowPerPage $=25 \&$ Line $=0$ \&searchMethod=contains\&Month $=6 \& D a y=2 \&$ txtStationName=ottawa\&timeframe $=2 \&$ Year $=2015$ 
Government of Canada. (2020). Historical Data: Daily Data Report for August 2016.

https://climate.weather.gc.ca/climate_data/daily_data_e.html?hlyRange=201209-10\%7C2020-06-29\&dlyRange=2012-09-13\%7C2020-06-

29\&mlyRange $=\% 7 C \& S t a t i o n I D=50621 \& P r o v=P E \& u r I E x t e n s i o n=\_e . h t m l \&$ search Type=stnName\&optLimit=specDate\&StartYear=1840\&EndYear=2020\&seIRowP erPage $=25 \&$ Line $=0 \&$ searchMethod $=$ contains $\&$ Month $=8 \& D a y=29 \&$ txtStationNam e $=$ Charlottetown\&timeframe $=2 \&$ Year $=2016$

Government of Canada. (2020). Historical Data: Daily Data Report for September 2016. https://climate.weather.gc.ca/climate_data/daily_data_e.html?hlyRange=201209-10\%7C2020-06-29\&dlyRange $=2012-09-13 \% 7 C 2020-06-$ 29\&mlyRange $=\% 7 C \& S t a t i o n I D=50621 \& P r o v=P E \& u r \mid E x t e n s i o n=\_e . h t m l \& s e a r c h$ Type $=$ stnName \&optLimit=specDate $\&$ StartYear=1840\&EndYear=2020\&seIRowP erPage $=25 \&$ Line $=0 \&$ searchMethod $=$ contains $\&$ Month $=9 \&$ Day $=29 \&$ txtStationNam e $=$ Charlottetown\&timeframe $=2 \&$ Year $=2016$

Government of Ontario. (2002). Nutrient Management Act, 2002. https://www.ontario.ca/laws/regulation/R03267"ONTARIO REGULATION 267/03

Government of Ontario. (2019). Nutrient Management Act, 2002 (2019 update). https://www.ontario.ca/laws/regulation/R19204" 204/19 
Gundersen, P., Laurén, A., Finér, L., Ring, E., Koivusalo, H., Sætersdal, M., Welien, JO., Sigurdsson, B.D., Högbom, L., Laine, J., \& Hansen, K. (2010). Environmental Services Provided from Riparian Forests in the Nordic Countries. Ambio, 39(8), 555-566. doi:10.1007/s13280-010-0073-9

Huylenbroeck, L., Laslier, M., Dufour, S., Georges, B., Lejeune, P., \& Michez, A. (2020). Using remote sensing to characterize riparian vegetation: A review of available tools and perspectives for managers. Journal of Environmental Management, 267(March), 110652. https://doi.org/10.1016/j.jenvman.2020.110652

Hylander, K. (2006). Riparian zones increase regional species richness by harboring different, not more, species. Ecology, 87(8), 2126-2128; discussion 2128-31. Retrieved from http://www.ncbi.nlm.nih.gov/pubmed/16937652

Javorek, S.K., \& Grant, M.C. (2011). Trends in wildlife habitat capacity on agricultural land in Canada, 1986-2006. Canadian Biodiversity: Ecosystem Status and Trends 2010, Technical Thematic Report No. 14. Canadian Councils of Resource Ministers. Ottawa, ON. vi +46 p. http://www.biodivcanada.ca/default.asp?lang=En\&n=137E1147-1

Javorek, S.K., Antonowitsch, R., Callaghan, C., Grant, M., \& Weins, T. (nd) AEI Technical Supplement, Wildlife Habitat on Farmland: Methodology. 
https://www5.agr.gc.ca/resources/prod/doc/env/naharppnarsa/pdf/wildlife_habitat_e.pdf. Retrieved on September 19, 2018.

Jeong, S.G., Mo, Y., Kim, H.G., Park, C.H., \& Lee, D.K. (2016). Mapping riparian habitat using a combination of remote-sensing techniques. International Journal of Remote Sensing, 37(5), 1069-1088. https://doi.org/10.1080/01431161.2016.1142685

Jiao, X., Kovacs, J. M., Shang, J., McNairn, H., Walters, D., Ma, B., \& Geng, X. (2014). Object-oriented crop mapping and monitoring using multi-temporal polarimetric RADARSAT-2 data. ISPRS Journal of Photogrammetry and Remote Sensing, 96, 38-46. https://doi.org/10.1016/j.isprsjprs.2014.06.014

Johansen, K., Phinn, S., \& Witte, C. (2010). Mapping of riparian zone attributes using discrete return LiDAR, QuickBird and SPOT-5 imagery: Assessing accuracy and costs. Remote Sensing of Environment, 114(11), 2679-2691. https://doi.org/10.1016/j.rse.2010.06.004

Kirby, P. (2015). Monte Carlo-based analysis of the effect of positional and thematic uncertainties in thematic maps on biodiversity model coefficients (October), 353354. 
Klemas, V. (2014). Remote Sensing of Riparian and Wetland Buffers: An Overview. Journal of Coastal Research, 30(5), 869-880. https://doi.org/10.2112/JCOASTRES-D-14-00013.1

Knight, J.F., \& Lunetta, R. S. (2003). An experimental assessment of minimum mapping unit size. IEEE Transactions on Geoscience and Remote Sensing, 41 (9 PART II), 2132-2134. https://doi.org/10.1109/TGRS.2003.816587

Krzeminska, D., Kerkhof, T., Skaalsveen, K., \& Stolte, J. (2019). Effect of riparian vegetation on stream bank stability in small agricultural catchments. Catena, 172 (August 2018), 87-96. https://doi.org/10.1016/j.catena.2018.08.014

Li, G., Jackson, C.R., \& Kraseski, K.A. (2012). Modeled riparian stream shading: Agreement with field measurements and sensitivity to riparian conditions. Journal of Hydrology, 428-429, 142-151. https://doi.org/10.1016/j.jhydrol.2012.01.032

Li, M., Zang, S., Zhang, B., Li, S., \& Wu, C. (2017). A Review of Remote Sensing Image Classification Techniques: The Role of Spatio-contextual Information. European Journal of Remote Sensing, 2279-7254. https://doi.org/10.5721/EuJRS20144723

Li, X., Du, Y., \& Ling, F. (2015). Sub-pixel-scale land cover map updating by integrating change detection and sub-pixel mapping. Photogrammetric Engineering and Remote Sensing, 81(1), 59-67. https://doi.org/10.14358/PERS.81.1.59 
Li, Z., Huffman, T., McConkey, B., \& Townley-Smith, L. (2013). Monitoring and modeling spatial and temporal patterns of grassland dynamics using time-series MODIS NDVI with climate and stocking data. Remote Sensing of Environment, 138: 232244.

Lillesand, T. M., Kiefer, R. W., \& Chipman, J. W. (2004). Remote sensing and image interpretation. (5th ed.). Wiley (763pp.).

Liu, D., \& Xia, F. (2010). Assessing object-based classification: Advantages and limitations. Remote Sensing Letters, 1(4), 187-194. https://doi.org/10.1080/01431161003743173

Lu, D., \& Weng, Q. (2007). A survey of image classification methods and techniques for improving classification performance. International Journal of Remote Sensing, 28(5), 823-870. https://doi.org/10.1080/01431160600746456

Lyon, J.P., Bird, T.J., Kearns, J., Nicol, S., Tonkin, Z., Todd, C. R., Tonkin, Z., Todd, C.R., O'Mahony, J., Hackett, G., Raymond, S., Lieschke, J., Kitchingman, A., \& Bradshaw, C. J. A. (2019). Increased population size of fish in a lowland river following restoration of structural habitat. Ecological Applications, 29(4), 1-11. https://doi.org/10.1002/eap.1882 
Maillard, P., \& Alencar-Silva, T. (2013). A method for delineating riparian forests using region-based image classification and depth-to-water analysis. International Journal of Remote Sensing, 34(22), 7991-8010. https://doi.org/10.1080/01431161.2013.827847

Makinde, E. O., Salami, A. T., Olaleye, J. B., \& Okewusi, O. C. (2016). Object Based and Pixel Based Classification Using RapidEye Satellite Imager of ETI-OSA, Lagos, Nigeria. Geoinformatics FCE CTU, 15(2), 59-70. https://doi.org/10.14311/gi.15.2.5

Marczak, L.A.B., Sakamaki, T.A., Turvey, S.H.L., Deguise, I.S., Wood, S.Y.L.R., \& Richardson, J.S. (2010). Are forested buffers an effective conservation strategy for riparian fauna? An assessment using meta-analysis. Ecological Applications, 20(1), 126-134.

Maseyk, F.J.F., Dominati, E.J., White, T., \& Mackay, A.D. (2017). Farmer perspectives of the on-farm and off-farm pros and cons of planted multifunctional riparian margins. Land Use Policy, 61, 160-170. https://doi.org/10.1016/j.landusepol.2016.10.053

Maskell, L.C., Botham, M., Henrys, P., Jarvis, S., Maxwell, D., Robinson, D.A., ... \& Emmett, B.A. (2019). Exploring relationships between land use intensity, habitat heterogeneity and biodiversity to identify and monitor areas of High Nature Value 
farming. Biological Conservation, 231(July 2018), 30-38.

https://doi.org/10.1016/j.biocon.2018.12.033

Maxwell, A.E., Warner, T.A., \& Fang, F. (2018). Implementation of machine-learning classification in remote sensing: An applied review. International Journal of Remote Sensing, 39(9), 2784-2817. https://doi.org/10.1080/01431161.2018.1433343

McNairn, H., Champagne, C., Shang, J., Holmstrom, D., \& Reichert, G. (2009). Integration of optical and Synthetic Aperture Radar (SAR) Imagery for Delivering operational annual crop inventories. ISPRS Journal of Photogrammetry and Remote Sensing, 64(5), 434-449. https://doi.org/10.1016/j.isprsjprs.2008.07.006

Merchant, M.A., Warren, R.K., Edwards, R., \& Kenyon, J.K. (2019). An Object-Based Assessment of Multi-Wavelength SAR, Optical Imagery and Topographical Datasets for Operational Wetland Mapping in Boreal Yukon, Canada. Canadian Journal of Remote Sensing, 45(3-4), 308-332.

https://doi.org/10.1080/07038992.2019.1605500

Michez, A., Piégay, H., Brogna, D., Bonnet, S., Lejeune, P., \& Claessens, H. (2013). LiDAR derived ecological integrity indicators for riparian zones: Application to the Houille river in Southern Belgium / Northern France. Ecological Indicators, 34, 627-640. https://doi.org/10.1016/j.ecolind.2013.06.024 
Microsoft Corporation. (2018). Microsoft Excel. Retrieved from https://office.microsoft.com/excel

Ministry of Natural Resources and Forestry. (2019). Digital Raster Acquisition Project Eastern Ontario (DRAPE) 2014 Classified LAS Users Guide. http://geo1.scholarsportal.info/\#r/details/_uri@=3469315595

Mitchell, S.W., Remmel, T.K., Csillag, F., \& Wulder, M.A. (2008). Distance to second cluster as a measure of classification confidence. Remote Sensing of Environment, 112: 2615-2626,

Muise, A. (2011). Raster Image Processing Tips and Tricks — Part 4: Image Classification. ESRI ArcGIS Blog Analytics. https://www.esri.com/arcgisblog/products/arcgis-desktop/analytics/raster-image-processing-tips-and-trickspart-4-image-classification/

Natural Resources Canada. (2006). Atlas of Canada 1,000,000 National Frameworks Data, Hydrology - Drainage Network - St. Lawrence. http://geogratis.gc.ca/api/en/nrcan-rncan/ess-sst/ee69c4de-d1e5-5d93-ba3b3ff16137d544.html 
Natural Resources Canada. (2008). Atlas of Canada 1,000,000 National Frameworks Data, Hydrology - Drainage Network - Maritimes. http://geogratis.gc.ca/api/en/nrcan-rncan/ess-sst/1f869c8f-ff66-51ec-942b1fc1cdf0c1e8.html

Natural Resources Canada. (2016). National Hydro Network (NHN) - 02LB004 - Lower Ottawa - South Nation (part of), Ontario, Quebec. http://open.canada.ca/data/en/dataset/622b5bd7-7dc0-4268-87d7$59613248634 c$

Natural Resources Canada. (2017). National Road Network - NRN - GeoBase Series. http://www.geogratis.gc.ca/

Natural Resources Canada. (2017). Canadian Forest Attribute Maps. https://open.canada.ca/data/en/dataset/ec9e2659-1c29-4ddb-87a26aced147a990

Neave, P., \& Neave, E. (1998). Agroecosystem Biodiversity Indicator: Habitat Component: Review and Assessment of Concepts and Indicators of Wildlife Habitat and Habitat Availability In The Agricultural Landscape: Concept Paper. Prepared for the Prairie Farm Rehabilitation Administration and the AgriEnvironmental Indicator Project Agriculture and Agri-Food Canada, (March). 
Neave, P., \& Neave, E. (1998). Habitat and habitat availability indicator. Technical Report for the Agri-Environmental Indicator project. Environment Bureau, Policy Branch, Agriculture and Agri-Food Canada. Ottawa, ON. 193 pp

Nguyen, U., Glenn, E.P., Duc, T., \& Pham, L.T.H. (2019). Ecological Informatics Mapping vegetation types in semi-arid riparian regions using random forest and object-based image approach: A case study of the Colorado River Ecosystem, Grand Canyon, Arizona. Ecological Informatics, 50(December 2018), 43-50. https://doi.org/10.1016/j.ecoinf.2018.12.006

Novoa, J., Chokmani, K., \& Lhissou, R. (2018). A novel index for assessment of riparian strip efficiency in agricultural landscapes using high spatial resolution satellite imagery. Science of the Total Environment, 644, 1439-1451. https://doi.org/10.1016/j.scitotenv.2018.07.069

Nutrient Management Act. (2002). 9.5 Buffer Zones Ontario http://www.omafra.gov.on.ca/english/nm/regs/nmpro/nmpro09-jun03.htm\#5

Olson, D.H., Anderson, P.D., Frissell, C.A., Welsh, H.H., \& Bradford, D.F. (2007). Biodiversity management approaches for stream-riparian areas: Perspectives for Pacific Northwest headwater forests, microclimates, and amphibians. Forest Ecology and Management, 246(1), 81-107. https://doi.org/10.1016/j.foreco.2007.03.053 
Ontario Ministry of Natural Resources. (2010). Watershed Secondary. http://geo.scholarsportal.info/\#r/details/_uri@=1589523613

Ontario Ministry of Natural Resources. (2015). Digital Raster Acquisition Project Eastern Ontario (DRAPE) 2014-Ontario Geospatial Data Exchange. http://geo1.scholarsportal.info/\#r/details/_uri@=3469315595

Pande-Chhetri, R., Abd-Elrahman, A., Liu, T., Morton, J., \& Wilhelm, V.L. (2017). Object-based classification of wetland vegetation using very high-resolution unmanned air system imagery. European Journal of Remote Sensing, 50(1), 564-576. https://doi.org/10.1080/22797254.2017.1373602

Parks Canada. (2003). Terrestrial Ecozones of Canada. http://parkscanadahistory.com/publications/fact-sheets/eng/ecozones.pdf

Pei, Z., Zhang, S., Guo, L., McNairn, H., Shang, J., \& Jiao, X. (2011). Rice identification and change detection using TerraSAR-X data. Canadian Journal of Remote Sensing, 37: 151-156.

Piedelobo, L., Taramelli, A., Schiavon, E., Valentini, E., Molina, J. L., Xuan, A. N., \& González-Aguilera, D. (2019). Assessment of green infrastructure in Riparian 
zones using copernicus programme. Remote Sensing, 11(24).

https://doi.org/10.3390/rs11242967

Planet Labs. (2016). RapidEye Imagery Product Specifications.

https://www.planet.com/products/satellite-imagery/files/160625-

RapidEye\%20Image-Product-Specifications.pdf

Planet Labs. (2015). RapidEye Imagery: South Nation watershed.

https://www.planet.com/

Planet Labs. (2016). RapidEye Imagery: Prince Edward Island. https://www.planet.com/

Rapinel, S., Clement, B., Magnanon, S., Sellin, V., \& Hubert-Moy, L. (2014).

Identification and mapping of natural vegetation on a coastal site using a Worldview-2 satellite image. Journal of Environmental Management, 144, 236246. https://doi.org/10.1016/j.jenvman.2014.05.027

Remmel, T. K., Csillag, F., Mitchell, S., \& Wulder, M. A. (2005). Integration of forest inventory and satellite imagery: a Canadian status assessment and research issues. 207, 405-428. https://doi.org/10.1016/j.foreco.2004.11.023

Richardson, J.S., Naiman, R.J., \& Bisson, P.A. (2012). How did fixed-width buffers become standard practice for protecting freshwaters and their riparian areas from 
forest harvest practices? Freshwater Science, 31(1), 232-238. doi:10.1899/11031.1

Saha, D., Das, D., Dasgupta, R., \& Patel, P. (2020). Application of ecological and aesthetic parameters for riparian quality assessment of a small tropical river in eastern India. Ecological Indicators, 117. https://doi.org/10.1016/j.ecolind.2020.106627

Santolini, R., Morri, E., Pasini, G., Giovagnoli, G., Morolli, C., \& Salmoiraghi, G. (2015). Assessing the quality of riparian areas: the case of River Ecosystem Quality Index applied to the Marecchia river (Italy). International Journal of River Basin Management, 13(1), 1-16. https://doi.org/10.1080/15715124.2014.945091

Sass, G. Z., Wheatley, M., Aldred, D. A., Gould, A. J., \& Creed, I. F. (2012). Defining protected area boundaries based on vascular-plant species richness using hydrological information derived from archived satellite imagery. Biological Conservation, 147(1), 143-152. https://doi.org/10.1016/j.biocon.2011.12.025

Shang, J., McNairn, H., Champagne, C., \& Jiao, X. (2008). Contribution of multifrequency, multi-sensor, and multi-temporal radar data to operational annual crop mapping. In: Proc. IGARSS Annual Conference, Boston, MA, July 8-11, pp. III - 378-381. 
Shmueli, B. (July, 2019). Multi-Class Metrics Made Simple, Part I: Precision and Recall. https://shmueli.medium.com/

Shmueli, B. (December, 2019). Multi-Class Metrics Made Simple, Part III: the Kappa Score (aka Cohen's Kappa Coefficient). https://shmueli.medium.com/

Statistics Canada. (2016). Data Tables: Land and freshwater area, by province and territory. https://www150.statcan.gc.ca/n1/pub/11-402x/2010000/chap/geo/tbl/tbl07-eng.htm Accessed on October 26, 2020.

Statistics Canada. (2018). Geography. https://www150.statcan.gc.ca/n1/pub/11-402x/2011000/chap/geo/geo-eng.htm. Accessed on October 26, 2020.

Sosa, L.L., Glanville, H.C., Marshall, M.R., Prysor Williams, A., \& Jones, D.L. (2018). Quantifying the contribution of riparian soils to the provision of ecosystem services. Science of the Total Environment, 624, 807-819. https://doi.org/10.1016/j.scitotenv.2017.12.179

Souris \& Area Branch PEI Wildlife Federation. (2006). Souris River Watershed Management Plan. http://souriswl.com/wpcontent/uploads/2019/03/souris_river_watershed_plan.pdf 
South Nation Conservation. (2018) South Nation Conservation: Maps.

https://www.nation.on.ca/resources/maps

South Nation River. (2020) Wikipedia. https://en.wikipedia.org/wiki/South_Nation_River Accessed on August 15, 2020.

del Tánago, M. G., \& de Jalón, D. G. (2011). Riparian Quality Index (RQI): A methodology for characterising and assessing the environmental conditions of riparian zones. Limnetica, 30(2), 235-254.

United Nations Environment Program. (2020). Convention on Biological Diversity. https://www.cbd.int/

United Nations General Assembly. (2015). Transforming our World: The 2030 Agenda for Sustainable Development. https://sdgs.un.org/2030agenda. Accessed November 23, 2020.

USGS. (2019). USGS Data handbook, version 5. https://prd-wret.s3.us-west2.amazonaws.com/assets/palladium/production/atoms/files/LSDS1574_L8_Data_Users_Handbook-v5.0.pdf 
USGS. (2020). Landsat Missions. https://www.usgs.gov/landresources/nli/landsat/landsat-8?qt-science_support_page_related_con=0\#qtscience_support_page_related_con

Wen, L. and Hughes, M. (2020). Algorithms: A Comparative Study of Bagging, Boosting and Stacking Techniques. Remote Sensing, 12(10), 1683.

Woodward, B. D., Evangelista, P. H., Young, N. E., Vorster, A. G., West, A. M., Carroll, S. L., ..., \& Jarnevich, C. (2018). CO-RIP: A riparian vegetation and corridor extent dataset for Colorado river basin streams and rivers. ISPRS International Journal of Geo-Information, 7(10). https://doi.org/10.3390/ijgi7100397 


\section{Appendix}

\section{A. Classification Results}

\section{A - $1 . \quad$ South Nation Whole Area Treatment}

Table A - 1: Confusion matrix of accuracy results from the South Nation watershed pixel-based classification of 2015 RapidEye imagery using the Whole area treatment.

\begin{tabular}{|c|c|c|c|c|c|c|c|c|c|c|}
\hline $\begin{array}{l}\text { South } \\
\text { Nation } \\
\text { Whole }\end{array}$ & $\begin{array}{l}\frac{0}{5} \\
\frac{5}{5} \\
.0 \\
\frac{0}{0} \\
4\end{array}$ & $\frac{\bar{d}}{\bar{N}}$ & 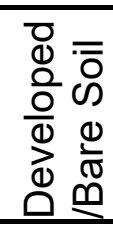 & $\begin{array}{l}\text { D } \\
\frac{\pi}{0} \\
\frac{0}{0} \\
\mathbb{0} \\
0\end{array}$ & 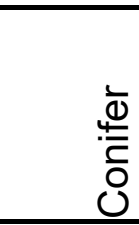 & $\begin{array}{l}\frac{0}{2} \\
\frac{0}{2} \\
\frac{0}{0} \\
\Phi \\
0 \\
\end{array}$ & 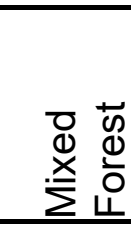 & $\begin{array}{l}\bar{\pi} \\
\stackrel{0}{0}\end{array}$ & 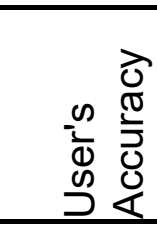 & $\begin{array}{l}\mathbb{0} \\
\stackrel{0}{2} \\
\underline{\pi} \\
\underline{\pi}\end{array}$ \\
\hline Agriculture & 41 & 4 & 3 & 1 & 6 & 0 & 1 & 56 & 0.73 & 0 \\
\hline Water & 0 & 45 & 0 & 0 & 0 & 0 & 0 & 45 & 1.00 & 0 \\
\hline $\begin{array}{l}\text { Developed/ } \\
\text { Bare Soil }\end{array}$ & 9 & 1 & 41 & 4 & 7 & 4 & 7 & 73 & 0.56 & 0 \\
\hline Grassland & 0 & 0 & 6 & 38 & 0 & 0 & 0 & 44 & 0.86 & 0 \\
\hline Conifer & 0 & 0 & 0 & 0 & 18 & 2 & 7 & 27 & 0.67 & 0 \\
\hline Deciduous & 0 & 0 & 0 & 7 & 2 & 9 & 19 & 37 & 0.24 & 0 \\
\hline $\begin{array}{l}\text { Mixed } \\
\text { Forest }\end{array}$ & 0 & 0 & 0 & 0 & 17 & 35 & 16 & 68 & 0.24 & 0 \\
\hline Total & 50 & 50 & 50 & 50 & 50 & 50 & 50 & 350 & 0.00 & 0 \\
\hline $\begin{array}{l}\text { Producer's } \\
\text { Accuracy }\end{array}$ & 0.82 & 0.9 & 0.82 & 0.76 & 0.36 & 0.18 & 0.32 & 0 & 0.594 & 0 \\
\hline Kappa & \begin{tabular}{|l|}
0 \\
\end{tabular} & 0 & 0 & 0 & 0 & 0 & 0 & 0 & 0 & 0.527 \\
\hline
\end{tabular}


Table A - 2: Confusion matrix of accuracy results from the South Nation watershed object-based classification of 2015 RapidEye imagery using the Whole area treatment.

\begin{tabular}{|c|c|c|c|c|c|c|c|c|c|c|}
\hline $\begin{array}{l}\text { South Nation } \\
\text { Whole } \\
\text { (Object) }\end{array}$ & $\begin{array}{l}\frac{0}{2} \\
\frac{3}{5} \\
\frac{0}{2} \\
\frac{0}{2} \\
\end{array}$ & $\begin{array}{l}\frac{1}{\Phi} \\
\omega^{\pi}\end{array}$ & 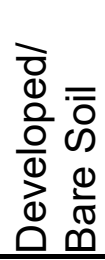 & $\begin{array}{l}\overline{0} \\
\frac{\pi}{\pi} \\
\frac{0}{0} \\
\frac{0}{0} \\
0\end{array}$ & 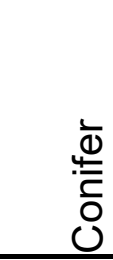 & $\begin{array}{l}\frac{0}{7} \\
\frac{0}{2} \\
\frac{0}{0} \\
0 \\
0\end{array}$ & 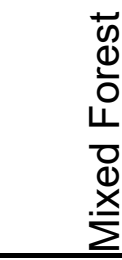 & $\begin{array}{l}\bar{\pi} \\
\stackrel{\pi}{0} \\
\end{array}$ & 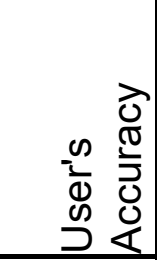 & 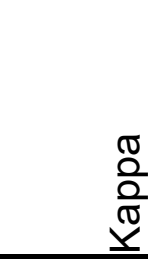 \\
\hline Agriculture & 49 & 17 & 4 & 5 & 21 & 4 & 1 & 101 & 0.49 & 0 \\
\hline Water & 0 & 33 & 0 & 0 & 0 & 0 & 6 & 39 & 0.85 & 0 \\
\hline $\begin{array}{l}\text { Developed/ } \\
\text { Bare Soil }\end{array}$ & 1 & 0 & 39 & 1 & 8 & 0 & 1 & 50 & 0.78 & 0 \\
\hline Grassland & 0 & 0 & 7 & 36 & 0 & 4 & 1 & 48 & 0.75 & 0 \\
\hline Conifer & 0 & 0 & 0 & 0 & 11 & 3 & 7 & 21 & 0.52 & 0 \\
\hline Deciduous & 0 & 0 & 0 & 8 & 0 & 5 & 17 & 30 & 0.17 & 0 \\
\hline Mixed Forest & 0 & 0 & 0 & 0 & 10 & 34 & 17 & 61 & 0.28 & 0 \\
\hline Total & 50 & 50 & 50 & 50 & 50 & 50 & 50 & 350 & 0.00 & 0 \\
\hline $\begin{array}{l}\text { Producer's } \\
\text { Accuracy }\end{array}$ & 0.98 & 0.66 & 0.78 & 0.72 & 0.22 & 0.1 & 0.34 & 0 & 0.543 & 0 \\
\hline Kappa & 0 & 0 & 0 & 0 & 0 & 0 & 0 & 0 & 0 & 0.467 \\
\hline
\end{tabular}




\section{A - 2. South Nation Crop Cookie Cutter Treatment}

Table A - 3: Confusion matrix of accuracy results from pixel-based classification of 2015 RapidEye imagery from the South Nation watershed using the Crop Cookie Cutter treatment.

\begin{tabular}{|c|c|c|c|c|c|c|c|c|c|c|}
\hline $\begin{array}{l}\text { South } \\
\text { Nation Crop }\end{array}$ & 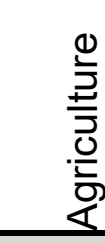 & 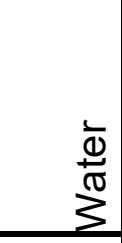 & 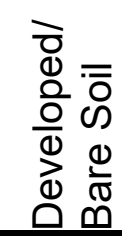 & $\begin{array}{l}\overline{0} \\
\frac{\pi}{\pi} \\
\mathbb{N} \\
\mathbb{N} \\
\frac{0}{0} \\
\end{array}$ & 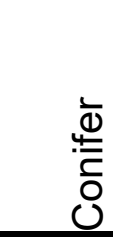 & 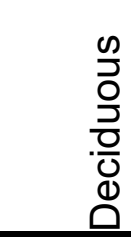 & 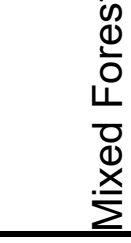 & $\begin{array}{l}\bar{\pi} \\
\stackrel{0}{0} \\
\end{array}$ & 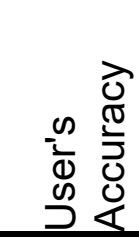 & $\begin{array}{l}\mathbb{0} \\
\frac{0}{0} \\
\underline{\mathbb{N}} \\
\end{array}$ \\
\hline Agriculture & 22 & 0 & 5 & 0 & 1 & 0 & 0 & 28 & 0.79 & 0 \\
\hline Water & 0 & 50 & 0 & 0 & 0 & 0 & 0 & 50 & 1.00 & 0 \\
\hline $\begin{array}{l}\text { Developed/ } \\
\text { Bare Soil } \\
\end{array}$ & 21 & 0 & 38 & 0 & 9 & 4 & 5 & 77 & 0.49 & 0 \\
\hline Grassland & 0 & 0 & 0 & 25 & 0 & 0 & 0 & 25 & 1.00 & 0 \\
\hline Conifer & 2 & 0 & 0 & 0 & 37 & 3 & 2 & 44 & 0.84 & 0 \\
\hline Deciduous & 0 & 0 & 1 & 17 & 0 & 18 & 14 & 50 & 0.36 & 0 \\
\hline \begin{tabular}{|l|} 
Mixed \\
Forest
\end{tabular} & 0 & 0 & 0 & 0 & 3 & 25 & 29 & 57 & 0.51 & 0 \\
\hline Total & 45 & 50 & 44 & 42 & 50 & 50 & 50 & 331 & 0.00 & 0 \\
\hline $\begin{array}{l}\text { Producer's } \\
\text { Accuracy }\end{array}$ & 0.49 & 1.00 & 0.86 & 0.60 & 0.74 & 0.36 & 0.58 & 0 & 0.662 & 0 \\
\hline Kappa & 0 & 0 & 0 & 0 & 0 & 0 & 0 & 0 & 0 & 0.605 \\
\hline
\end{tabular}


Table A - 4: Confusion matrix of accuracy results from object-based classification of the South Nation watershed 2015 RapidEye imagery using the Crop Cookie Cutter treatment with segmented data.

\begin{tabular}{|c|c|c|c|c|c|c|c|c|c|c|}
\hline $\begin{array}{l}\text { South } \\
\text { Nation Crop } \\
\text { (Object) }\end{array}$ & 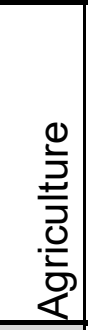 & $\frac{\bar{d}}{\frac{\Phi}{\pi}}$ & 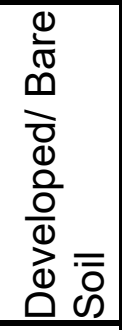 & $\begin{array}{l}\overline{0} \\
\frac{\pi}{\mathbb{N}} \\
\mathscr{T} \\
\mathbb{0} \\
\mathbb{0}\end{array}$ & 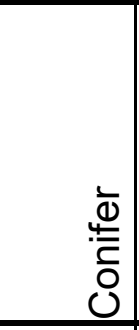 & $\begin{array}{l}\text { on } \\
\text { 웅 } \\
\text { 응 } \\
0 \\
\end{array}$ & 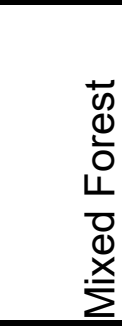 & $\begin{array}{l}\bar{\pi} \\
\stackrel{0}{0}\end{array}$ & 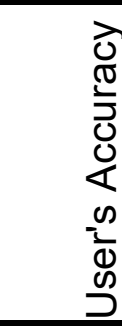 & $\begin{array}{l}\widetilde{\pi} \\
\stackrel{0}{0} \\
\underline{\mathbb{T}} \\
\end{array}$ \\
\hline Agriculture & 0 & 0 & 0 & 0 & 0 & 0 & 0 & 0 & 0.00 & 0 \\
\hline Water & 0 & 13 & 0 & 0 & 0 & 0 & 0 & 13 & 1.00 & 0 \\
\hline $\begin{array}{l}\text { Developed/ } \\
\text { Bare Soil }\end{array}$ & 19 & 0 & 37 & 5 & 1 & 4 & 0 & 66 & 0.56 & 0 \\
\hline Grassland & 9 & 0 & 0 & 5 & 1 & 0 & 0 & 15 & 0.33 & 0 \\
\hline Conifer & 4 & 26 & 5 & 31 & 48 & 46 & 50 & 210 & 0.23 & 0 \\
\hline Deciduous & 14 & 11 & 0 & 4 & 0 & 0 & 0 & 29 & 0.00 & 0 \\
\hline $\begin{array}{l}\text { Mixed } \\
\text { Forest } \\
\end{array}$ & 0 & 0 & 0 & 0 & 0 & 0 & 0 & 0 & 0.00 & 0 \\
\hline Total & 46 & 50 & 42 & 45 & 50 & 50 & 50 & 333 & 0.00 & 0 \\
\hline $\begin{array}{l}\text { Producer's } \\
\text { Accuracy }\end{array}$ & 0 & 0.26 & 0.88 & 0.11 & 0.96 & 0 & 0 & 0 & 0.309 & 0 \\
\hline Kappa & 0 & 0 & 0 & 0 & 0 & 0 & 0 & 0 & 0 & 0.192 \\
\hline
\end{tabular}




\section{A - 3. South Nation 60 m Buffer Treatment}

Table A - 5: Confusion matrix of accuracy results from pixel-based classification of the South Nation watershed 2015 RapidEye imagery using the $60 \mathrm{~m}$ buffer treatment.

\begin{tabular}{|c|c|c|c|c|c|c|c|c|c|c|}
\hline $\begin{array}{l}\text { South } \\
\text { Nation } \\
60 \mathrm{~m} \\
\end{array}$ & $\begin{array}{l}\frac{0}{2} \\
\frac{2}{5} \\
.0 \\
\frac{0}{2} \\
\end{array}$ & $\frac{1}{\frac{1}{\pi}}$ & 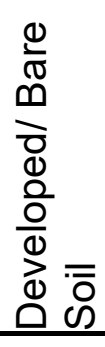 & $\begin{array}{l}\overline{0} \\
\frac{\pi}{\sigma} \\
\frac{\pi}{0} \\
\mathbb{\pi} \\
\mathbb{0} \\
0\end{array}$ & 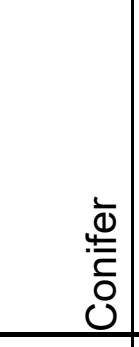 & 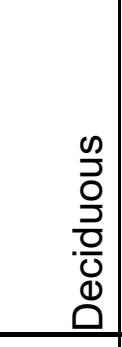 & 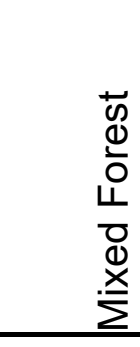 & 莡 & 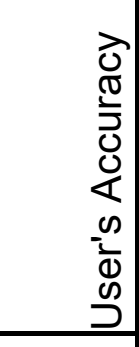 & $\begin{array}{l}\widetilde{0} \\
\stackrel{0}{2} \\
\underline{\pi} \\
\end{array}$ \\
\hline Agriculture & 50 & 0 & 0 & 0 & 4 & 0 & 0 & 54 & 0.93 & 0 \\
\hline Water & 0 & 47 & 0 & 0 & 0 & 0 & 0 & 47 & 1.00 & 0 \\
\hline \begin{tabular}{|l|} 
Developed \\
/ Bare Soil
\end{tabular} & 0 & 3 & 50 & 2 & 6 & 0 & 7 & 68 & 0.74 & 0 \\
\hline Grassland & 0 & 0 & 0 & 41 & 0 & 0 & 1 & 42 & 0.98 & 0 \\
\hline Conifer & 0 & 0 & 0 & 0 & 17 & 0 & 3 & 20 & 0.85 & 0 \\
\hline Deciduous & 0 & 0 & 0 & 4 & 9 & 20 & 16 & 49 & 0.41 & 0 \\
\hline \begin{tabular}{|l|} 
Mixed \\
Forest
\end{tabular} & 0 & 0 & 0 & 3 & 14 & 30 & 23 & 70 & 0.33 & 0 \\
\hline Total & 50 & 50 & 50 & 50 & 50 & 50 & 50 & 350 & 0.00 & 0 \\
\hline $\begin{array}{l}\text { Producer's } \\
\text { Accuracy }\end{array}$ & 1 & 0.94 & 1 & 0.82 & 0.34 & 0.4 & 0.46 & 0 & 0.709 & 0 \\
\hline Kappa & 0 & 0 & 0 & 0 & 0 & 0 & 0 & 0 & 0 & 0.660 \\
\hline
\end{tabular}


Table A - 6: Confusion matrix of accuracy results from object-based classification of the South Nation watershed 2015 RapidEye imagery using the 60m buffer treatment.

\begin{tabular}{|c|c|c|c|c|c|c|c|c|c|c|}
\hline $\begin{array}{l}\text { South } \\
\text { Nation } \\
60 \mathrm{~m} \\
\text { (Object) }\end{array}$ & $\begin{array}{l}\frac{0}{3} \\
\frac{1}{5} \\
\frac{0}{0} \\
\frac{1}{4}\end{array}$ & 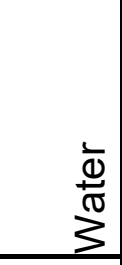 & 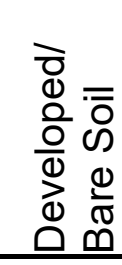 & $\begin{array}{l}\overline{0} \\
\frac{\pi}{\sigma} \\
\frac{0}{\pi} \\
\frac{\pi}{0} \\
\end{array}$ & $\begin{array}{l}\grave{\Phi} \\
\stackrel{\stackrel{ \pm}{Ј}}{\overline{0}} \\
\mathcal{U}\end{array}$ & $\begin{array}{l}\frac{0}{2} \\
\text { 음 } \\
. \frac{0}{0} \\
\Phi \\
0 \\
\end{array}$ & 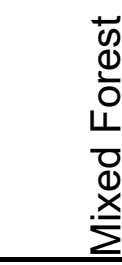 & 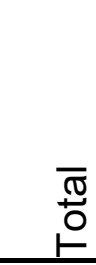 & 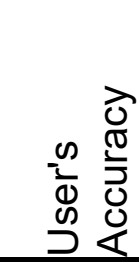 & $\begin{array}{r}\mathbb{\mathbb { a }} \\
\frac{0}{\mathbb{N}} \\
\underline{\mathbb{x}} \\
\end{array}$ \\
\hline Agriculture & 50 & 0 & 11 & 0 & 5 & 0 & 0 & 66 & 0.76 & 0 \\
\hline Water & 0 & 50 & 0 & 0 & 4 & 0 & 7 & 61 & 0.82 & 0 \\
\hline $\begin{array}{l}\text { Developed } \\
\text { / Bare Soil }\end{array}$ & 0 & 0 & 39 & 0 & 0 & 0 & 0 & 39 & 1.00 & 0 \\
\hline Grassland & 0 & 0 & 0 & 32 & 3 & 4 & 0 & 39 & 0.82 & 0 \\
\hline Conifer & 0 & 0 & 0 & 8 & 3 & 2 & 7 & 20 & 0.15 & 0 \\
\hline Deciduous & 0 & 0 & 0 & 7 & 11 & 28 & 18 & 64 & 0.44 & 0 \\
\hline $\begin{array}{l}\text { Mixed } \\
\text { Forest }\end{array}$ & 0 & 0 & 0 & 3 & 24 & 16 & 18 & 61 & 0.30 & 0 \\
\hline Total & 50 & 50 & 50 & 50 & 50 & 50 & 50 & 350 & 0.00 & 0 \\
\hline $\begin{array}{l}\text { Producer's } \\
\text { Accuracy }\end{array}$ & 1 & 1 & 0.78 & 0.64 & 0.06 & 0.56 & 0.36 & 0 & 0.629 & 0 \\
\hline Kappa & 0 & 0 & 0 & 0 & 0 & 0 & 0 & 0 & 0 & 0.567 \\
\hline
\end{tabular}




\section{A - 4. Dunk River Whole Area Treatment}

Table A - 7: Confusion matrix of accuracy results from pixel-based classification of 2016 RapidEye imagery of the Dunk River watershed using the Whole area treatment.

\begin{tabular}{|c|c|c|c|c|c|c|c|c|c|c|c|}
\hline $\begin{array}{l}\text { Dunk } \\
\text { River } \\
\text { Whole }\end{array}$ & 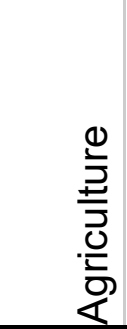 & $\begin{array}{l}\frac{\bar{\phi}}{\pi} \\
\frac{\pi}{3}\end{array}$ & 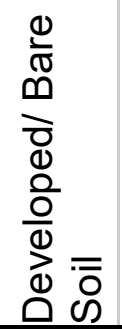 & $\begin{array}{l}\frac{0}{2} \\
\frac{2}{\omega}\end{array}$ & $\begin{array}{l}\frac{0}{\pi} \\
\frac{\pi}{\pi} \\
\frac{\pi}{3}\end{array}$ & $\begin{array}{l}\overline{0} \\
\frac{\pi}{\omega} \\
\frac{\pi}{\pi} \\
\frac{\pi}{0}\end{array}$ & 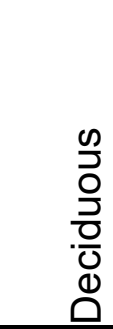 & 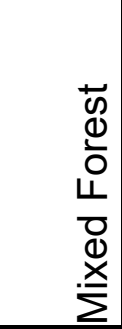 & 要 & 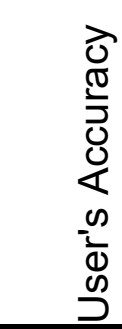 & $\begin{array}{l}\frac{\pi}{0} \\
\frac{0}{2} \\
\underline{\pi}\end{array}$ \\
\hline Agriculture & 26 & 0 & 16 & 4 & 1 & 3 & 2 & 0 & 52 & 0.5 & 0 \\
\hline Water & 0 & 50 & 0 & 0 & 0 & 0 & 0 & 0 & 50 & 1 & 0 \\
\hline $\begin{array}{l}\text { Developed } \\
\text { / Bare Soil }\end{array}$ & 1 & 0 & 22 & 0 & 0 & 0 & 0 & 0 & 23 & 0.96 & 0 \\
\hline Shrub & 13 & 0 & 5 & 15 & 8 & 18 & 8 & 2 & 69 & 0.22 & 0 \\
\hline Wetland & 1 & 0 & 2 & 4 & 21 & 0 & 1 & 3 & 32 & 0.66 & 0 \\
\hline Grassland & 8 & 0 & 2 & 12 & 9 & 28 & 2 & 0 & 61 & 0.46 & 0 \\
\hline Deciduous & 1 & 0 & 3 & 12 & 5 & 1 & 20 & 16 & 58 & 0.34 & 0 \\
\hline $\begin{array}{l}\text { Mixed } \\
\text { Forest }\end{array}$ & 0 & 0 & 0 & 3 & 6 & 0 & 17 & 29 & 55 & 0.53 & 0 \\
\hline Total & 50 & 50 & 50 & 50 & 50 & 50 & 50 & 50 & 400 & 0 & 0 \\
\hline $\begin{array}{l}\text { Producer's } \\
\text { Accuracy }\end{array}$ & 0.52 & 1 & 0.44 & 0.3 & 0.42 & 0.56 & 0.4 & 0.58 & 0 & $\begin{array}{l}0.527 \\
5\end{array}$ & 0 \\
\hline Kappa & 0 & 0 & 0 & 0 & 0 & 0 & 0 & 0 & 0 & 0 & 0.46 \\
\hline
\end{tabular}


Table A - 8: Confusion matrix of accuracy results from object-based classification of the Dunk River watershed 2016 RapidEye imagery using the Whole area treatment.

\begin{tabular}{|c|c|c|c|c|c|c|c|c|c|c|c|}
\hline $\begin{array}{l}\text { Dunk } \\
\text { River } \\
\text { Whole } \\
\text { (Object) }\end{array}$ & 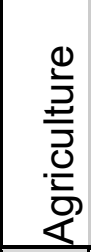 & 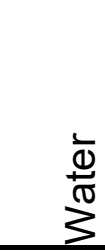 & 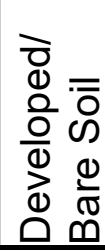 & $\begin{array}{l}\frac{0}{2} \\
\frac{1}{\omega} \\
\end{array}$ & 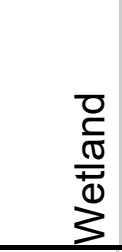 & $\begin{array}{l}\overline{0} \\
\frac{0}{\omega} \\
\frac{\pi}{0} \\
\frac{\pi}{0} \\
0 \\
\end{array}$ & $\begin{array}{l}\frac{\infty}{0} \\
\frac{0}{2} \\
\frac{0}{0} \\
0 \\
0\end{array}$ & 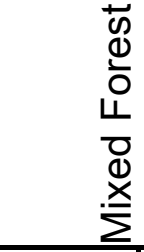 & 跑 & 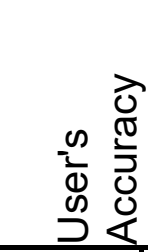 & $\begin{array}{l}\text { व } \\
\stackrel{0}{0} \\
\underline{\mathbb{0}}\end{array}$ \\
\hline Agriculture & 25 & 0 & 18 & 7 & 1 & 2 & 0 & 2 & 55 & 0.45 & 0 \\
\hline Water & 0 & 49 & 0 & 0 & 1 & 0 & 0 & 0 & 50 & 0.98 & 0 \\
\hline $\begin{array}{l}\text { Developed } \\
\text { / Bare Soil }\end{array}$ & 8 & 0 & 22 & 3 & 4 & 0 & 2 & 0 & 39 & 0.56 & 0 \\
\hline Shrub & 6 & 0 & 7 & 21 & 15 & 16 & 12 & 3 & 80 & 0.26 & 0 \\
\hline Wetland & 0 & 0 & 0 & 1 & 18 & 0 & 0 & 0 & 19 & 0.95 & 0 \\
\hline Grassland & 9 & 0 & 1 & 3 & 11 & 32 & 5 & 0 & 61 & 0.52 & 0 \\
\hline Deciduous & 1 & 0 & 2 & 7 & 0 & 0 & 19 & 17 & 46 & 0.41 & 0 \\
\hline $\begin{array}{l}\text { Mixed } \\
\text { Forest } \\
\end{array}$ & 1 & 1 & 0 & 8 & 0 & 0 & 12 & 28 & 50 & 0.56 & 0 \\
\hline Total & 50 & 50 & 50 & 50 & 50 & 50 & 50 & 50 & 400 & 0 & 0 \\
\hline \begin{tabular}{|l|} 
Producer's \\
Accuracy
\end{tabular} & 0.5 & 0.98 & 0.44 & 0.42 & 0.36 & 0.64 & 0.38 & 0.56 & 0 & 0.535 & 0 \\
\hline Kappa & 0 & 0 & 0 & 0 & 0 & 0 & 0 & 0 & 0 & 0 & 0.469 \\
\hline
\end{tabular}




\section{A - 5. Dunk River Crop Cookie Cutter Treatment}

Table A - 9: Confusion matrix of accuracy results from pixel-based classification of 2016 RapidEye imagery of the Dunk River watershed using the Crop Cookie Cutter treatment.

\begin{tabular}{|c|c|c|c|c|c|c|c|c|c|c|c|}
\hline $\begin{array}{l}\text { Dunk } \\
\text { River Crop }\end{array}$ & $\begin{array}{l}\stackrel{0}{3} \\
\frac{1}{5} \\
\frac{0}{5} \\
\frac{0}{4}\end{array}$ & $\frac{\bar{\Phi}}{\frac{\Phi}{\pi}}$ & 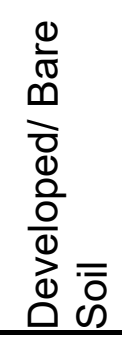 & $\begin{array}{l}\frac{0}{2} \\
\frac{1}{\omega} \\
\end{array}$ & 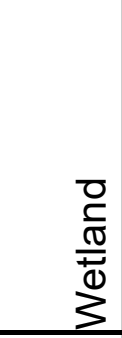 & $\begin{array}{l}\overline{0} \\
\frac{0}{0} \\
0 \\
\mathbb{0} \\
\mathbb{0} \\
\end{array}$ & $\begin{array}{l}\frac{0}{7} \\
\text { 음 } \\
\text { 응 } \\
\Phi \\
0\end{array}$ & 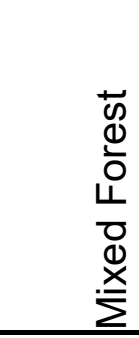 & 覀 & 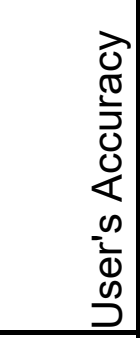 & $\begin{array}{r}\mathbb{0} \\
\stackrel{2}{2} \\
\stackrel{0}{\mathbb{2}} \\
\end{array}$ \\
\hline Agriculture & 25 & 0 & 5 & 10 & 16 & 37 & 1 & 0 & 94 & 0.27 & 0 \\
\hline Water & 0 & 16 & 0 & 0 & 0 & 0 & 0 & 0 & 16 & 1.00 & 0 \\
\hline $\begin{array}{l}\text { Developed } \\
\text { / Bare Soil }\end{array}$ & 2 & 19 & 33 & 0 & 1 & 0 & 0 & 0 & 55 & 0.60 & 0 \\
\hline Shrub & 6 & 0 & 4 & 7 & 3 & 9 & 3 & 5 & 37 & 0.19 & 0 \\
\hline Wetland & 2 & 0 & 3 & 6 & 20 & 3 & 5 & 0 & 39 & 0.51 & 0 \\
\hline Grassland & 8 & 0 & 1 & 12 & 8 & 1 & 0 & 0 & 30 & 0.03 & 0 \\
\hline Deciduous & 0 & 0 & 1 & 6 & 1 & 0 & 22 & 7 & 37 & 0.59 & 0 \\
\hline $\begin{array}{l}\text { Mixed } \\
\text { Forest }\end{array}$ & 2 & 5 & 1 & 0 & 1 & 0 & 19 & 31 & 59 & 0.53 & 0 \\
\hline Total & 45 & 40 & 48 & 41 & 50 & 50 & 50 & 43 & 367 & 0.00 & 0 \\
\hline $\begin{array}{l}\text { Producer's } \\
\text { Accuracy }\end{array}$ & 0.56 & 0.40 & 0.69 & 0.17 & 0.40 & 0.02 & 0.44 & 0.72 & 0 & 0.422 & 0 \\
\hline Kappa & 0 & 0 & 0 & 0 & 0 & 0 & 0 & 0 & 0 & 0 & 0.340 \\
\hline
\end{tabular}


Table A - 10: Confusion matrix of accuracy results from object-based classification of 2016 RapidEye imagery of the Dunk River watershed using the Crop Cookie Cutter method.

\begin{tabular}{|c|c|c|c|c|c|c|c|c|c|c|c|}
\hline $\begin{array}{l}\text { Dunk } \\
\text { River Crop } \\
\text { (Object) }\end{array}$ & $\begin{array}{l}\frac{0}{2} \\
\frac{1}{5} \\
\frac{0}{5} \\
\frac{0}{4}\end{array}$ & $\frac{\bar{\Phi}}{\frac{\bar{d}}{\bar{\omega}}}$ & 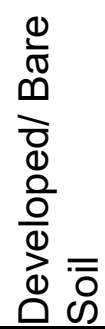 & $\begin{array}{l}\frac{0}{2} \\
\frac{1}{\omega}\end{array}$ & $\begin{array}{l}\frac{0}{0} \\
\frac{\pi}{\pi} \\
\frac{\pi}{0} \\
3\end{array}$ & $\begin{array}{l}\bar{D} \\
\frac{D}{\mathbb{N}} \\
\frac{\mathbb{N}}{\mathbb{N}} \\
\frac{\mathbb{N}}{0}\end{array}$ & $\begin{array}{l}\frac{\infty}{2} \\
\text { 음 } \\
\text { 음 }\end{array}$ & 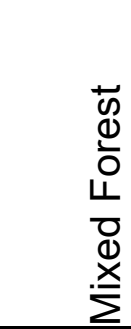 & $\begin{array}{l}\bar{\pi} \\
\stackrel{0}{0}\end{array}$ & 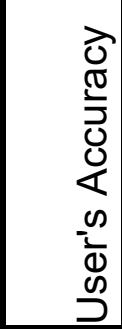 & $\begin{array}{l}\frac{\pi}{2} \\
\frac{0}{2} \\
\frac{\pi}{2}\end{array}$ \\
\hline Agriculture & 9 & 0 & 2 & 16 & 20 & 27 & 0 & 0 & 74 & 0.12 & 0 \\
\hline Water & 0 & 18 & 0 & 0 & 0 & 0 & 0 & 0 & 18 & 1 & 0 \\
\hline $\begin{array}{l}\text { Developed } \\
\text { / Bare Soil }\end{array}$ & 18 & 12 & 45 & 34 & 5 & 23 & 0 & 2 & 139 & 0.32 & 0 \\
\hline Shrub & 8 & 0 & 1 & 0 & 3 & 0 & 2 & 2 & 16 & 0 & 0 \\
\hline Wetland & 1 & 6 & 1 & 0 & 19 & 0 & 0 & 4 & 31 & 0.61 & 0 \\
\hline Grassland & 0 & 0 & 0 & 0 & 0 & 0 & 0 & 0 & 0 & 0 & 0 \\
\hline Deciduous & 0 & 0 & 1 & 0 & 3 & 0 & 16 & 11 & 31 & 0.52 & 0 \\
\hline \begin{tabular}{|l|} 
Mixed \\
Forest
\end{tabular} & 0 & 12 & 0 & 0 & 0 & 0 & 28 & 30 & 70 & 0.43 & 0 \\
\hline Total & 36 & 48 & 50 & 50 & 50 & 50 & 46 & 49 & 379 & 0 & 0 \\
\hline \begin{tabular}{|l|} 
Producer's \\
Accuracy
\end{tabular} & $\begin{array}{c}0.2 \\
5\end{array}$ & 0.375 & 0.9 & 0 & 0.38 & 0 & 0.35 & 0.61 & 0 & 0.361 & 0 \\
\hline Kappa & 0 & 0 & 0 & 0 & 0 & 0 & 0 & 0 & 0 & 0 & 0.272 \\
\hline
\end{tabular}




\section{A - $6 . \quad$ Dunk River 60 m Buffer Treatment}

Table A - 11: Confusion matrix of accuracy results from pixel-based classification of 2016 RapidEye imagery of the Dunk River watershed using the $60 \mathrm{~m}$ buffer treatment.

\begin{tabular}{|c|c|c|c|c|c|c|c|c|c|c|c|}
\hline $\begin{array}{l}\text { Dunk River } \\
60 \mathrm{~m}\end{array}$ & $\begin{array}{l}\frac{0}{2} \\
\frac{D}{2} \\
\frac{0}{\frac{0}{2}} \\
\end{array}$ & $\begin{array}{l}\frac{\bar{\Phi}}{\bar{\omega}} \\
\sum^{\pi}\end{array}$ & 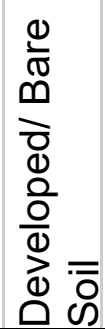 & $\frac{0}{\frac{2}{2}}$ & $\begin{array}{l}\overline{0} \\
\frac{0}{\pi} \\
\frac{\pi}{ \pm 0} \\
3\end{array}$ & $\begin{array}{l}\bar{D} \\
\frac{\mathbb{N}}{\mathbb{N}} \\
\mathbb{N} \\
\mathbb{N} \\
\frac{\mathbb{d}}{1}\end{array}$ & 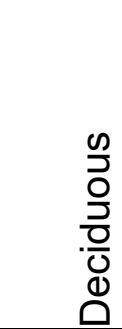 & 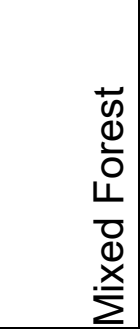 & 要 & 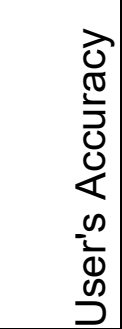 & $\begin{array}{l}\frac{\mathbb{2}}{0} \\
\frac{\mathbb{Q}}{\mathbb{1}}\end{array}$ \\
\hline Agriculture & 26 & 0 & 7 & 0 & 2 & 9 & 0 & 0 & 44 & 0.59 & 0 \\
\hline Water & 0 & 49 & 0 & 0 & 2 & 0 & 0 & 0 & 51 & 0.96 & 0 \\
\hline $\begin{array}{l}\text { Developed } \\
\text { / Bare Soil }\end{array}$ & 2 & 1 & 40 & 2 & 4 & 0 & 0 & 0 & 49 & 0.82 & 0 \\
\hline Shrub & 2 & 0 & 1 & 3 & 4 & 17 & 8 & 2 & 37 & 0.08 & 0 \\
\hline Wetland & 0 & 0 & 1 & 6 & 18 & 0 & 3 & 5 & 33 & 0.55 & 0 \\
\hline Grassland & 17 & 0 & 1 & 25 & 13 & 24 & 4 & 0 & 84 & 0.29 & 0 \\
\hline Deciduous & 2 & 0 & 0 & 12 & 3 & 0 & 21 & 20 & 58 & 0.36 & 0 \\
\hline $\begin{array}{l}\text { Mixed } \\
\text { Forest }\end{array}$ & 1 & 0 & 0 & 2 & 4 & 0 & 14 & 23 & 44 & 0.52 & 0 \\
\hline Total & 50 & 50 & 50 & 50 & 50 & 50 & 50 & 50 & 400 & 0 & 0 \\
\hline \begin{tabular}{|l|} 
Producer's \\
Accuracy
\end{tabular} & 0.52 & 0.98 & 0.8 & $\begin{array}{c}0.0 \\
6 \\
\end{array}$ & 0.36 & 0.48 & 0.42 & 0.46 & 0 & 0.51 & 0 \\
\hline Kappa & 0 & 0 & 0 & 0 & 0 & 0 & 0 & 0 & 0 & 0 & 0.44 \\
\hline
\end{tabular}


Table A - 12: Confusion matrix of accuracy results from object-based classification of the Dunk River watershed 2016 RapidEye imagery using the 60m buffer treatment.

\begin{tabular}{|c|c|c|c|c|c|c|c|c|c|c|c|}
\hline \begin{tabular}{|l|} 
Dunk \\
River 60m \\
(Object) \\
\end{tabular} & \begin{tabular}{|l}
$\frac{0}{3}$ \\
$\frac{3}{5}$ \\
.0 \\
$\frac{0}{2}$ \\
\end{tabular} & $\frac{\bar{\Phi}}{\frac{1}{10}}$ & 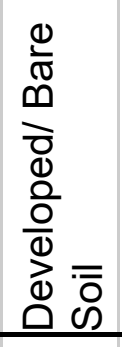 & $\frac{0}{2}$ & $\begin{array}{l}\bar{O} \\
\frac{\pi}{0} \\
\overline{0} \\
3\end{array}$ & 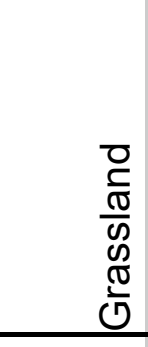 & $\begin{array}{l}0 \\
0 \\
\text { 음 } \\
.0 \\
.0 \\
0 \\
0 \\
0\end{array}$ & 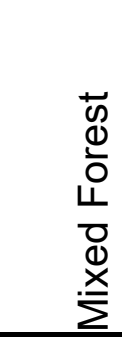 & $\begin{array}{l}\bar{\Gamma} \\
\stackrel{0}{0}\end{array}$ & 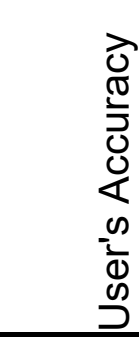 & $\begin{array}{r}\frac{\pi}{O} \\
\frac{0}{\mathbb{N}} \\
\underline{\underline{N}}\end{array}$ \\
\hline Agriculture & 20 & 0 & 2 & 4 & 7 & 30 & 0 & 0 & 63 & 0.32 & 0 \\
\hline Water & 0 & 50 & 0 & 0 & 3 & 0 & 0 & 0 & 53 & 0.94 & 0 \\
\hline $\begin{array}{l}\text { Developed } \\
\text { / Bare Soil }\end{array}$ & 6 & 0 & 43 & 2 & 0 & 0 & 1 & 0 & 52 & 0.83 & 0 \\
\hline Shrub & 13 & 0 & 4 & 17 & 16 & 2 & 9 & 3 & 64 & 0.27 & 0 \\
\hline Wetland & 1 & 0 & 1 & 18 & 12 & 0 & 19 & 28 & 79 & 0.15 & 0 \\
\hline Grassland & 4 & 0 & 0 & 9 & 12 & 18 & 9 & 0 & 52 & 0.35 & 0 \\
\hline Deciduous & 4 & 0 & 0 & 0 & 0 & 0 & 8 & 6 & 18 & 0.44 & 0 \\
\hline $\begin{array}{l}\text { Mixed } \\
\text { Forest }\end{array}$ & 2 & 0 & 0 & 0 & 0 & 0 & 4 & 13 & 19 & 0.68 & 0 \\
\hline Total & 50 & 50 & 50 & 50 & 50 & 50 & 50 & 50 & 400 & 0 & 0 \\
\hline \begin{tabular}{|l|} 
Producer's \\
Accuracy
\end{tabular} & 0.4 & 1 & 0.86 & $\begin{array}{c}0.3 \\
4\end{array}$ & 0.24 & 0.36 & 0.16 & 0.26 & 0 & 0.453 & 0 \\
\hline Kappa & 0 & 0 & 0 & 0 & 0 & 0 & 0 & 0 & 0 & 0 & 0.374 \\
\hline
\end{tabular}




\section{A - $7 . \quad$ Souris River Whole Area Treatment}

Table A - 13: Confusion matrix of accuracy results from pixel-based classification of 2016 RapidEye imagery of the Souris River watershed using the Whole area treatment.

\begin{tabular}{|c|c|c|c|c|c|c|c|c|c|c|}
\hline $\begin{array}{l}\text { Souris River } \\
\text { Whole } \\
\text { (Pixel) }\end{array}$ & $\begin{array}{r}\stackrel{0}{3} \\
\stackrel{2}{5} \\
\stackrel{0}{\frac{0}{2}} \\
\end{array}$ & $\begin{array}{l}\bar{\Phi} \\
\stackrel{ \pm}{J}\end{array}$ & 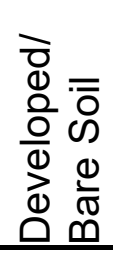 & $\begin{array}{l}0 \\
\frac{2}{2} \\
\infty\end{array}$ & $\begin{array}{l}\frac{0}{c} \\
\frac{c}{\pi} \\
\frac{\pi}{0} \\
3\end{array}$ & 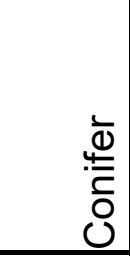 & 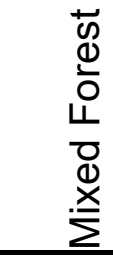 & $\begin{array}{l}\bar{\pi} \\
\overline{0} \\
\circ\end{array}$ & 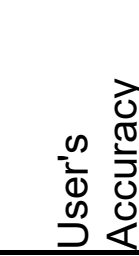 & $\begin{array}{l}\frac{\pi}{0} \\
\frac{0}{\pi} \\
\underline{\underline{x}} \\
\end{array}$ \\
\hline Agriculture & 28 & 0 & 16 & 4 & 3 & 0 & 0 & 51 & 0.549 & 0 \\
\hline Water & 0 & 21 & 0 & 0 & 0 & 0 & 0 & 21 & 1 & 0 \\
\hline $\begin{array}{l}\text { Developed/ } \\
\text { Bare Soil } \\
\end{array}$ & 1 & 13 & 32 & 4 & 0 & 0 & 1 & 51 & 0.627 & 0 \\
\hline Shrub & 12 & 0 & 0 & 27 & 32 & 0 & 0 & 71 & 0.38 & 0 \\
\hline Wetland & 9 & 16 & 2 & 1 & 7 & 0 & 1 & 36 & 0.194 & 0 \\
\hline Conifer & 0 & 0 & 0 & 2 & 3 & 41 & 14 & 60 & 0.683 & 0 \\
\hline $\begin{array}{l}\text { Mixed } \\
\text { Forest }\end{array}$ & 0 & 0 & 0 & 12 & 5 & 9 & 34 & 60 & 0.567 & 0 \\
\hline Total & 50 & 50 & 50 & 50 & 50 & 50 & 50 & 350 & 0 & 0 \\
\hline $\begin{array}{l}\text { Producer's } \\
\text { Accuracy } \\
\end{array}$ & 0.56 & 0.42 & 0.64 & 0.54 & 0.14 & 0.82 & 0.68 & 0 & 0.543 & 0 \\
\hline Kappa & 0 & 0 & 0 & 0 & 0 & 0 & 0 & 0 & 0 & 0.467 \\
\hline
\end{tabular}


Table A - 14: Confusion matrix of accuracy results from object-based classification of the Souris River watershed 2016 RapidEye imagery using the Whole area treatment.

\begin{tabular}{|c|c|c|c|c|c|c|c|c|c|c|}
\hline $\begin{array}{l}\text { Souris } \\
\text { River } \\
\text { Whole } \\
\text { (Object) } \\
\end{array}$ & $\begin{array}{l}\frac{0}{3} \\
\frac{1}{7} \\
.0 \\
\frac{0}{4} \\
\end{array}$ & $\frac{\bar{\Phi}}{\stackrel{ \pm}{\pi}}$ & 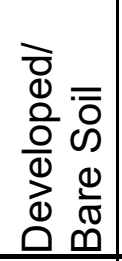 & $\begin{array}{l}\frac{0}{2} \\
\frac{2}{2} \\
\frac{5}{\omega}\end{array}$ & $\begin{array}{l}\frac{0}{\pi} \\
\frac{\pi}{\mathbb{N}} \\
3 \\
3\end{array}$ & $\begin{array}{l}\grave{\Phi} \\
\stackrel{.}{\circ} \\
\mathcal{O} \\
\end{array}$ & 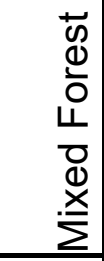 & $\begin{array}{l}\bar{\pi} \\
0\end{array}$ & 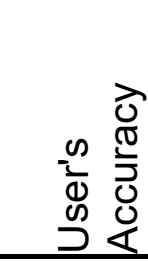 & $\begin{array}{l}\frac{\pi}{O} \\
\frac{O}{\mathbb{N}} \\
\underline{\mathbb{N}}\end{array}$ \\
\hline Agriculture & 40 & 24 & 27 & 16 & 21 & 0 & 6 & 134 & 0.299 & 0 \\
\hline Water & 0 & 13 & 0 & 0 & 0 & 0 & 0 & 13 & 1 & 0 \\
\hline \begin{tabular}{|l|} 
Developed \\
/ Bare Soil \\
\end{tabular} & 0 & 0 & 21 & 0 & 0 & 0 & 0 & 21 & 1 & 0 \\
\hline Shrub & 4 & 0 & 2 & 9 & 0 & 0 & 0 & 15 & 0.6 & 0 \\
\hline Wetland & 4 & 13 & 0 & 3 & 10 & 0 & 0 & 30 & 0.333 & 0 \\
\hline Conifer & 0 & 0 & 0 & 5 & 0 & 2 & 9 & 16 & 0.125 & 0 \\
\hline $\begin{array}{l}\text { Mixed } \\
\text { Forest }\end{array}$ & 2 & 0 & 0 & 17 & 19 & 48 & 35 & 121 & 0.289 & 0 \\
\hline Total & 50 & 50 & 50 & 50 & 50 & 50 & 50 & 350 & 0 & 0 \\
\hline $\begin{array}{l}\text { Producer's } \\
\text { Accuracy }\end{array}$ & 0.8 & 0.26 & 0.42 & 0.18 & 0.2 & 0.04 & 0.7 & 0 & 0.371 & 0 \\
\hline Kappa & 0 & 0 & 0 & 0 & 0 & 0 & 0 & 0 & 0 & 0.267 \\
\hline
\end{tabular}




\section{A - 8. Souris River Crop Cookie Cutter Treatment}

Table A - 15: Confusion matrix of accuracy results from pixel-based classification of the Souris River watershed 2016 RapidEye imagery using the Crop Cookie Cutter treatment.

\begin{tabular}{|c|c|c|c|c|c|c|c|c|c|}
\hline $\begin{array}{l}\text { Souris } \\
\text { River Crop } \\
\text { (Pixel) }\end{array}$ & $\begin{array}{l}\frac{0}{3} \\
\frac{1}{5} \\
.00 \\
\frac{0}{2}\end{array}$ & $\frac{\bar{\Phi}}{\stackrel{\omega}{\pi}}$ & $\begin{array}{l}\frac{0}{2} \\
\frac{1}{\omega}\end{array}$ & 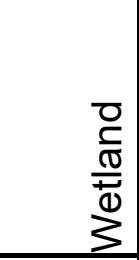 & 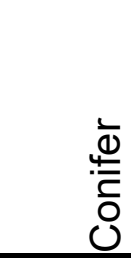 & 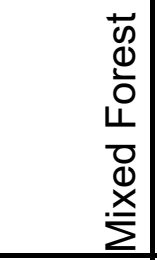 & $\begin{array}{l}\bar{\pi} \\
\stackrel{5}{\circ} \\
\end{array}$ & 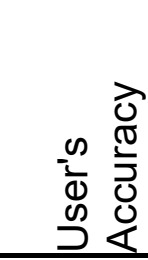 & $\begin{array}{l}\sqrt[0]{0} \\
\frac{0}{2} \\
\underline{\pi} \\
\end{array}$ \\
\hline Agriculture & 41 & 0 & 17 & 18 & 0 & 0 & 76 & 0.539 & 0 \\
\hline Water & 0 & 25 & 0 & 0 & 0 & 0 & 25 & 1 & 0 \\
\hline Shrub & 1 & 0 & 2 & 14 & 0 & 0 & 17 & 0.118 & 0 \\
\hline Wetland & 0 & 25 & 14 & 8 & 0 & 1 & 48 & 0.167 & 0 \\
\hline Conifer & 0 & 0 & 6 & 3 & 38 & 13 & 60 & 0.633 & 0 \\
\hline $\begin{array}{l}\text { Mixed } \\
\text { Forest }\end{array}$ & 0 & 0 & 9 & 4 & 12 & 34 & 59 & 0.576 & 0 \\
\hline Total & 42 & 50 & 48 & 47 & 50 & 48 & 285 & 0 & 0 \\
\hline $\begin{array}{l}\text { Producer's } \\
\text { Accuracy }\end{array}$ & $\begin{array}{c}0.97 \\
6 \\
\end{array}$ & 0.5 & 0.042 & 0.17 & 0.76 & 0.708 & 0 & 0.519 & 0 \\
\hline Kappa & 0 & 0 & 0 & 0 & 0 & 0 & 0 & 0 & 0.425 \\
\hline
\end{tabular}


Table A - 16: Confusion matrix of accuracy results from object-based classification of the Souris River watershed 2016 RapidEye imagery using the Crop Cookie Cutter treatment.

\begin{tabular}{|c|c|c|c|c|c|c|c|c|c|}
\hline $\begin{array}{l}\text { Souris River } \\
\text { Crop } \\
\text { (Object) }\end{array}$ & $\begin{array}{l}0 \\
\frac{0}{3} \\
\frac{1}{5} \\
.0 \\
\frac{0}{4}\end{array}$ & $\frac{\sqrt{0}}{\frac{\pi}{\pi}}$ & $\begin{array}{l}0 \\
\stackrel{2}{2} \\
\text { c) }\end{array}$ & $\begin{array}{l}\frac{0}{0} \\
\frac{\pi}{0} \\
\frac{1}{0} \\
3\end{array}$ & 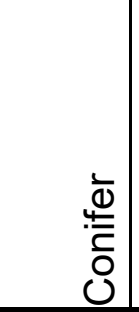 & 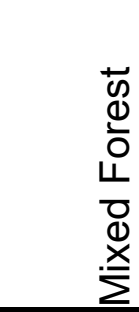 & $\begin{array}{l}\bar{\pi} \\
\text { 으 }\end{array}$ & 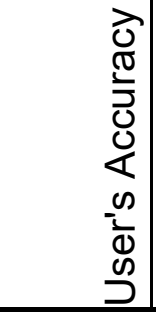 & $\begin{array}{l}\frac{\pi}{2} \\
\frac{0}{2} \\
\underline{\pi} \\
\end{array}$ \\
\hline Agriculture & 40 & 0 & 18 & 17 & 0 & 0 & 75 & 0.533 & 0 \\
\hline Water & 0 & 25 & 0 & 0 & 0 & 0 & 25 & 1 & 0 \\
\hline Shrub & 0 & 0 & 0 & 8 & 0 & 0 & 8 & 0 & 0 \\
\hline Wetland & 2 & 25 & 4 & 21 & 0 & 4 & 56 & 0.375 & 0 \\
\hline Conifer & 0 & 0 & 0 & 0 & 20 & 6 & 26 & 0.769 & 0 \\
\hline \begin{tabular}{|l|} 
Mixed \\
Forest \\
\end{tabular} & 0 & 0 & 26 & 1 & 30 & 38 & 95 & 0.4 & 0 \\
\hline Total & 42 & 50 & 48 & 47 & 50 & 48 & 285 & 0 & 0 \\
\hline $\begin{array}{l}\text { Producer's } \\
\text { Accuracy }\end{array}$ & $\begin{array}{c}0.95 \\
2 \\
\end{array}$ & 0.5 & 0 & 0.447 & 0.4 & 0.792 & 0 & 0.505 & 0 \\
\hline Kappa & 0 & 0 & 0 & 0 & 0 & 0 & 0 & 0 & 0.409 \\
\hline
\end{tabular}




\section{A - $9 . \quad$ Souris River $60 \mathrm{~m}$ Buffer Treatment}

Table A - 17: Confusion matrix of accuracy results from pixel-based classification of the Souris River watershed 2016 RapidEye imagery using the $60 \mathrm{~m}$ buffer treatment.

\begin{tabular}{|c|c|c|c|c|c|c|c|c|c|c|}
\hline $\begin{array}{l}\text { Souris } \\
\text { River 60m } \\
\text { (Pixel) } \\
\end{array}$ & $\begin{array}{l}\stackrel{0}{\frac{0}{3}} \\
\frac{1}{5} \\
.00 \\
\frac{0}{2}\end{array}$ & $\frac{\frac{1}{\Phi}}{\frac{ \pm}{\pi}}$ & 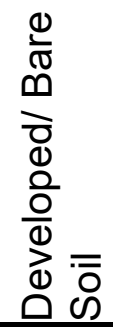 & $\frac{\text { 을 }}{\text { क }}$ & $\begin{array}{l}\frac{0}{c} \\
\frac{\pi}{0} \\
\frac{1}{0} \\
3\end{array}$ & 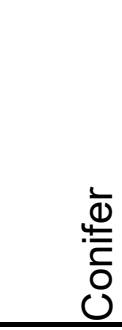 & 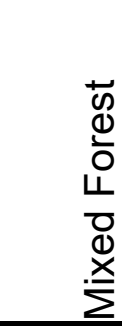 & 元 & 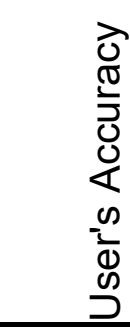 & $\begin{array}{l}\mathbb{\pi} \\
\stackrel{0}{0} \\
\stackrel{\pi}{\pi} \\
\end{array}$ \\
\hline Agriculture & 20 & 0 & 5 & 2 & 2 & 0 & 0 & 29 & 0.69 & 0 \\
\hline Water & 0 & 25 & 0 & 0 & 0 & 0 & 0 & 25 & 1 & 0 \\
\hline $\begin{array}{l}\text { Developed } \\
\text { / Bare Soil }\end{array}$ & 0 & 12 & 41 & 3 & 0 & 0 & 0 & 56 & 0.732 & 0 \\
\hline Shrub & 26 & 0 & 3 & 28 & 33 & 0 & 0 & 90 & 0.311 & 0 \\
\hline Wetland & 2 & 13 & 1 & 0 & 7 & 0 & 0 & 23 & 0.304 & 0 \\
\hline Conifer & 0 & 0 & 0 & 5 & 6 & 38 & 12 & 61 & 0.623 & 0 \\
\hline $\begin{array}{l}\text { Mixed } \\
\text { Forest }\end{array}$ & 0 & 0 & 0 & 11 & 2 & 6 & 38 & 57 & 0.667 & 0 \\
\hline Total & 48 & 50 & 50 & 49 & 50 & 44 & 50 & 341 & 0 & 0 \\
\hline $\begin{array}{l}\text { Producer's } \\
\text { Accuracy }\end{array}$ & 0.42 & 0.5 & 0.82 & 0.57 & 0.14 & 0.86 & 0.76 & 0 & 0.578 & 0 \\
\hline Kappa & 0 & 0 & 0 & 0 & 0 & 0 & 0 & 0 & 0 & 0.508 \\
\hline
\end{tabular}


Table A - 18: Confusion matrix of accuracy results from object-based classification of the Souris River watershed 2016 RapidEye imagery using the $60 \mathrm{~m}$ buffer treatment.

\begin{tabular}{|c|c|c|c|c|c|c|c|c|c|c|}
\hline $\begin{array}{l}\text { Souris } \\
\text { River 60m } \\
\text { (Object) }\end{array}$ & $\begin{array}{l}\frac{0}{3} \\
\frac{1}{5} \\
.0 \\
\end{array}$ & $\frac{\frac{1}{\Phi}}{\stackrel{N}{J}}$ & 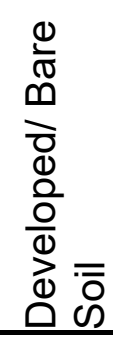 & $\begin{array}{l}0 \\
\frac{2}{2} \\
\frac{2}{\infty} \\
\end{array}$ & 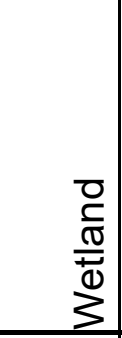 & 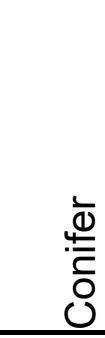 & 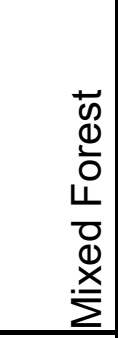 & $\begin{array}{l}\bar{\pi} \\
\stackrel{0}{0}\end{array}$ & 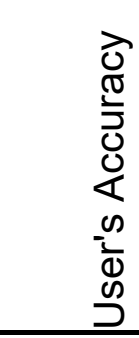 & $\begin{array}{r}\frac{\pi}{0} \\
\stackrel{0}{0} \\
\underline{\mathbb{T}} \\
\end{array}$ \\
\hline Agriculture & 16 & 3 & 48 & 7 & 8 & 0 & 0 & 82 & 0.195 & 0 \\
\hline Water & 0 & 0 & 0 & 2 & 0 & 0 & 0 & 2 & 0 & 0 \\
\hline \begin{tabular}{|l|} 
Developed \\
/ Bare Soil \\
\end{tabular} & 0 & 0 & 0 & 0 & 0 & 0 & 0 & 0 & 0 & 0 \\
\hline Shrub & 26 & 0 & 2 & 17 & 20 & 0 & 0 & 65 & 0.262 & 0 \\
\hline Wetland & 0 & 9 & 0 & 9 & 1 & 0 & 0 & 19 & 0.053 & 0 \\
\hline Conifer & 6 & 38 & 0 & 14 & 21 & 44 & 50 & 173 & 0.254 & 0 \\
\hline \begin{tabular}{|l|} 
Mixed \\
Forest
\end{tabular} & 0 & 0 & 0 & 0 & 0 & 0 & 0 & 0 & 0 & 0 \\
\hline Total & 48 & 50 & 50 & 49 & 50 & 44 & 50 & 341 & 0 & 0 \\
\hline \begin{tabular}{|l|} 
Producer's \\
Accuracy
\end{tabular} & 0.33 & 0 & 0 & 0.35 & 0.02 & 1 & 0 & 0 & 0.229 & 0 \\
\hline Kappa & 0 & 0 & 0 & 0 & 0 & 0 & 0 & 0 & 0 & 0.108 \\
\hline
\end{tabular}

